Universidad de Lima

Facultad de Ciencias Empresariales y Económicas

Carrera de Contabilidad

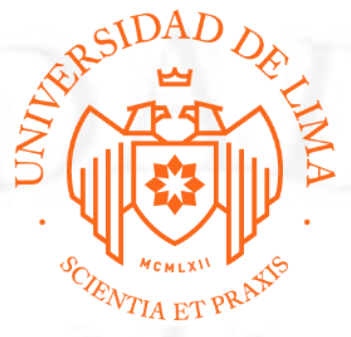

\title{
EL ANÁLISIS Y LA INTERPRETACIÓN DE LOS ESTADOS FINANCIEROS Y SU IMPORTANCIA EN LA TOMA DE DECISIONES. CASO FINANCIERA OH S.A - PERIODO 2015 -2017
}

Trabajo de suficiencia profesional para optar el Título Profesional de Contador Público

\section{Nila Katerin Alvino Zelaya}

Código 20082041

\author{
ASESOR \\ Miguel Delfín Carazas Pérez
}

Lima - Perú

Setiembre del 2018 


\section{EL ANÁLISIS Y LA INTERPRETACIÓN DE LOS ESTADOS FINANCIEROS Y SU IMPORTANCIA EN LA TOMA DE DECISIONES. CASO FINANCIERA OH S.A -}

PERIODO 2015 -2017 
A mi madre Petronila por su gran apoyo incondicional y a mi hija Alessandra quien es mi motivo de superación. 
Agradezco de manera especial a mi asesor CPCC Miguel Delfín Carazas Pérez por su apoyo, seguimiento y supervisión constante durante la elaboración del trabajo. 


\section{TABLA DE CONTENIDO}

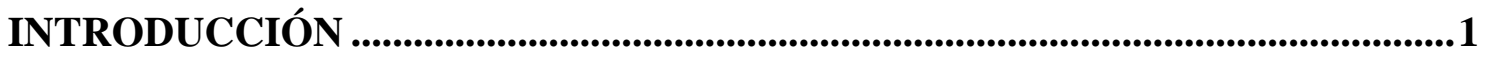

CAPÍTULO I: ANTECEDENTES DE LA ENTIDAD ............................................3

1.1 Identificación y actividad económica de la entidad.........................................3

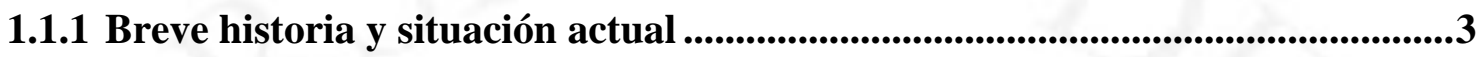

1.1.2 Descripción de la empresa. .................................................................................4

1.1.3 Objetivo de la empresa..................................................................................5

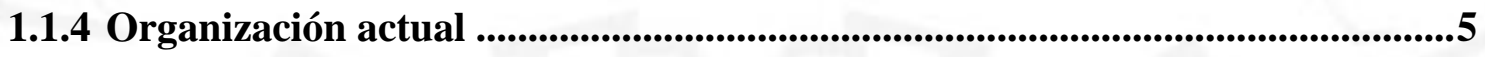

1.2 Presencia en el mercado....................................................................................6

1.2.1 Identificación de las oportunidades y riesgos del sector ...................................6

CAPÍTULO II: DESCRIPCIÓN Y OBJETIVOS DEL TRABAJO DE

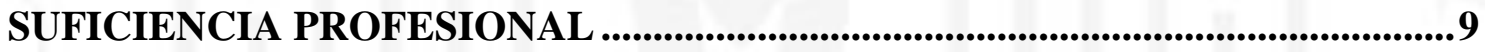

2.1 Descripción del caso de investigación ..........................................................9

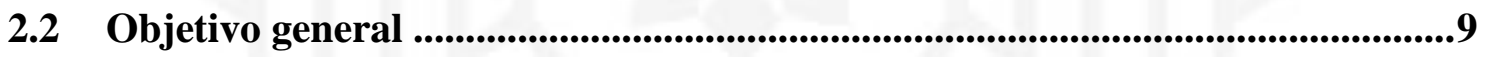

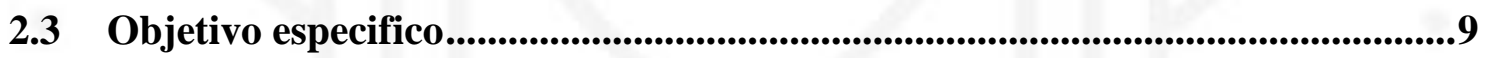

CAPITULO III: MARCO METODOLOGICO ...................................................

3.1 Metodología de recolección de la información...............................................11

3.2 Metodología de análisis de información ............................................................11

CAPITULO IV: ANÁLISIS Y PRESENTACIÓN Y DISCUSIÓN DE

RESULTADOS.............................................................12

4.1 Análisis de la información ..........................................................................12

4.2 Presentación y discusión de resultados........................................................................23

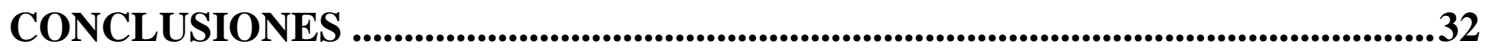

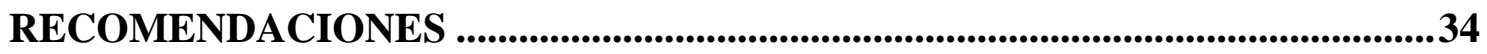




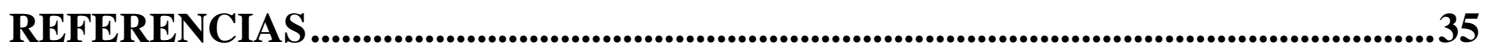

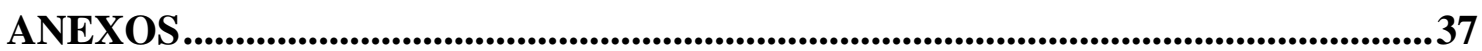




\section{ÍNDICE DE FIGURAS}

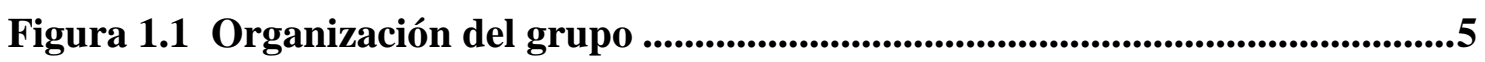

Figura 1.2 Organigrama de la empresa ......................................................................6

Figura 1.3 Participación por el número de tarjetas de consumo................................7

Figura 1.4 Evolución del ratio de cartera de alto riesgo (deteriorada) .....................8

Figura 4.1 Análisis vertical y horizontal del estado de situación financiera. ..........13

Figura 4.2 Análisis horizontal de la cuenta disponible.............................................14

Figura 4.3 Análisis horizontal de la cartera de créditos.................................................14

Figura 4.4 Crecimiento del número de tarjetas emitidas......................................15

Figura 4.5 Análisis vertical y horizontal del estado de resultados ..........................17

Figura 4.6 Composición de los ingresos financieros .................................................17

Figura 4.7 Formula del ratio de liquidez según la S.B.S ..............................................19

Figura 4.8 Formula del ratio de capital global según SBS.......................................19

Figura 4.9 Evolución de los indicadores financieros .............................................20

Figura 4.10 Evolución de la rentabilidad.........................................................................21

Figura 4.11 Crecimiento de las colocaciones. .......................................................................22

Figura 4.12 Crecimiento del ratio de cartera atrasada. ............................................23

Figura 4.13 Ratio de liquidez con la competencia...................................................24

Figura 4.14 Ratio de morosidad según criterio contable S.B.S. (\%).......................25

Figura 4.15 Principales cuentas del activo en (M.M.) ...........................................26

Figura 4.16 Principales cuentas del pasivo y patrimonio...........................................27

Figura 4.17 Proyección de los estados de resultados. ..............................................28

Figura 4.18 Proyección del estado de situación financiera. ......................................29 


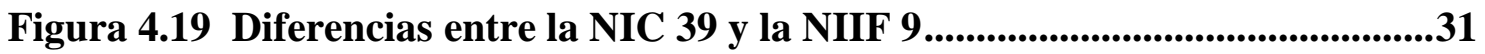




\section{ÍNDICE DE ANEXOS}

Anexo 1: Estado de situación financiera 2017 - 2016 ..................................................38

Anexo 2: Estado de resultados integrales 2017 - 2016 ..................................................39

Anexo 3: Estado de situación financiera 2016 - 2015 ....................................................40

Anexo 4: Estado de resultados integrales 2016 - 2015 ................................................41

Anexo 5: Encuesta de expectativa macroeconómica del P.B.I/1...............................42

Anexo 6: Estados financieros al 31 de diciembre de 2017 y de 2016 junto con el dictamen de los auditores independientes 


\section{INTRODUCCIÓN}

Actualmente muchas entidades de diversos sectores, no necesariamente el financiero, saben la importancia del análisis de la información financiera, ya que con la correcta interpretación de los estados financieros se puede tomar decisiones importantes de manera oportuna.

En este sentido, el presente trabajo de investigación realizó este análisis enfocado a un caso en específico para tener un mayor entendimiento del mismo. Siendo la entidad financiera escogida Financiera Oh S.A, es una empresa que pertenece al grupo Intercorp y que hace unos ocho años aproximadamente forma parte del mercado financiero, logrando en este corto tiempo una gran participación mediante su Tarjeta Oh.

Este documento se encuentra conformado por capítulos, siendo estos los siguientes:

En el primer capítulo se comenta sobre los antecedentes de la entidad financiera para que se pueda tener un mayor entendimiento de la empresa, es por ello que se explica un breve resumen de la Financiera desde el inicio de sus operaciones hasta la fecha.

En el segundo capítulo se describe el caso de la investigación y el objetivo que se tiene con la elaboración del mismo.

En el tercer capítulo se detalla el marco de la metodología utilizada para la elaboración del presente documento, encontrando en el mismo como se obtuvo la información utilizada. 
Siendo el penúltimo capítulo, se detalla el análisis, presentación y discusión de los resultados obtenidos durante nuestra investigación.

Y como es de esperar, en el último capítulo se encuentra las conclusiones, recomendaciones, referencias y anexos del trabajo. 


\section{CAPÍTULO I: ANTECEDENTES DE LA ENTIDAD}

\subsection{Identificación y actividad económica de la entidad.}

\subsubsection{Breve historia y situación actual}

La empresa obtuvo la autorización de organizarse como una entidad financiera mediante la Resolución $N^{\circ} 3371-2009$, documento que fue emitida por la Superintendencia de Banca, Seguros y AFP. Pero recién a inicios del 2010, mediante la Resolución №3972010, obtienen la autorización para su funcionamiento. Es importante mencionar que en dicho documento se lee lo siguiente: “(...) podrá realizar las operaciones señaladas en el artículo $284^{\circ}$ de la Ley General, debiendo para la captación de depósitos contar con la previa autorización de esta Superintendencia, conforme a lo señalado en la Resolución SBS N³371-2009" (SBS, 2017,3).

Desde marzo del 2010 la empresa comenzó a realizar sus operaciones como una entidad financiera exclusiva para el uso de tarjetas de consumo en las Tiendas Oeschle, pero su contante búsqueda de convenios que resulten atractivos para sus usuarios junto con el buen sistema de software de sus operaciones les permitió ir en constante crecimiento.

En este sentido, en el 2013 la empresa realiza la alianza más importante desde su inicio, ya que firma un Contrato de Emisión y Administración de la Tarjetas de Crédito Oh con Supermercados Peruanos S.A (Plaza Vea). En dicho documento, Financiera Oh S.A. se compromete en pagar el importe de S/ 30,000,000 más IGV con la finalidad de contar con promociones y descuentos que ofrezcan a sus clientes por el uso exclusivo de la Tarjeta Oh. Es por ello que, en el 2014, la tarjeta Plaza Vea de Interbank es reemplazada por la Tarjeta Oh Con esta transacción la entidad financiera obtuvo un gran crecimiento, tal como lo detalla de la siguiente manera: “(...) Financiera Oh S.A. logró consolidar un parque de 638 mil tarjetas en 2014, lo cual representa un incremento en $22 \%$ con respecto al cierre del año anterior.” (Financiera Oh S.A., Documento de Información Anual2017, 7) 
Hasta el 2015 todas las Tarjetas Oh solo eran MasterCard, pero a partir del 2016 este esquema cambia totalmente, ya que en dicho año se realiza el acuerdo con Visa Internacional. Como se detalla:

“(...) Financiera Oh S.A consolidara un parque de 820 mil tarjetas, que representa un incremento de $13 \%$ con respecto al cierre del año anterior (727 mil tarjetas), este crecimiento estuvo acompañado por el crecimiento importante de la cartera de créditos cerrando el año con 828 millones de soles en colocaciones" (Financiera Oh S.A., Documento de Información Anual2017, 8)

Asimismo, desde el 15 de julio del 2016 la entidad financiera cambia su razón social, con lo cual pasa de ser Financiera Uno S.A. a Financiera Oh S.A. Esta decisión fue con la finalidad de que sus clientes pueden asociar con mayor facilidad la tarjeta con la empresa.

Por último, el año 2017 fue de muchos retos para la empresa, ya que desde marzo tuvieron autorización para la captación de recursos con el público en los productos CTS y Depósitos a Plazo, el cual fue comunicado mediante Resolución SBS N 1045-2017 Oficio $\mathrm{N}^{\circ}$ 9210-2017SBS.Por el presente año la financiera tiene como captaciones de CTS a los aportes de sus colaboradores y los pertenecientes al Grupo Intercorp Perú. Teniendo como objetivo para el siguiente año contar con las captaciones del público en general.

Aunque a inicio del mismo año la entidad financiera fue afectada por el Fenómeno del Niño, este último no afecto a su meta de utilidad presupuestada (S/ 46.6 MM). Como se detalla en la Memoria de la empresa, obtuvieron “(...) un parque de 850 mil tarjetas en diciembre (4\% mayor al del cierre del año anterior)" (Financiera Oh S.A., Documento de Información Anual 2017,8).

\subsubsection{Descripción de la empresa.}

Financiera Oh S.A es una empresa financiera que pertenece al Grupo Intercorp Perú, siendo la subsidiaria de Intercorp Perú LTD. (antes IFH Retail Corp.), ya que este último cuenta con el 94\% de las acciones de la financiera. 
Figura 1.1

Organización del grupo

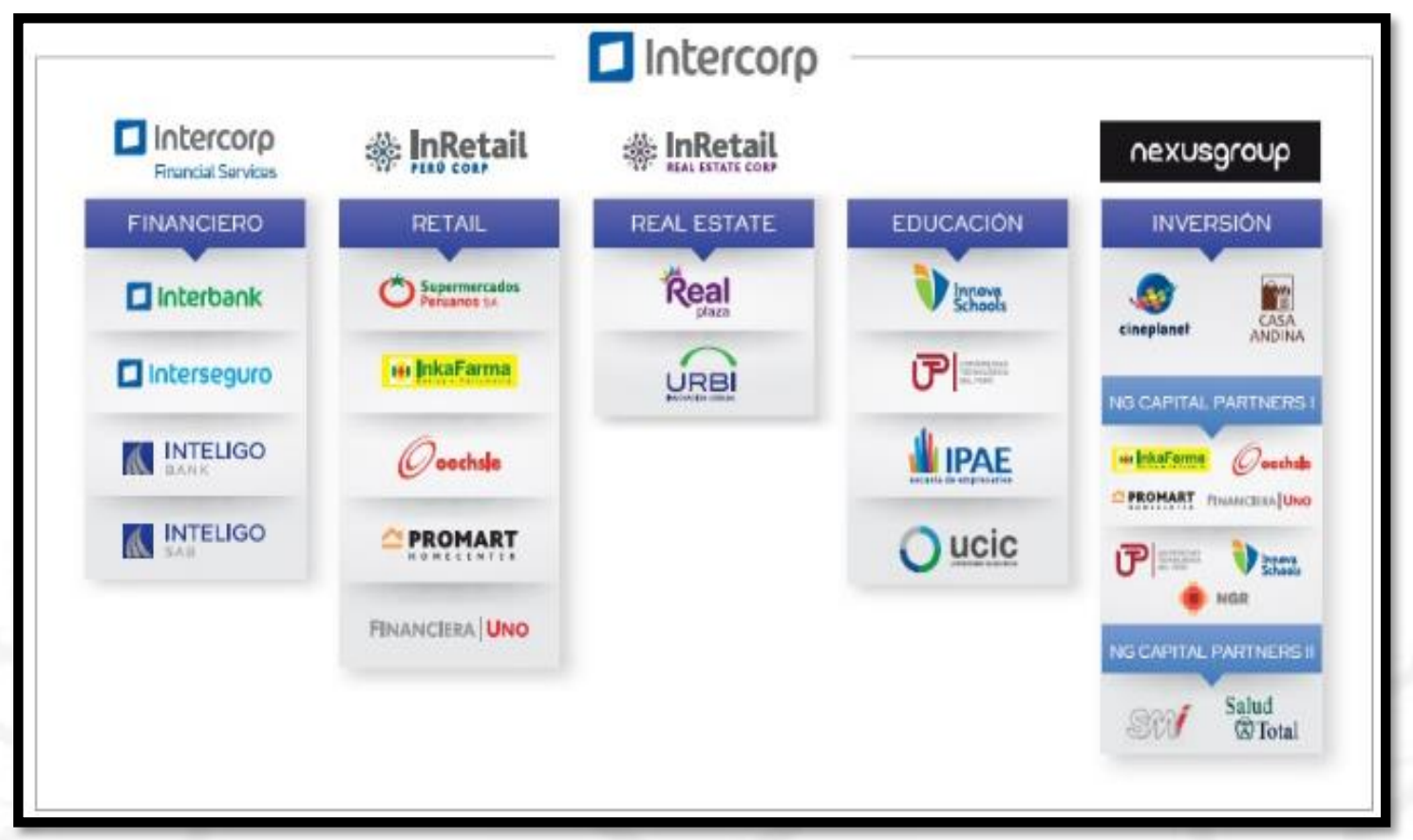

Fuente: Inteligo Bank Ltd. (2017). Empresas Grupo Intercorp.

\subsubsection{Objetivo de la empresa}

Según como lo detalla Financiera Oh S.A. en su Documento de Información Anual 2017, sus principales objetivos son las siguientes:

- Incrementar la relevancia de Tarjeta Oh dentro de Plaza Vea, Oeschle, Promart e Inkafarma; compartir la visión y fortalecer la relación.

- Incrementar el parque y aumentar la principalidad de Tarjeta Oh para los clientes.

- Incrementar los ingresos financieros y no financieros.

- $\quad$ Reducir el riesgo de la cartera.

- Convertir el recurso humano en valor.

- Mejorar la eficiencia operativa.

\subsubsection{Organización actual}

Financiera Oh S.A se encuentra organizada de la siguiente manera: 
Figura 1.2

Organigrama de la empresa

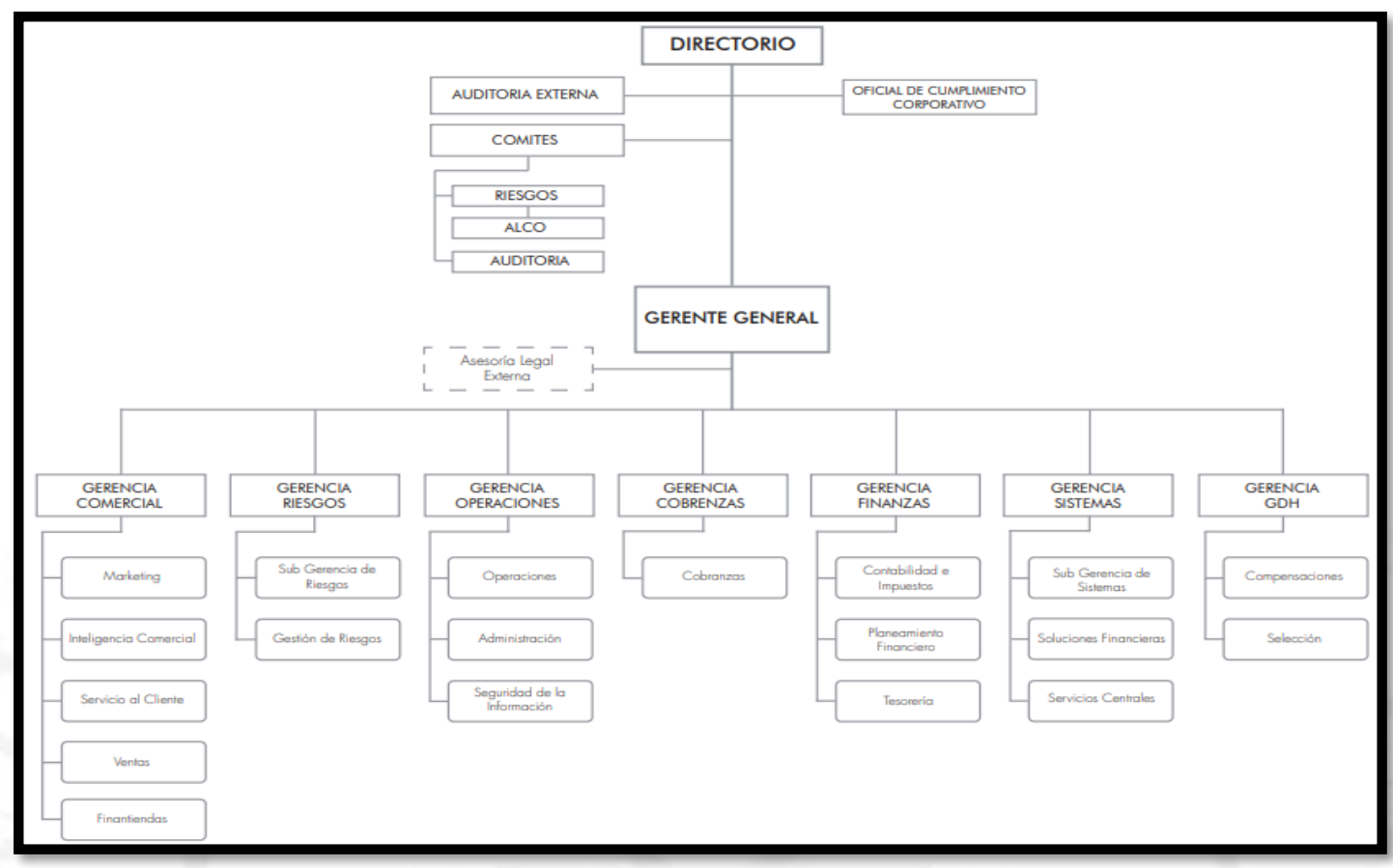

Fuente: Tarjeta Oh (2018). Buen Gobierno Corporativo - Estructura de la sociedad

\subsection{Presencia en el mercado}

\subsubsection{Identificación de las oportunidades y riesgos del sector}

Si bien es cierto, Financiera Oh S.A. comenzó sus transacciones como una tarjeta de crédito de consumo exclusivo a Tiendas Oeschle, ahora con los convenios logrados, cuentan con otros puntos autorizados que les permite tener un crecimiento en su cartera de clientes cada año.

En este sentido, en el transcurso de los años se observa un rápido crecimiento de las tarjetas de crédito al consumo no bancarizados, tal como es el caso de Tarjeta Oh, que se han vuelto más atractivas para el público. El cual se espera que seguirá creciendo en los próximos años, al ser un sector que recién se está explorando.

Por ello se procedió a realizar un cuadro con la participación por tarjeta de consumo de los bancos y entidades financieras al cierre del año 2017. Como resultado del mismo, se tiene como competidores directos a Financiera Oh S.A. a: Ripley (con sus Tarjeta Ripley cuentan con un $16 \%$ del total), Falabella (con su Tarjeta CMR cuentan con el $18 \%$ ) y Cencosud (con su Tarjeta Cencosud tienen el $8 \%$ del total). 
Figura 1.3

Participación por el número de tarjetas de consumo

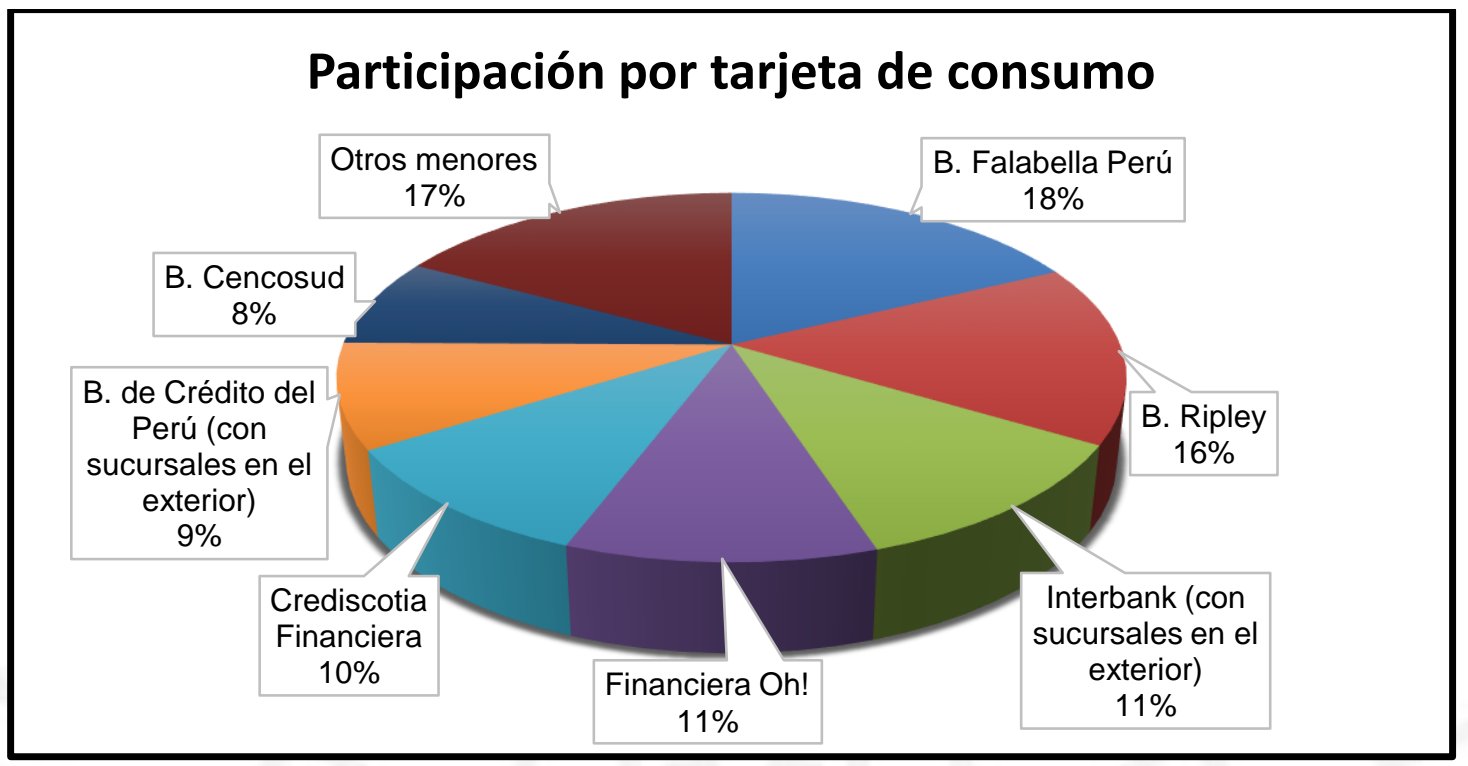

Fuente: Superintendencia de Banca, Seguros y AFP (2017)

Elaboración: Propia

En una comparación de la evolución del número de las tarjetas de créditos emitidas (en miles) en los últimos tres años, “(...) la financiera ha logrado un crecimiento superior al de sus peers, incrementando el 3.7\% en el parque" (Financiera Oh S.A., Memoria Anual 2017,10), siendo esta comparación con respecto al año anterior y a su vez mayor a de sus competidores, ya que también mencionan que Ripley y Falabella obtuvieron un crecimiento del $1.6 \%$ y $0.9 \%$, respectivamente. Pero Cencosud una disminución del $2.2 \%$.

Cuando analizaron el indicador de la morosidad promedio de las compañías, se obtuvo como resultado que, en los últimos tres años, Ripley presento el menor porcentaje de morosidad obteniendo, solo un 3\%, a diferencia de ello, tal como dice “(...) Financiera Oh S.A. presenta un indicador de morosidad de 3.5\% ubicándose por debajo de Falabella (7.8\%) y Cencosud (4.1\%). (Financiera Oh S.A., Memoria Anual 2017, 10).

Como es de nuestro conocimiento, en los primeros meses del presente año, nuestro país fue afectado por el Fenómeno del Niño, el cual impacto al crecimiento económico de diferentes sectores, incluyendo esté ya que impacto a la cartera de las empresas como se muestra a continuación: 
Figura 1.4

Evolución del ratio de cartera de alto riesgo (deteriorada)

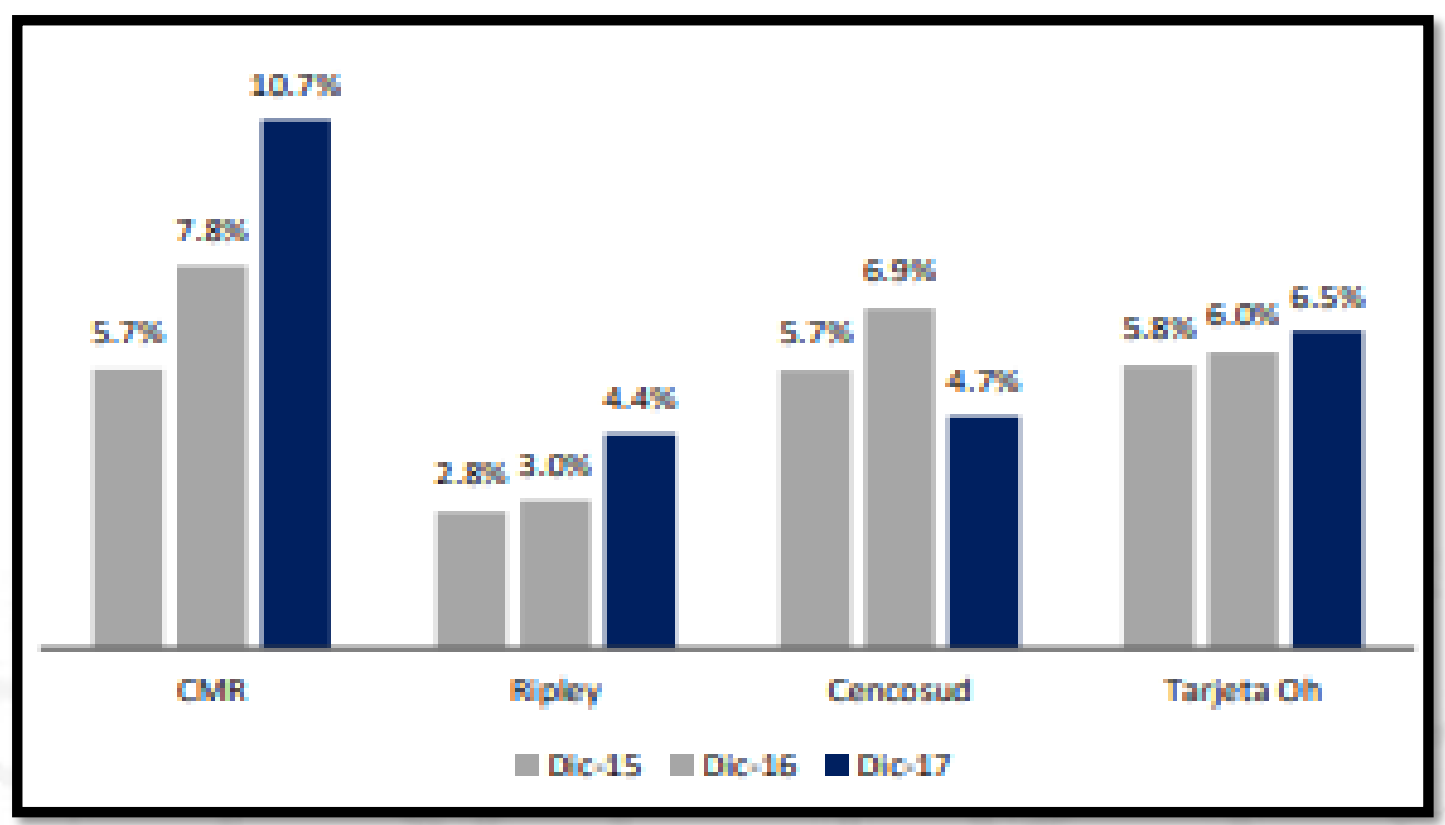

Fuente: Financiera Oh S.A (2018). Documento de Información Anual 2017 


\section{CAPÍTULO II: DESCRIPCIÓN Y OBJETIVOS DEL TRABAJO DE SUFICIENCIA PROFESIONAL}

\subsection{Descripción del caso de investigación}

Si bien, Financiera Oh S.A. comenzó sus operaciones como una tarjeta de crédito exclusivo de las tiendas Oeschle, pero al pasar de los años, con los convenios que alcanzo hasta la fecha le permite tener posicionamiento en el público en poco tiempo. Siendo sus otros puntos exclusivos, las tiendas Plaza Vea y Promart. Pero al ser una tarjeta en su mayoría Visa, origina que su cartera crezca en muy poco tiempo.

En este sentido, su plan estratégico se basa en sus tres pilares, los cuales son: incrementar el valor para el cliente, el crecimiento rentable y con eficiencia interna. Y estos pueden ser fácilmente medidos mediante el crecimiento de la cartera, la disminución del riesgo y con la eficiencia interna, respectivamente.

Como Financiera Oh S.A., en tan poco tiempo ha logrado tener un crecimiento en su cartera y parque. En el presente caso de investigación se realiza el análisis e interpretación de sus estados financieros con el fin de determinar la relación que tiene el crecimiento de su cartera con el nivel de riesgo que asumió para ello. Así como también analizar las posibles transacciones contables incurridas en cada situación.

\subsection{Objetivo general}

El objetivo general del presente trabajo es desarrollar un análisis de los estados financieros que permitan entender transacciones contables con la finalidad de evaluar el crecimiento de la cartera versus el retorno de la rentabilidad.

\subsection{Objetivo especifico}

Los objetivos específicos permitirán alcanzar el objetivo general, los cuales son los siguientes:

- Análisis de indicadores financieros relevantes para la empresa, específicamente el ratio de liquidez, ratio de solvencia, índice de morosidad, 
rentabilidad sobre los activos (ROA) y rentabilidad sobre el patrimonio (ROE).

- Evaluar la importancia de la toma de decisiones con el propósito de identificar su impacto en la tasa de morosidad.

- Evaluar el comportamiento de la liquidez con la evolución del apalancamiento. 


\section{CAPITULO III: MARCO METODOLOGICO}

\subsection{Metodología de recolección de la información}

El presente trabajo inicia con la recolección de la información usando la metodología cuantitativa, para lo cual se procedió con la recopilación de información de la empresa y su entorno que se encuentra de manera pública en la página de entes reguladoras como son la SMV, BVL y la SBS.

\subsection{Metodología de análisis de información}

La metodología de análisis de información es por el método de casos. Para lo cual se procedió a la revisión y análisis de la información contenida en los Estados Financieros Auditados de la empresa, como también a la preparación de cuadros e información pertinente al análisis. 


\section{CAPITULO IV: ANÁLISIS Y PRESENTACIÓN Y DISCUSIÓN DE RESULTADOS}

\subsection{Análisis de la información}

Para el análisis de la información se procedió a utilizar solo la información de los años 2016 y 2017 respectivamente, de repente para un mayor detalle lo adecuado sería también utilizar el 2015, pero al ser esté último año donde la entidad comienza a tener resultados de los convenios anteriormente firmados, se consideró adecuado no utilizar estos montos dentro del análisis, ya que no reflejaría el correcto crecimiento entre un año y otro, sin embargo para tener un análisis que pueda reflejar un mejor detalle se utilizó la información de los años seleccionados por una periodicidad trimestral.

En este sentido, para iniciar con el análisis de la información se realizó un análisis vertical entre los años 2016 y 2017, con la intención de determinar cuáles son las principales cuentas que tiene mayor comportamiento para la Financiera y de esta manera se pueda brindar un entendimiento de manera global de sus principales transacciones que tiene la empresa. 
Figura 4.1

Análisis vertical y horizontal del estado de situación financiera.

\begin{tabular}{|c|c|c|c|c|c|c|}
\hline \multirow[b]{3}{*}{ Actiro } & \multirow{2}{*}{$\begin{array}{c}\text { Saldo al } \\
31.12 .2016\end{array}$} & & \multirow{2}{*}{$\begin{array}{c}\text { Saldo al } \\
31.12 .2017\end{array}$} & & \multicolumn{2}{|c|}{ Yariaciós Dic 17 - Dic 16} \\
\hline & & & & & $s i(000)$ & $z$ \\
\hline & & & & & & \\
\hline Disponible & 107,719 & 112 & 114,997 & $10 z$ & 7,278 & $7 \mathbf{z}$ \\
\hline Corters de créditos, neto & 785,280 & $79 z$ & 945,121 & 812 & 159,841 & $20 z$ \\
\hline Mobilisrio y equipos, neto & 10,958 & 12 & 11,336 & 12 & 378 & $3 \mathbf{z}$ \\
\hline Intongibles, neto & 14,682 & 12 & 8,832 & 12 & $(5,850)$ & $-40 z$ \\
\hline Cuentos por cobrsr y otroes sctivos & 68,573 & $\pi x$ & 79,029 & $7 z$ & 10,456 & $15 \%$ \\
\hline Activo por impuceto s lo rento diferido & 7,469 & 12 & 9,837 & 12 & 2,368 & $32 x$ \\
\hline Total actiro & 994,681 & $100 z$ & $1,169,152$ & $100 z$ & 174,471 & $18 z$ \\
\hline \multicolumn{7}{|l|}{ Pasiro , patrieonio neto } \\
\hline \multicolumn{7}{|l|}{ Pasiro } \\
\hline Obligsciones con el público & 2,328 & $0 \mathbf{z}$ & 21,137 & $2 x$ & 18,809 & $808 \%$ \\
\hline Adeudsdos & 250,465 & $25 x$ & 125,122 & $11 \%$ & $(125,343)$ & $-50 z$ \\
\hline Cuentos por pogsr & 47,060 & $5 x$ & 55,697 & $5 z$ & 8,637 & $18 \mathrm{z}$ \\
\hline Volores y títulos & 477,151 & $48 x$ & 707,551 & 612 & 230,400 & $48 x$ \\
\hline otros posives & 13,331 & 12 & 8,646 & 12 & $-4,685$ & $-35 z$ \\
\hline Total pasiro & 790,335 & $79 z$ & 918,153 & $79 z$ & 127,818 & $16 z$ \\
\hline \multicolumn{7}{|l|}{ Patrinonio neto } \\
\hline Copitol social & 220,256 & $22 x$ & 220,256 & $19 z$ & - & $0 z$ \\
\hline Pérdidse scumulsdse & $-46,448$ & $-5 z$ & 16,323 & $1 \%$ & $62, \pi 71$ & $-135 z$ \\
\hline Réultodoe del ejércicio & 30,538 & $3 \mathbf{z}$ & 14,420 & 12 & $(16,118)$ & $-53 z$ \\
\hline Total patrienenio etto & 204,346 & $21 z$ & 250,999 & 212 & 46,653 & $23 \%$ \\
\hline Total pasiro y patrieonio neto & 994,681 & $100 z$ & $\overline{1,169,152}$ & $100 z$ & 174,471 & $18 z$ \\
\hline
\end{tabular}

Fuente: dictamen

Elaboración: propia

Entre las principales cuentas de activos, tenemos mayor comportamiento el disponible y cartera de crédito, y como estas dos últimas al ser las más importantes para el sector del sistema financiero. Se procedió a ver el detalle en cómo está compuesto cada cuenta y analizar a que corresponde su incremento. 
Figura 4.2

Análisis horizontal de la cuenta disponible.

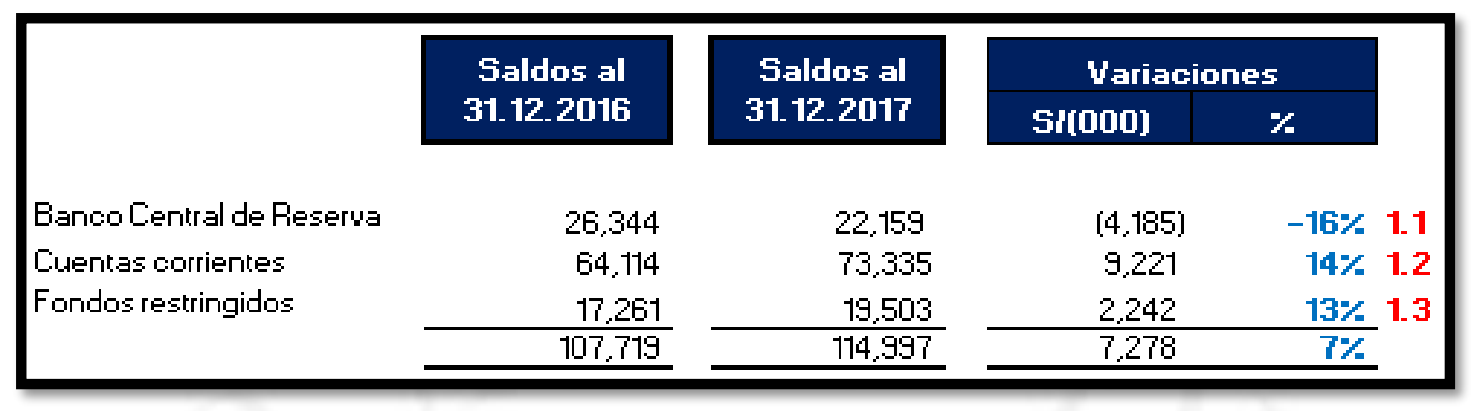

Fuente: dictamen

Elaboración: propia

Como análisis de cada detalle que la compone se tiene lo siguiente:

En el punto 1.1 del grafico anterior se tiene que la disminución del $16 \%$ en los movimientos de la cuenta del Banco Central de Reserva corresponde a la reducción de la tasa del encaje legal en moneda nacional, pasando de $6.5 \%$ al 6\% en el 2017.

Continuando con el siguiente punto, el incremento del 14\% de "cuentas corrientes bancarias" es el resultado propio de las actividades del negocio registrados al cierre del año.

Por último, el incremento del $13 \%$ en los "fondos restringidos" corresponde a depósitos en garantía por los adeudos y los valores y títulos

En el caso de la cartera de créditos su detalle de los componentes que la confirman está a continuación:

Figura 4.3

Análisis horizontal de la cartera de créditos.

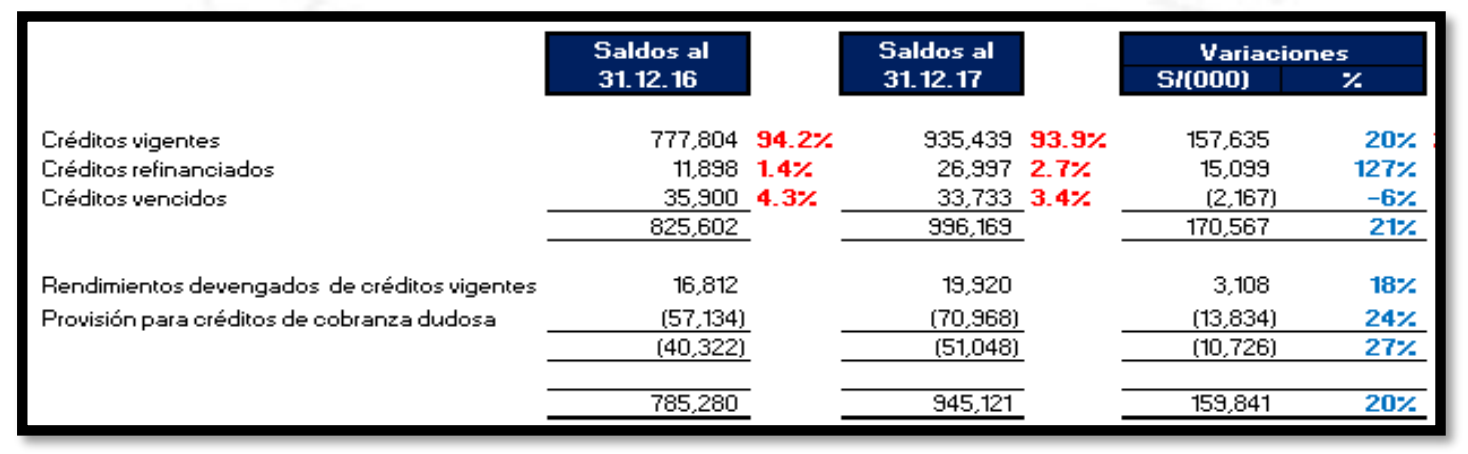

Fuente: dictamen

Elaboración: propia 
El incremento en un $20 \%$ de la cartera de créditos vigentes se debe principalmente a las fuertes inversiones en captar nuevos clientes y mayor consumo de los tarjetahabientes, ello se refleja en el incremento del número de tarjetas emitidas a diciembre 2017, ascendiendo a 851,205; siendo el $4 \%$ adicional con respecto a diciembre del 2016 (820,165 tarjetahabientes al 31.12.2016), la asociación con los retailers en donde mantienen exclusividad en las promociones con el uso de la Tarjeta Oh, sigue impulsando el rápido crecimiento del negocio relacionado al grado de madurez de la cartera de Financiera Oh S.A. y el crecimiento en el número de finantiendas.

En este sentido, la Financiera cuenta con 73 finantiendas al cierre de diciembre que permite el rápido crecimiento de las ventas y la entrega inmediata de las tarjetas de créditos, todas o portada por una fuerte inversión en términos de fuerza de venta y activos.

Es por ello que se procedió en realizar un análisis de la evolución del número de tarjetas emitidas hasta la fecha, logrado como resultado la siguiente imagen.

\section{Figura 4.4}

Crecimiento del número de tarjetas emitidas

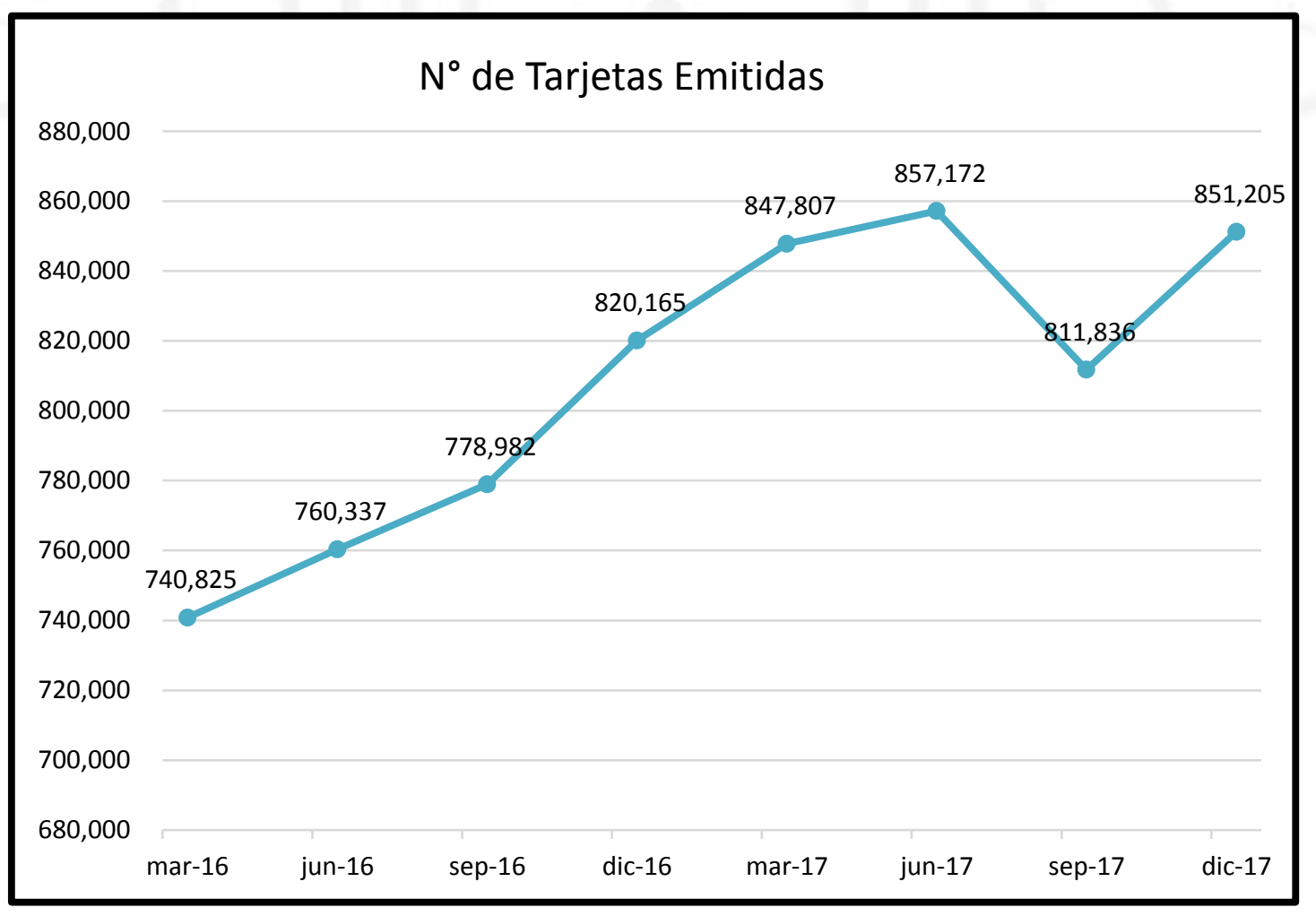

Fuente: Superintendencia de Banca, Seguros y AFP (2016-2017)

Elaboración: propia 
El número de tarjetas emitidas de manera histórica de la Financiera ha estado en constante crecimiento, excepto por el mes de setiembre, en el cual se puede verificar que en comparación a junio del mismo año se tiene registrado una disminución del $5 \%$, aunque no sé sabe con certeza a que corresponde este impacto, se asume que corresponde a cancelación de tarjetas por decisión de los mismos usuarios.

Continuando con el mismo enfoque, en la parte de los pasivos el mayor porcentaje de análisis lo tiene los adeudos y los valores y títulos, y esto se debe a que como la compañía necesita tener liquidez para poder continuar con el negocio principal que son las colocaciones de cartera. La financiera opta en su mayoría por emitir bonos, certificados de depósito y como también solicitar préstamos bancarios, en este sentido el monto y la duración de cada uno son determinados por el área de planeamiento, la Gerencia Financiera y el área de riesgo de empresa.

Por último, en la cuenta de patrimonio no se ha determinado algún cambio significativo, ya que principalmente el capital se ha mantenido constante, sin embargo, al registrar una utilidad S/ (000) 46, 653 al cierre del año, esto permitió que se revierta la pérdida acumulada que venía registrando la Financiera hasta cierre del año 2016.

Al igual que el anterior análisis se realizó el mismo procedimiento para visualizar las principales variaciones del Estado de Resultados. 
Figura 4.5

Análisis vertical y horizontal del estado de resultados

\begin{tabular}{|c|c|c|c|c|c|c|}
\hline \multirow[b]{2}{*}{$\begin{array}{l}\text { Ingresos financieros } \\
\text { Gostos finsncieros }\end{array}$} & \multirow{2}{*}{$\begin{array}{c}\begin{array}{c}\text { Saldo al } \\
\text { 31.12.2016 }\end{array} \\
\\
\\
373,053 \\
(51,531)\end{array}$} & \multicolumn{2}{|c|}{\begin{tabular}{|c|} 
Saldo al \\
31.12 .2017 \\
\end{tabular}} & \multicolumn{3}{|c|}{\begin{tabular}{|c|c} 
Yariación Dic 17 - Dic 16 \\
Str(000) & $z$ \\
\end{tabular}} \\
\hline & & $\begin{array}{l}100 x \\
-14 x\end{array}$ & $\begin{array}{l}456,061 \\
{[57,729)}\end{array}$ & $\begin{array}{r}100 x \\
-13 x\end{array}$ & $\begin{array}{l}83,008 \\
{[6,198]}\end{array}$ & $\begin{array}{l}22 x \\
12 x\end{array}$ \\
\hline Hargen fieanciero breto & 321,522 & $86 x$ & 398,332 & $87 z$ & 76,810 & $24 x$ \\
\hline Provizión pars créditos de cobronso dudoss & {$[94,804)$} & $-25 x$ & $(121,182)$ & $-27 z$ & $(26,378)$ & $28 x$ \\
\hline Margen financiero. neto & 226,718 & 612 & 277,150 & 612 & 50,432 & $22 x$ \\
\hline $\begin{array}{l}\text { Ingresos por scrvicios finsncieros } \\
\text { Resultsdo por opersciones finsncierse }\end{array}$ & $\begin{array}{c}31,815 \\
(39,902)\end{array}$ & $\begin{array}{r}9 x \\
-11 x\end{array}$ & $\begin{array}{c}45,369 \\
(35,012)\end{array}$ & $\begin{array}{l}10 x \\
-8 x\end{array}$ & $\begin{array}{l}13,554 \\
4,890\end{array}$ & $\begin{array}{r}43 x \\
-12 x\end{array}$ \\
\hline Hargen operacional & 218,631 & $59 x$ & 287,507 & $63 x$ & 68,876 & $32 x$ \\
\hline $\begin{array}{l}\text { Gostoe de sdminiztración } \\
\text { Deprecisción } \\
\text { Amortissción }\end{array}$ & $\begin{array}{r}(156,508) \\
(3,338) \\
(8,429)\end{array}$ & $\begin{array}{r}-42 z \\
-12 \\
-2 z\end{array}$ & $\begin{array}{r}(196,715) \\
(3,331) \\
(8,667)\end{array}$ & $\begin{array}{r}-43 x \\
-1 z \\
-2 z\end{array}$ & $\begin{array}{r}(40,207) \\
7 \\
(238)\end{array}$ & $\begin{array}{r}26 x \\
0 x \\
3 x\end{array}$ \\
\hline Déficit operacional. meto & 50,356 & $13 x$ & 78,794 & $17 z$ & 28,438 & $56 x$ \\
\hline Provisión pars litigios y demandse & {$[1,001)$} & $\mathbf{0 x}$ & (847) & $0 z$ & 154 & $-15 x$ \\
\hline Pérdids de operaciós & 49,355 & $13 x$ & 77,947 & $17 x$ & 28,592 & $58 x$ \\
\hline Otros ingreses o gates, neto & $(2,990)$ & -12 & $(5,866)$ & $-1 z$ & $(2,876)$ & $96 x$ \\
\hline Utilidad antes del iepuesto a la resta & 46,365 & $12 x$ & 72,081 & $16 x$ & 25,716 & $55 x$ \\
\hline Impuesto s lo rents & $(15,827)$ & $-4 x$ & $(25,428)$ & $-6 z$ & {$[9,601)$} & 612 \\
\hline Pérdida neta & $\overline{30,538}$ & $8 x$ & 46,653 & $10 x$ & 16,115 & 537 \\
\hline
\end{tabular}

Fuente: dictamen

Elaboración: propia

En este estado financiero lo primordial es los ingresos financieros, por ello que al ser una de las cuentas principales le procedió a desglosar su composición para visualizar al detalle a que corresponde su incremento en comparación al año anterior.

Los ingresos financieros están compuestos de la siguiente manera:

Figura 4.6

Composición de los ingresos financieros

\begin{tabular}{|c|c|c|c|c|}
\hline & $\begin{array}{l}\text { Saldos al } \\
31.12 .16 \\
\end{array}$ & $\begin{array}{l}\text { Saldos al } \\
31.12 .17 \\
\end{array}$ & $\begin{array}{c}\text { Variaciones } \\
\text { SI }(000)\end{array}$ & $\%$ \\
\hline Intereses por tarjetas de crédito & 263,543 & 316,369 & 52,826 & $20 \% 1.1 .1$ \\
\hline Comisiones y gastos por cartera de créditos & 107,630 & 137,587 & 29,957 & $28 \% 1.1 .2$ \\
\hline \multirow[t]{2}{*}{ Intereses por disponible } & 1,880 & 2,105 & 225 & $12 \%$ small \\
\hline & 373,053 & 456,061 & 83,008 & $22 \%$ \\
\hline
\end{tabular}

Fuente: dictamen

Elaboración: propia 
La variación S/ (000) 52,826, el cual representa un incremento del 20\% se debe principalmente al aumento de la cartera de colocaciones relacionado a créditos de consumos revolventes y a préstamos personales (consumo no revolvente), este último se viene dando desde abril del 2014.

Como segundo punto de análisis del grafico anteriormente mostrado, se visualiza un incremento del $28 \%$ respecto al importe mostrado al 31.12.2016, se debe al mayor número de afiliados de la Financiera, lo cual ocasiona un mayor ingreso por envíos de estado de cuenta, así como por pago tardío de la cuota, entre otros.

En el caso de los gastos financieros la variación del 12\% corresponde principalmente a los intereses generados por las nuevas emisiones y préstamos realizados en el presente periodo.

También se puede visualizar un incremento en el $28 \%$ de la cuenta provisiones para créditos de cobranza dudosa, este aumento principalmente está relacionado con el incremento de la cartera, como también con los eventos que se han generado en el trascurso del año para la Financieros, siendo el caso del impacto del Fenómeno del Niño Costero como el impacto político.

En el caso de los ingresos por servicios financieros, el incremento del $43 \%$ de la cuenta, en comparación con los montos del mismo periodo corresponde al aumento en el número de tarjetas habientes emitidas hasta la fecha.

Por último el incremento del $26 \%$ en la cuenta gastos de administración, el cual corresponde a una variación de S/ 40,207, se debe principalmente al aumento de personal contratado, como también por el incremento de los gastos por servicios recibidos por terceros el cual se encuentra los gastos por seguro que incremento al estar esté relacionado directamente con el incremento de la tarjetahabiente, asimismo este último está relacionado con el aumento en el pago de servicios recibidos por la recaudación de los establecimientos asociados. Otro motivo por el cual se generó el aumento es por los gastos incurridos por los servicios prestados por tema de publicidad televisiva y marketing.

Continuando con el estudio de la información obtenida se realizó el análisis de los principales ratios de la empresa: los cuales se consideró para el trabajo el ratio de liquidez, 
el ratio de capital global (solvencia), índice de morosidad y rentabilidad. Como también el análisis de las principales cuentas relacionadas al crecimiento de la empresa.

Como se mencionó en el párrafo anterior, uno de los ratios que se analizará es el ratio de liquidez, ya que este nos permitirá medir la capacidad que tiene la Financiera para poder realizar sus deudas y obligaciones a corto plazo.

Para el cálculo del ratio de liquidez se utilizó la que proporciona la SBS, en el cual también da a conocer cuál es la fórmula que se ha utilizado para la realización de la misma, siendo esta última la siguiente.

Figura 4.7

Formula del ratio de liquidez según la S.B.S

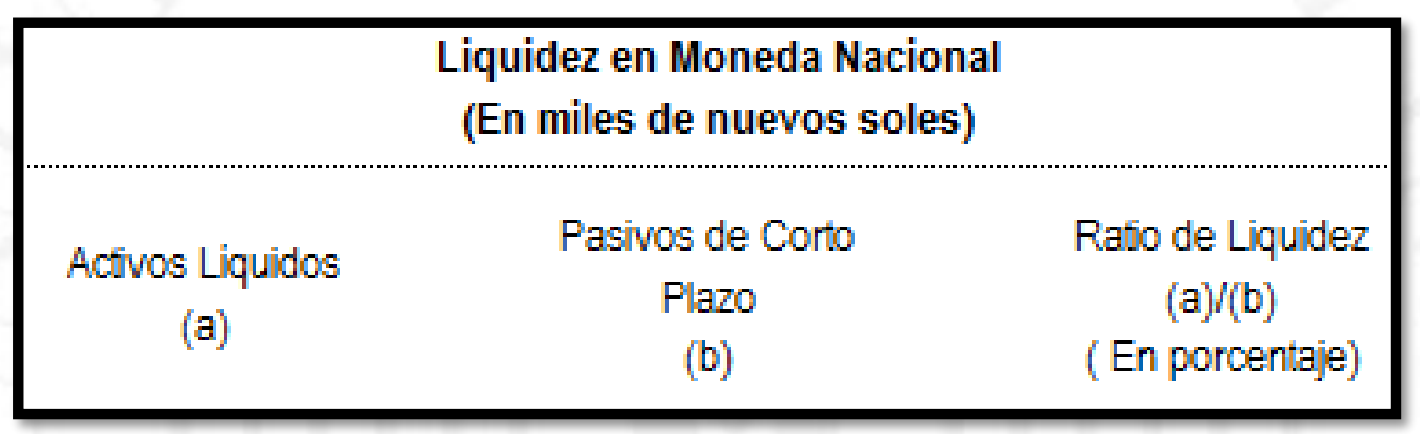

Fuente: Superintendencia de Banca, Seguros y AFP (2018)

De similar forma manera se analizó el ratio de solvencia, que para este caso en especificó también llamado con el nombre "Ratio de Capital Global", es importante mencionar que este ratio permite medir si la Financiera tiene la capacidad de poder cumplir con sus obligaciones a mediano o largo plazo. Al igual del anterior ratio, la fórmula es la proporcionada por la SBS.

Figura 4.8

Formula del ratio de capital global según SBS

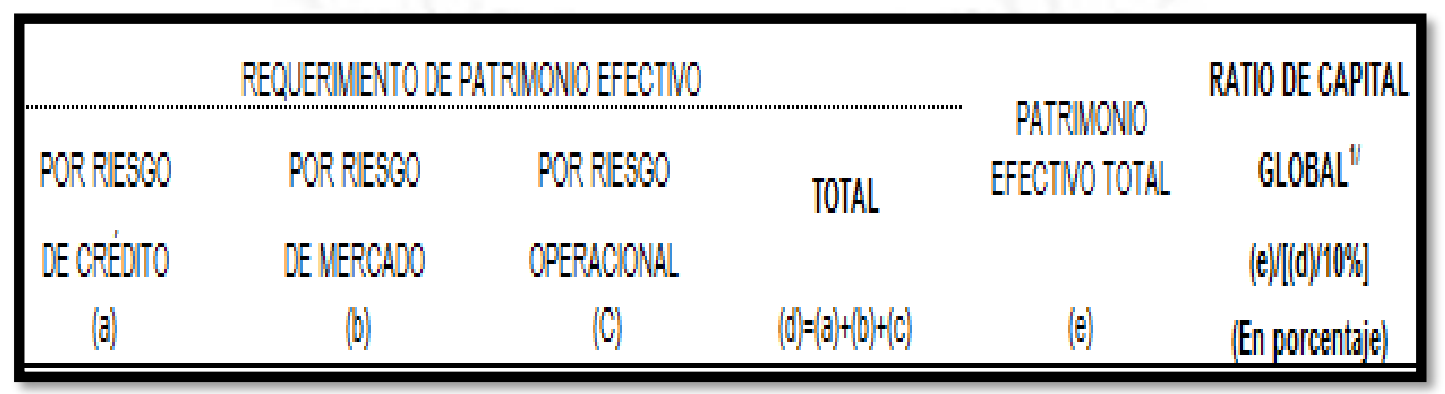

Fuente: Superintendencia de Banca, Seguros y AFP (2018) 
También se escogió como ratio de medición importante en la elaboración del trabajo, el indicador de la morosidad esto se ha determinado para que se analice como fue su crecimiento en el transcurso de estos años.

Por último, se consideró parte del análisis el ratio de rentabilidad siendo específicamente el ROE y ROA para poder medir su evolución en los últimos años.

Después de una breve explicación de los motivos por los cuales se escogió dichos ratios en específicos. Se realizó un análisis de la evolución de los mismos.

\section{Figura 4.9}

Evolución de los indicadores financieros

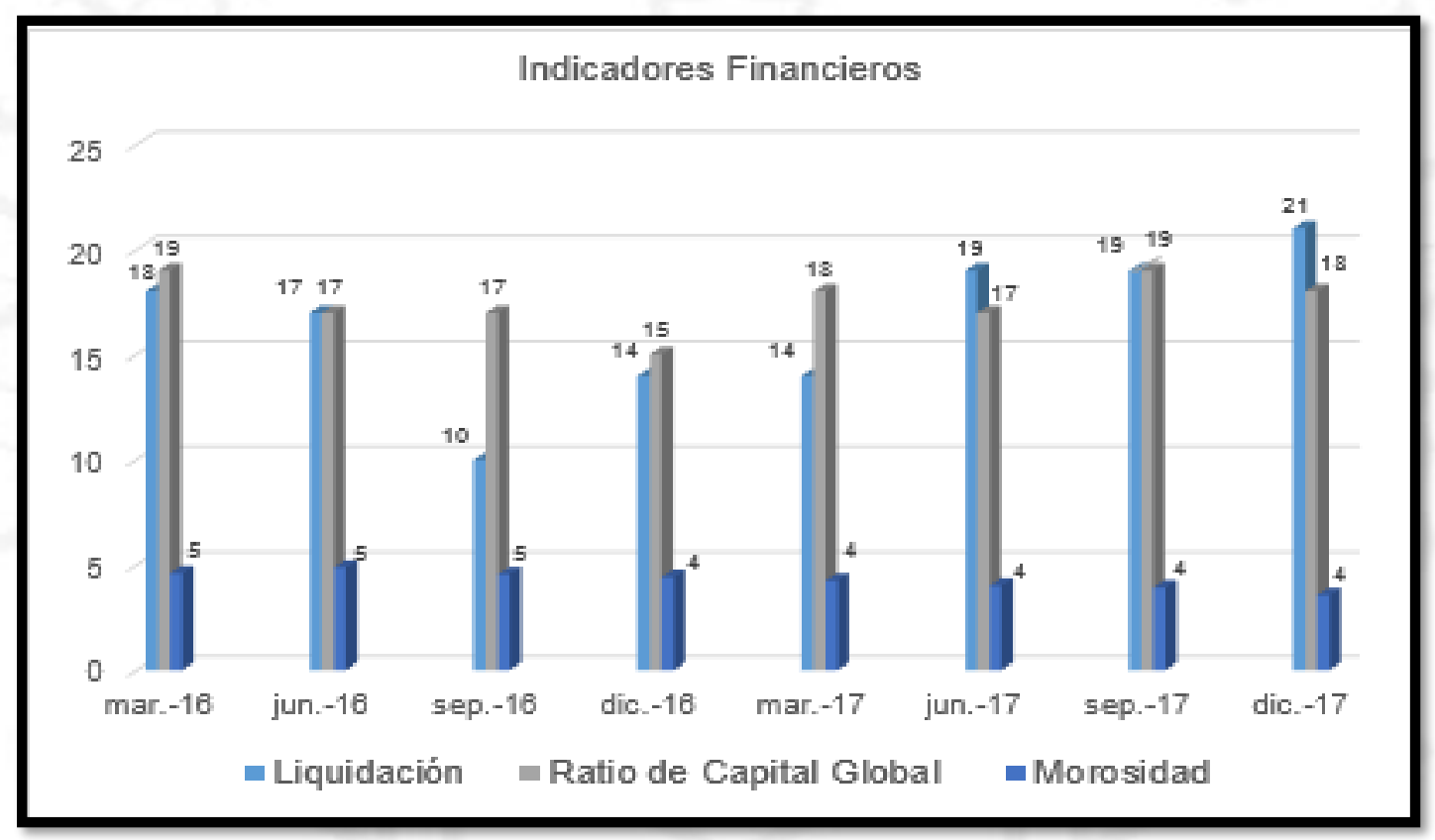

Fuente: Superintendencia de Banca, Seguros y AFP (2016-2017)

Elaboración: propia

Como se puede observar la evolución del ratio de liquidez vs el de solvencia no tiene mucha diferencia, siendo indicadores no muy favorables para la Financiera, ya que considerando que el fondeo que maneja la Financiera en su mayoría es a corto plazo. Es por ello, que tiende a ser preocupante debido a que lo ideal se esperaría que la brecha con el ratio de capital global sea distanciada para que se pueda tener una cobertura al largo plazo. Sin embargo, si se considera que la empresa es relativamente nueva en el sistema financiero por el corto tiempo que se encuentra en el mercado, es normal que a la fecha cuente condichos niveles de liquidez ya que el principal ingreso que tiene es por sus operaciones de cartera. 
Por otro lado, en el índice de morosidad si se logró en obtener buenos resultados ya que se ha mantenido constante desde el cierre del 2016.

En el caso del ratio de rentabilidad, la financiera a pesar de las adversidades del año 2017, se ha mantenido en un notable crecimiento en el ROE y un constante crecimiento en el ROA como se ve en el siguiente gráfico.

Figura 4.10

Evolución de la rentabilidad.

\section{Rentabilidad}

7.00

3000

1500

1000

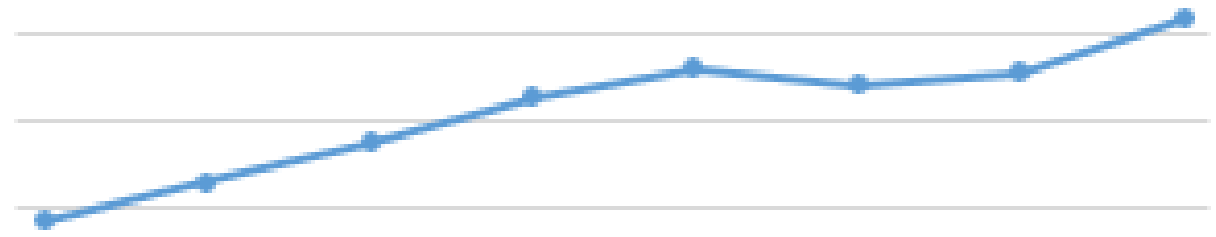

5.00

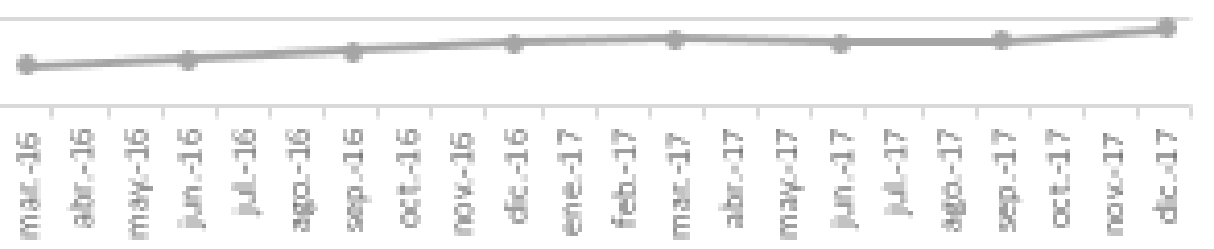

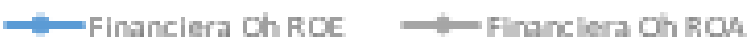

Fuente Superintendencia de Banca, Seguros y AFP (2016-2017)

Elaboración: propia

Con la intención de continuar con el análisis de las cuentas importantes que tiene la compañía se optó por continuar con el tema de la cartera. 
Figura 4.11

Crecimiento de las colocaciones.

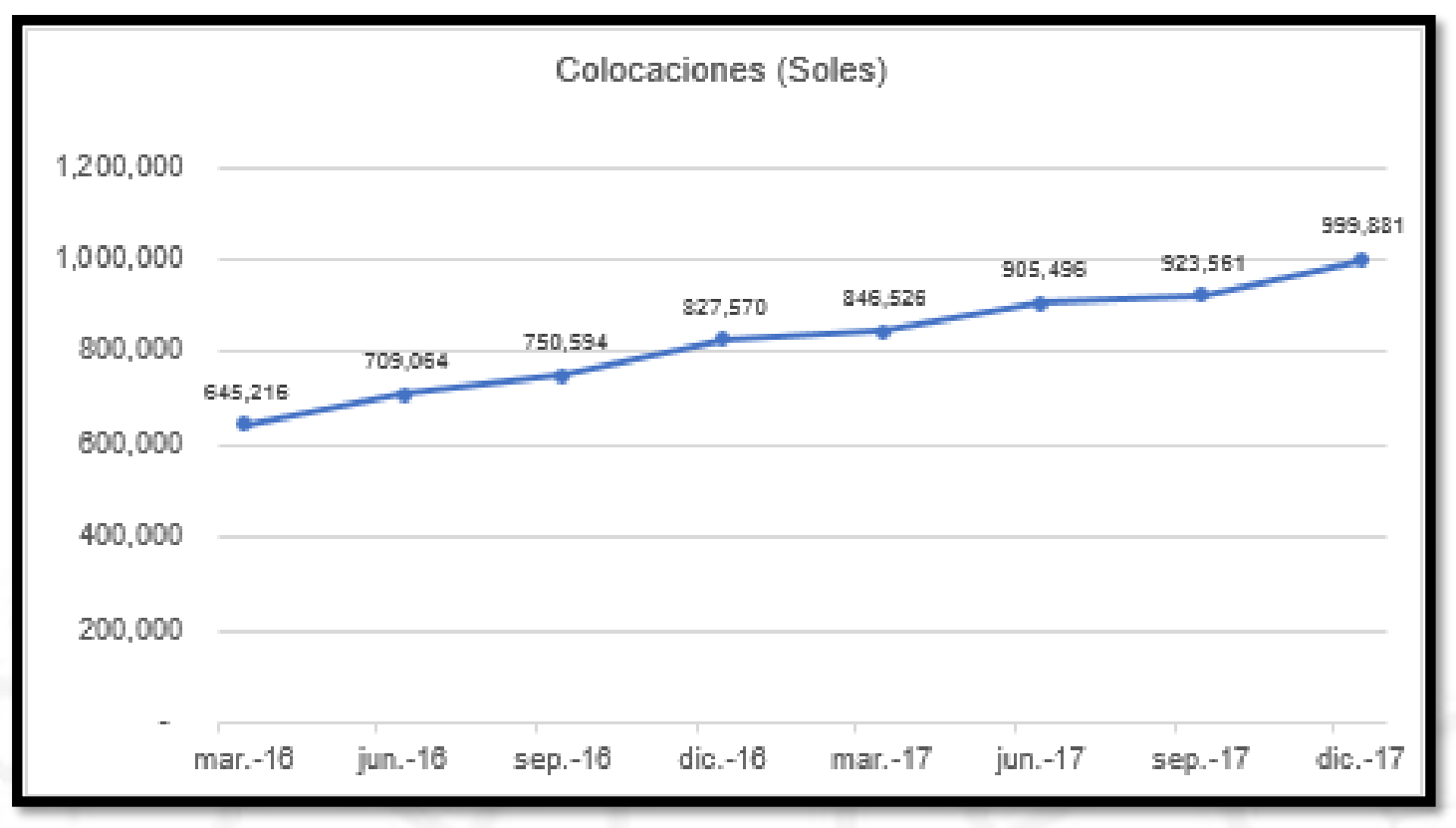

Fuente Superintendencia de Banca, Seguros y AFP (2016-2017)

Elaboración: propia

Como se muestra en el grafico anterior, la calidad de las colocaciones en soles solo se encuentra en constante crecimiento. Y esto se debe a las captaciones de cliente que está logrando la Financiera mediante el fuerte impulso en ofertas que sean llamativos para el público en general como también mayor publicidad televisiva.

Continuando con el análisis de la cartera, se procedió a determinar la evolución del ratio de la cartera atrasada, teniendo como resultado la siguiente imagen. 
Figura 4.12

Crecimiento del ratio de cartera atrasada.

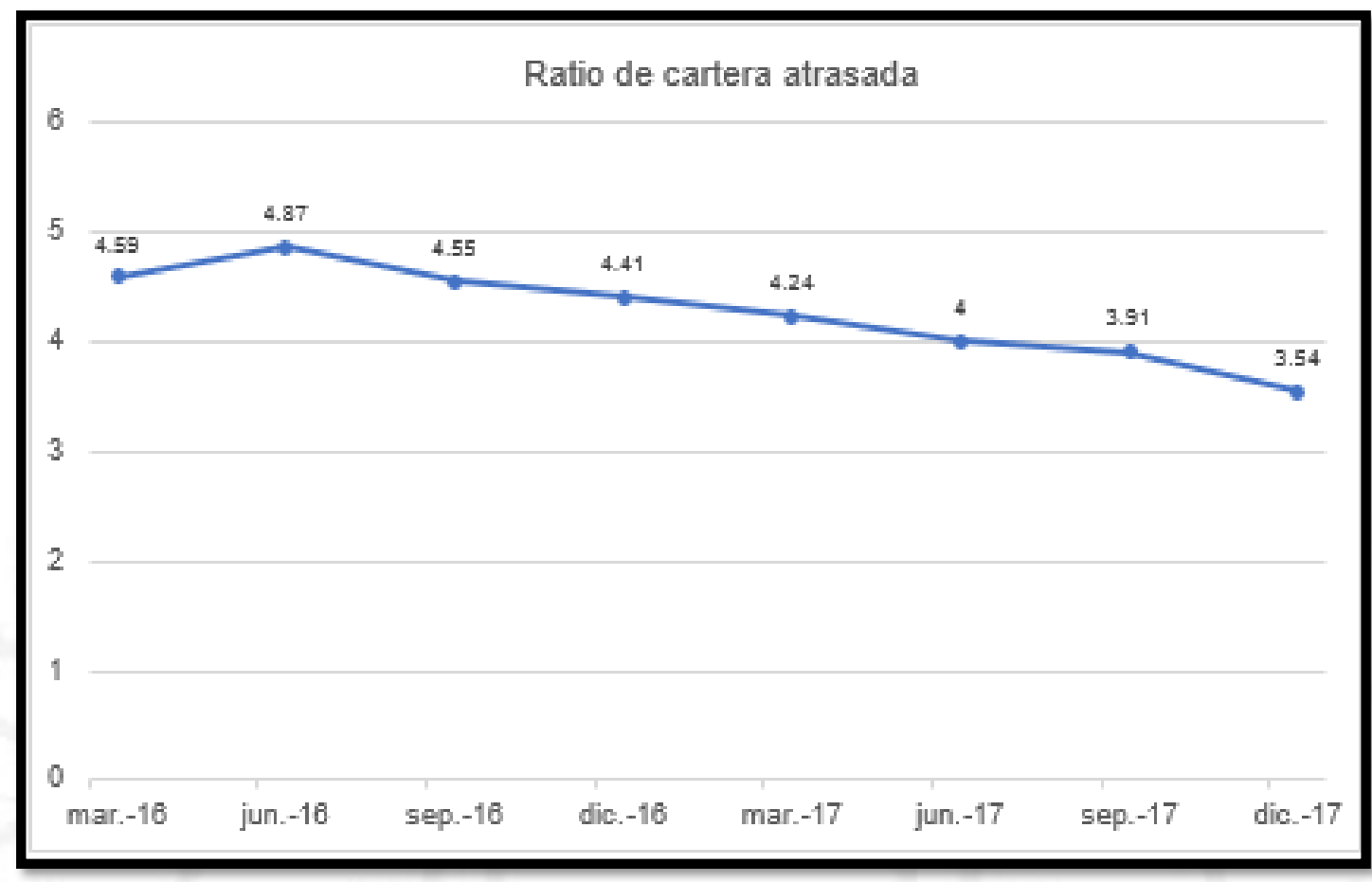

Fuente Superintendencia de Banca, Seguros y AFP (2016-2017)

Elaboración: propia

En este sentido, cabe mencionar que el ratio de cartera atrasada es un indicador que nos permite medir la competitividad de cartera, ya que este determinará que parte de la cartera atrasada se encuentra representada mediante la cartera directa. Si bien es cierto que se tiene un mayor riesgo observado en la industria, la Financiera tiene más controles de riesgo, de evaluación para la admisión y el seguimiento constante efectuado sobre la cartera. Con lo cual la calidad de cartera no se ha visto afectada.

\subsection{Presentación y discusión de resultados}

Como este contexto, se comenzará a realizar un análisis de la información que se obtuvo a la fecha con la intención de hacer un comparativo de como se ha dado el crecimiento con los competidores directos que tiene la empresa para poder determinar una discusión de los resultados.

En este sentido se comenzará a realizar un detalle de la liquidez que ha tenido Financiera Oh S.A. en comparación las demás entidades. 
Figura 4.13

Ratio de liquidez con la competencia.

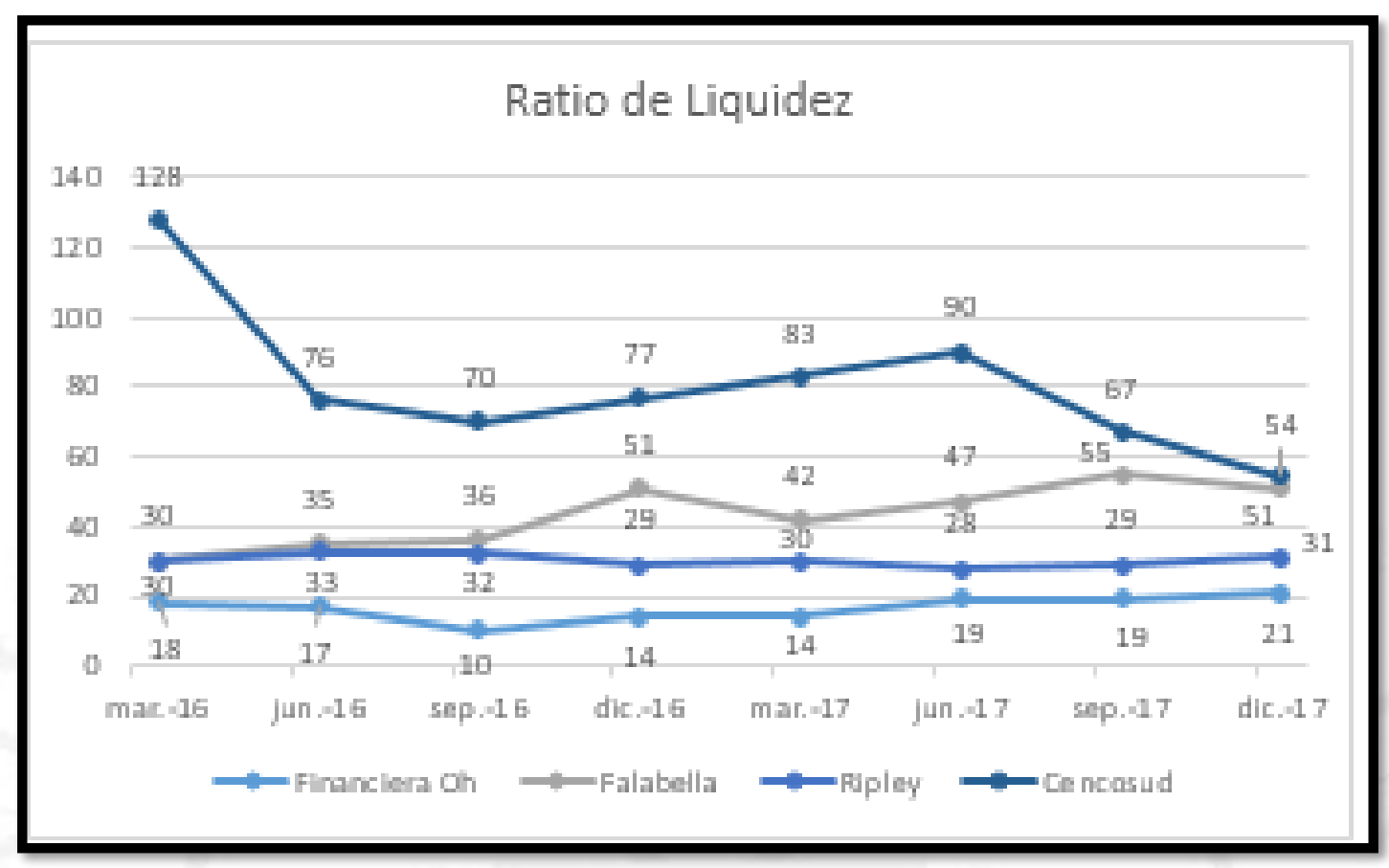

Fuente Superintendencia de Banca, Seguros y AFP (2016-2017)

Elaboración: propia

Con la imagen señalada líneas arriba, se puede verificar que Financiera Oh S.A. cuenta con el menor crecimiento de liquidez entre sus competidores directos. Pero también es importante mencionar, que recién a partir de marzo del 2017 se obtuvo la autorización por la SBS de las captaciones del público, y por tema de implementación del sistema adecuado y las pruebas realizadas para el inicio de sus operaciones por captación, esté comenzó a partir de mayo del mismo año. Es por ello que, a diciembre del 2017, la Financiera solo contaba con 17,116 personas naturas con depósitos por CTS y solo 1 persona natural con cuenta de depósito a plazo.

Por eso, que se espera que para el 2018 la compañía obtenga un mayor ratio de liquidez por las captaciones que comenzaran a realizar con mayor fuerza en dicho año.

En el mismo enfoque, se realizó un cuadro comparativo con el crecimiento del ratio de morosidad, siendo el detalle: 
Figura 4.14

Ratio de morosidad según criterio contable S.B.S. (\%)

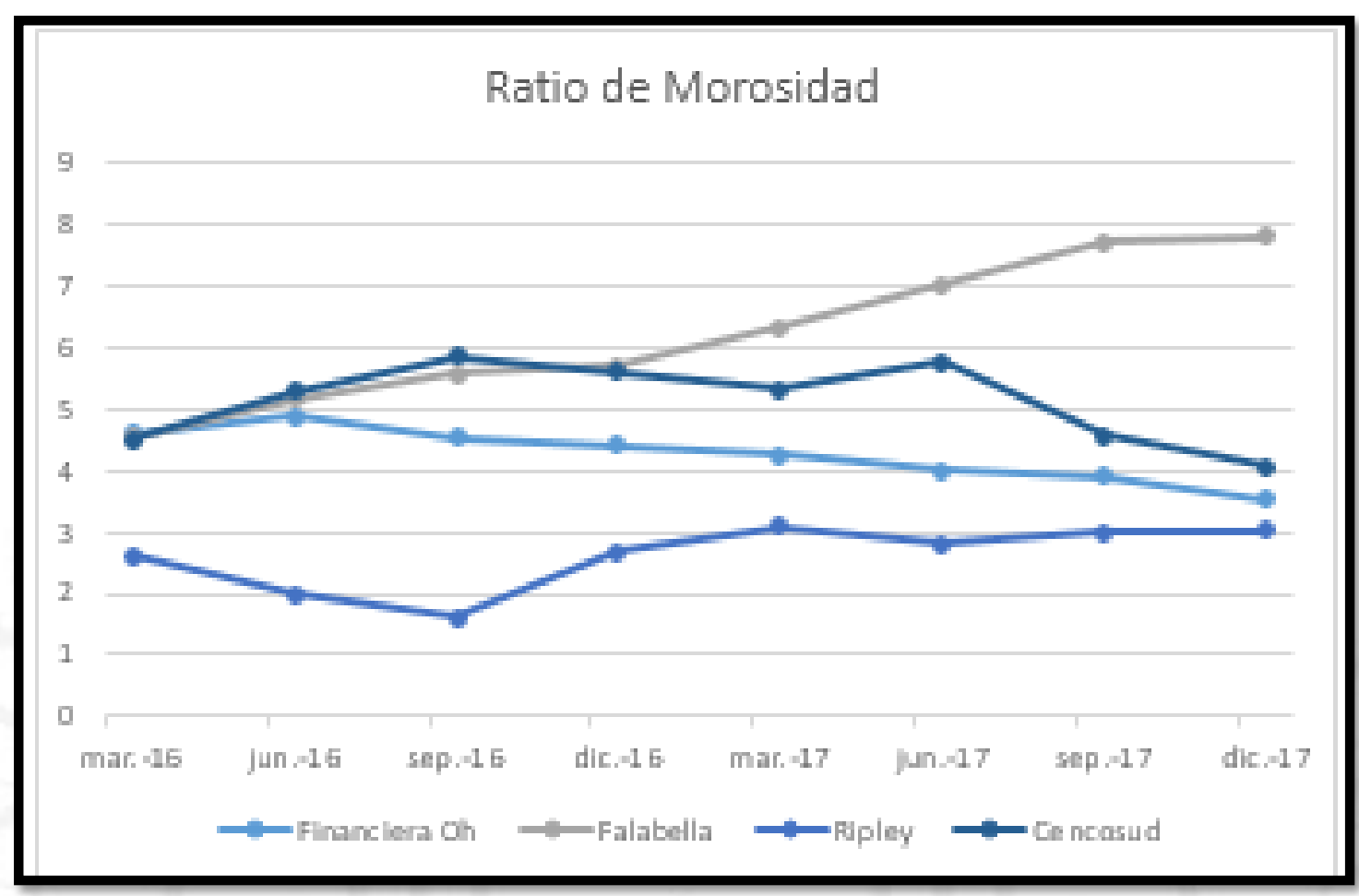

Fuente Superintendencia de Banca, Seguros y AFP (2016-2017)

Elaboración: propia

En el tema de morosidad, se puede confirmar que la Financiera se mantiene con un ratio de morosidad aceptada en comparación con sus principales competidores, ya que desde el primer trimestre del 2016 se encuentra en una leve disminución y a su vez se mantiene constante. Con estos resultados se puede afirmar que la Financiera a pesar de los pocos años que tiene de funcionamiento en el sector financiero, este tiene un buen enfoque en la determinación a que clientes se les otorga o no la tarjeta, por ello pasan por muchos filtros previos a la aprobación.

Ahora en un enfoque de cuentas del estado de situación financiera, se procedió a realizar el crecimiento de sus tres principales cuentas. 
Figura 4.15

Principales cuentas del activo en (M.M.)

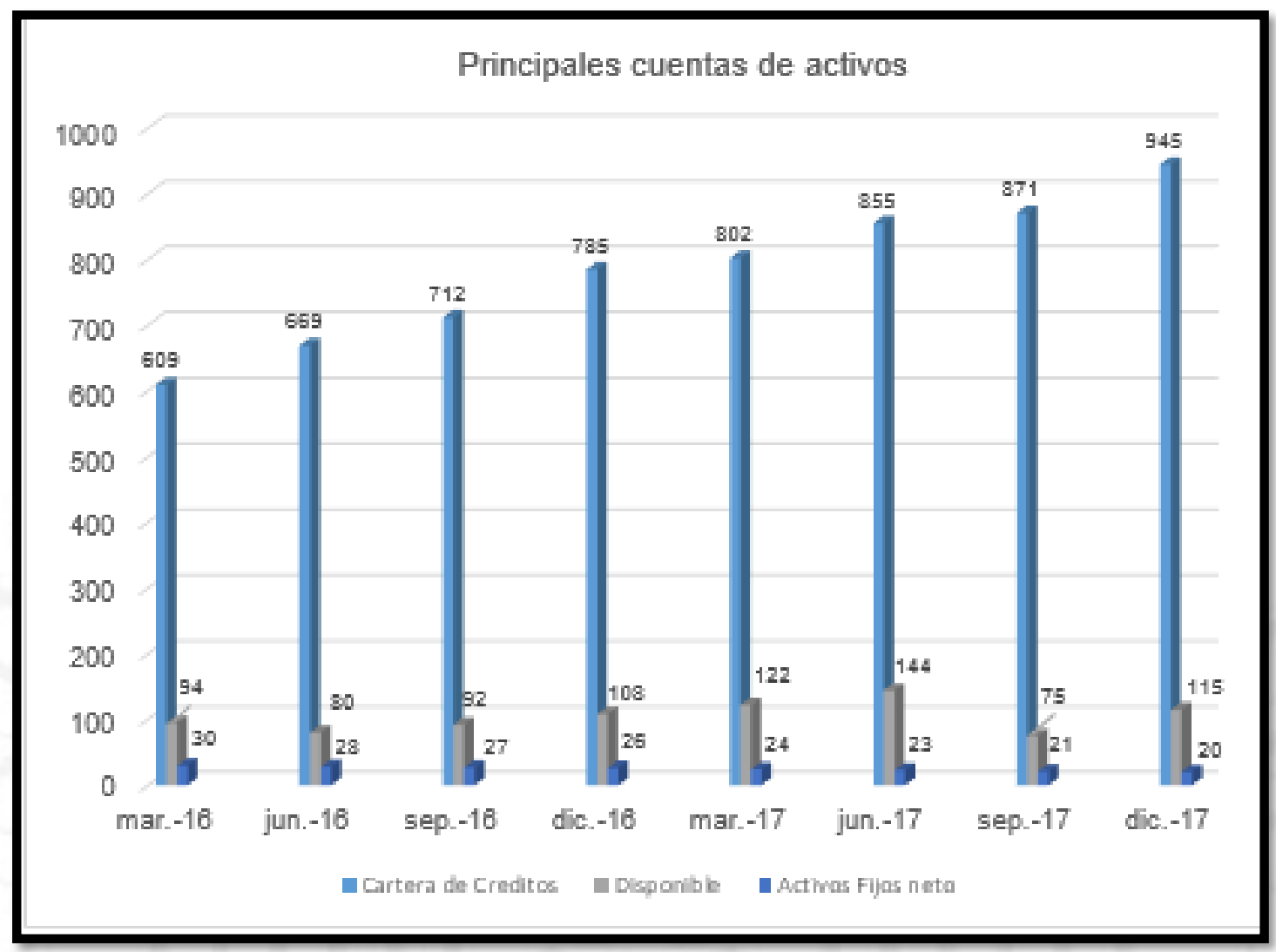

Fuente Superintendencia de Banca, Seguros y AFP (2016-2017)

Elaboración: propia

Como se mencionó anteriormente en uno de los análisis realizados, la principal cuenta que tiene la Financiera es la cartera de créditos como parte de los activos. Se puede visualizar el constante crecimiento del mismo, teniendo en diciembre de 2017 un crecimiento del $8.50 \%$ en comparación con setiembre del mismo año. Este crecimiento se debe al gran impulso en marketing y publicidad que están utilizando para la captación de más clientes al igual de estrategias de ofertas con sus establecimientos asociados con el objetivo que sea más interesantes para el público en general.

La cuenta disponible está compuesta principalmente de las cuentas corrientes, el encaje en el BCRP, y por los fondos en garantía.

Y por último en cuestión de los activos fijos, estos están en constante disminución, ya que desde el año pasado no realizan alguna compra significativa en activos. 
Para el tema de pasivos y patrimonio se realizó el mismo procedimiento. Con lo cual se obtuvo el siguiente cuadro.

Figura 4.16

Principales cuentas del pasivo y patrimonio.

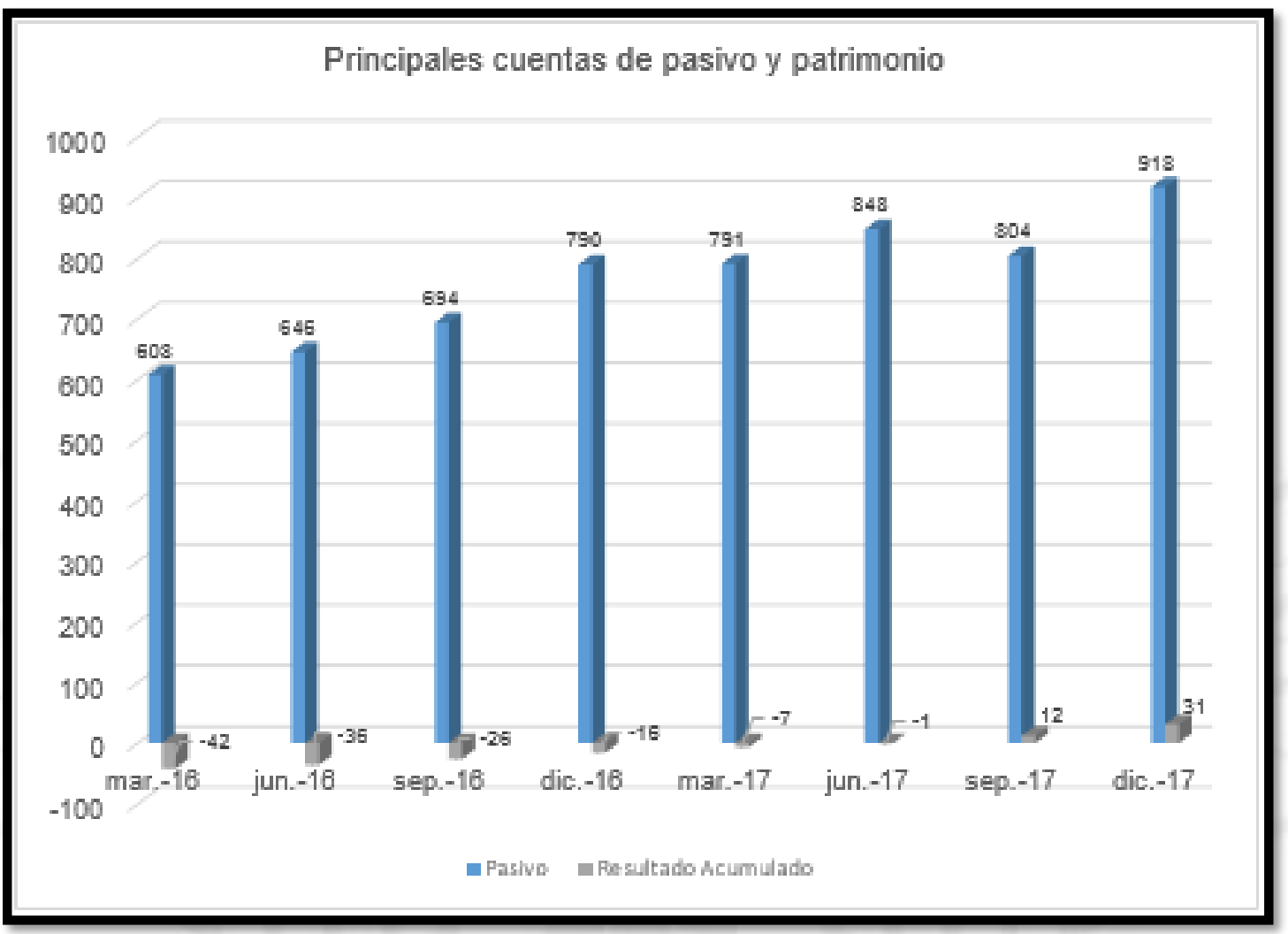

Fuente Superintendencia de Banca, Seguros y AFP (2016-2017)

Elaboración: propia

En el caso de los pasivos, en el cuadro está conformados por las deudas contratadas y las cuentas por pagar a corto plazo. Las cuales en su mayoría se orinaron por el incremento en la emisión de Certificados de depósito y por los adeudos.

La utilidad al cierre de diciembre del 2017 se registró por un monto de S/ 47 millones aproximadamente, dicho monto permitió que se revierta la pérdida acumulada que se tenía hasta los meses atrás.

Para la elaboración de la proyección por los años 2018, 2019 y 2020 se utilizó primero como datos históricos los estados financieros obtenidos de los dictámenes correspondientes a los años 2015, 2016 y 2017 respectivamente. Luego se procedió a realizar el cálculo de las variaciones por cada monto mediante el uso del análisis vertical, una vez determinada las cifras por cada periodo se armó la proyección para el cual se 
consideró el PBI estimado para nuestro sector financiero en los años seleccionados anteriormente para las cuentas que no son considerados significativos para la empresa, ya que para otras cuentas si se consideró otros criterios.

Figura 4.17

Proyección de los estados de resultados.

\begin{tabular}{|c|c|c|c|c|c|c|c|c|c|}
\hline \multirow{2}{*}{ (En nuevos soles) } & \multicolumn{3}{|c|}{ Projectado } & & & & \multicolumn{3}{|c|}{ EN PORCENTAJES } \\
\hline & 2020 & 2019 & 2018 & 2017 & 2016 & 2015 & 2017 & 2016 & 2015 \\
\hline & $6.00 \%$ & $6.00 \%$ & $6.00 \%$ & & & & & & \\
\hline Ingresos financieros & $543,175.95$ & $512,430.14$ & $483,424.66$ & $456,061.00$ & $373,053.00$ & $278,007.00$ & $100.00 \%$ & $100.00 \%$ & $100.00 \%$ \\
\hline Gastos financieros & $-69,370.81$ & $.65,444.16$ & $61,739.78$ & $.57,729.00$ & $.51,531.00$ & $.32,923.00$ & $.12 .66 \%$ & $.13 .81 \%$ & $.11 .84 \%$ \\
\hline Margen financiero Bruto & $473,805.13$ & 446.985 .98 & $421,684.88$ & $398,332.00$ & $321,522.00$ & $245,084.00$ & $87.34 \%$ & $86.19 \%$ & $88.16 \%$ \\
\hline Provisión para créditos de cobranza dudosa, net & . $150,024,06$ & $.141,532.13$ & $.133,520.88$ & $.121,182.00$ & $.94,804,00$ & $69,154,00$ & $.26 .57 \%$ & $.25 .41 \%$ & $.24 .87 \%$ \\
\hline Margen Financiero,neto & $334,644.60$ & $315,702.45$ & $297,832.50$ & $277,150.00$ & 226.718 .00 & 175.930 .00 & $60.77 \%$ & $60.77 \%$ & $63.28 \%$ \\
\hline Ingresos por servicios financieros & $48,158.68$ & $45,432.72$ & $42,861.06$ & $45,369.00$ & $31,815.00$ & $22,580.00$ & $9.95 \%$ & $8.53 \%$ & $8.12 \%$ \\
\hline Gastos por servicios financieros & .21.84 & .20 .60 & -19.43 & .55 .00 & 0.00 & 0.00 & .0.01\% & $0.00 \%$ & $0.00 \%$ \\
\hline Resultado por operaciones financieras & $.51,881.12$ & $.48,944.45$ & $-46,174,01$ & $.34,957,00$ & $.39,902,00$ & $.28,616,00$ & $.7 .66 \%$ & $.10 .70 \%$ & $-10.29 \%$ \\
\hline Margen operacional & $330,900.33$ & $312,170.12$ & $294,500.11$ & $287,507.00^{\prime}$ & $218,631.00$ & $169,894.00$ & $63.04 \%$ & $58.61 \%$ & $61.11 \%$ \\
\hline Gastos de administración & $.241,971.10$ & $.228,274.62$ & $.215,353.41$ & $.196,715,00$ & . $156,508.00$ & . $134,988.00$ & $.43 .13 \%$ & $.41 .95 \%$ & $.48 .56 \%$ \\
\hline Depreciación & $.4,543.98$ & $-4,286.78$ & $-4,044.13$ & $\cdot 3,331.00$ & $.3,338.00$ & $\cdot 2,459.00$ & $.0 .73 \%$ & $.0 .89 \%$ & $-0.88 \%$ \\
\hline Amortización & $.12,870.94$ & $\cdot 12,142,40$ & $.11,455.09$ & $-8,667.00$ & $-8,429.00$ & $8,198.00$ & $.1 .90 \%$ & $.226 \%$ & $.2 .95 \%$ \\
\hline Superávit operacional, neto & $71,514.30$ & $67,466.33$ & $63,647.48$ & $78.794 .00^{\top}$ & $50,356.00$ & $24,249.00$ & $17.28 \%$ & $13.50 \%$ & $8.72 \%$ \\
\hline Provisión para incobrabilidad, litigios y demanda: & $\cdot 12,464.53$ & $\cdot 11,758.99$ & $\cdot 11,093.39$ & .847 .00 & $\cdot 1,001.00$ & $-1,196.00$ & -0.19\% & $.0 .27 \%$ & $.0 .43 \%$ \\
\hline Utilidad de operación & $69,913.29$ & $65,955.93$ & $62,222.58$ & $77.947 .00^{\prime}$ & $49,355.00$ & $23,053.00$ & $17.09 \%$ & $13.23 \%$ & $8.29 \%$ \\
\hline Otros ingresos (gastos), neto & $-2,990.67$ & $\cdot 2,821.38$ & $-2,661.68$ & $.5,866.00$ & $-2,990.00$ & $1,212,00$ & $.1 .29 \%$ & $.0 .80 \%$ & $0.44 \%$ \\
\hline Utilidad antes de impuestos & 66.922 .62 & 63.134 .55 & 59.560 .90 & $72,081.00^{\prime}$ & 46.365 .00 & $24,265.00$ & $15.81 \%$ & $12.43 \%$ & $8.73 \%$ \\
\hline Impuesto a la renta & $.24,024.24$ & $\cdot 22,664.38$ & $\cdot 21,381.49$ & $.25,428,00$ & $\cdot 15,827,00$ & $-9,593.00$ & $.5 .58 \%$ & $.4 .24 \%$ & $.3 .45 \%$ \\
\hline Utilidad neta del año & $42,898.38$ & $40,470.17$ & $38,179.41$ & $46,653.00^{\prime}$ & $30,538.00$ & $14,672.00$ & $10.23 \%$ & $8.19 \%$ & $5.28 \%$ \\
\hline
\end{tabular}

Fuente Superintendencia de Banca, Seguros y AFP (2015-2017)

Elaboración: propia 
Figura 4.18

Proyección del estado de situación financiera.

\begin{tabular}{|c|c|c|c|c|c|c|c|c|c|}
\hline \multicolumn{4}{|c|}{ Profectado } & & & & \multicolumn{3}{|c|}{ EN PORCENTAJES } \\
\hline (En nuevos soles) & 2020 & 2019 & 2018 & 2017 & 2016 & 2015 & 2017 & 2016 & 2015 \\
\hline Depósitos en el Banco Central de Reservac & $41,911.77$ & $39,539.41$ & $37,301.33$ & $22,159.00$ & $26,344,00$ & $35,506.00$ & $1.90 \%$ & $2.65 \%$ & $4.49 \%$ \\
\hline Depósitos en bancos del país & $95,696.30$ & $90,279.53$ & $85,169.36$ & $72,771.00$ & $63,809.00$ & $63,146.00$ & $6.22 \%$ & $6.42 \%$ & $7.98 \%$ \\
\hline Depósitos en bancos del egtterior & 366.24 & 345.51 & 325.95 & 564.00 & 305.00 & . & $0.05 \%$ & $0.03 \%$ & $0.00 \%$ \\
\hline Fondos sujetos a restricción & $25,851.62$ & $24,388.32$ & $23,007.85$ & $19,503.00$ & $17,261.00$ & $17,145.00$ & $1.67 \%$ & $1.74 \%$ & $2.17 \%$ \\
\hline Total Activo Corriente & 163.825 .92 & $154,552.75$ & 145.804 .48 & $114,997.00$ & $107,719.00$ & $115,797.00$ & $9.84 \%$ & $10.83 \%$ & $14.63 \%$ \\
\hline Cartera de créditos, neto & $1,123,740.46$ & $1,060,132.51$ & $1,000,125.01$ & $945,121.00$ & $785,280.00$ & $586,009.00$ & $80.84 \%$ & $78.95 \%$ & $74.04 \%$ \\
\hline Mobiliario y equipos, neto & $15,921.41$ & $15,020.20$ & $14,170.00$ & $11,336.00$ & $10,958.00$ & $10,756.00$ & $0.97 \%$ & $1.10 \%$ & $1.36 \%$ \\
\hline Intangibles, neto & $22,903.39$ & $21,606.97$ & $20,383.93$ & $8,832.00$ & $14,682.00$ & $21,394,00$ & $0.76 \%$ & $1.48 \%$ & $2.70 \%$ \\
\hline Cuentas por cobrar y otros activos & $66,087.56$ & $62,346.76$ & $58,817,69$ & $79,029.00$ & $68,573.00$ & $52,157,00$ & $6.76 \%$ & $6.89 \%$ & $6.59 \%$ \\
\hline Activo por impuesto a la renta diferido & . & . & . & $9,837.00$ & $7,469.00$ & $5,405.00$ & $0.84 \%$ & $0.75 \%$ & $0.68 \%$ \\
\hline Total Activo No corriente & $1,228,652.82$ & $1,159,106.44$ & $1,093,496.63$ & $1,054,155.00$ & $886,962.00$ & $675,721.00$ & $90.16 \%$ & $89.17 \%$ & $85.37 \%$ \\
\hline Total Activo & $1,392,478.74$ & $1,313,659.19$ & $1,239,301.12$ & $1,169,152.00$ & $994,681.00$ & $791,518.00$ & $100.00 \%$ & $100.00 \%$ & $100.00 \%$ \\
\hline Obligaciones con el público & $38,353.06$ & $36,182.13$ & $34,134,09$ & $21,137,00$ & $2,328.00$ & $1,749.00$ & $1.81 \%$ & $0.23 \%$ & $0.22 \%$ \\
\hline Adeudados & $317,147.48$ & $299,195.74$ & $282,260.13$ & $125,122.00$ & $250,465.00$ & $256,807,00$ & $10.70 \%$ & $25.18 \%$ & $32.44 \%$ \\
\hline Valores y títulos en circulación & $589,479.24$ & $577,923.30$ & $567,021.48$ & $707,551.00$ & $477,151,00$ & $322,957.00$ & $60.52 \%$ & $47.97 \%$ & $40.80 \%$ \\
\hline Cuentas por pagar & $63,772.25$ & $60,162.50$ & $56,757.08$ & $55,697,00$ & $47,060.00$ & $33,594,00$ & $4.76 \%$ & $4.73 \%$ & $4.24 \%$ \\
\hline Otros pasivos & $11,179.75$ & $10,546.94$ & $9,949.94$ & $8,646.00$ & $13,331.00$ & $2,603.00$ & $0.74 \%$ & $1.34 \%$ & $0.33 \%$ \\
\hline Total pasivo & $1,019.931 .78$ & $984,010.61$ & 950.122 .71 & $918,153.00$ & $790,335.00$ & $617,710.00$ & $78.53 \%$ & $79.46 \%$ & $78.04 \%$ \\
\hline Capital Social & $220,256.00$ & $220,256,00$ & $220,256.00$ & $220,256,00$ & $220,256.00$ & $220,256.00$ & $18.84 \%$ & $22.14 \%$ & $27.83 \%$ \\
\hline Resultado del Ejercicio & $42,898.38$ & $40,470.17$ & $38,179.41$ & $46,653,00$ & $30,538.00$ & $14,672.00$ & $3.99 \%$ & $3.07 \%$ & $1.85 \%$ \\
\hline Resultados Acumulados & $109,392.58$ & $68,922.41$ & $30,743.00$ & $\cdot 15,910,00$ & $.46,448,00$ & $.61,120.00$ & $.1 .36 \%$ & $-4.67 \%$ & $.7 .72 \%$ \\
\hline Total Patrimonio & $372,546.96$ & $329,648.58$ & $289,178.41$ & $250,999.00$ & $204,346.00$ & $173,808.00$ & $21.47 \%$ & $20.54 \%$ & $21.96 \%$ \\
\hline Total Pasivo y Patrimonio & $1,392,478.74$ & $1,313,659.19$ & $1,239,301.12$ & $1,169,152.00$ & $994,681.00$ & $791,518.00$ & $100.00 \%$ & $100.00 \%$ & $100.00 \%$ \\
\hline
\end{tabular}

Fuente Superintendencia de Banca, Seguros y AFP (2015-2017)

Elaboración: propia

Continuando con el análisis, es importante mencionar que uno de los principales riesgos que tiene la Financiera Oh S.A., es el riesgo de mercado, el cual puede impactar a sus instrumentos financieros. Por ello es posible el impacto de la NIIF 9, en sus operaciones a partir del ejercicio 2018. Si bien es cierto, que hasta la fecha que se realiza este documento la SBS aún no se ha pronunciado sobre su aplicación para el sistema financiero. Pero para realizar las proyecciones del año 2018 al 2020 se consideró los posibles impactos que puede tener la financiera en sus Estados Financieros, es por ello que en las cuentas del Estado de Resultados, se incrementó en un $2 \%$ adicional el crecimiento de los ingresos financieros considerando que esta cuenta está en crecimiento y a su vez en el mismo porcentaje las cuentas de provisiones para créditos de cobranza dudosa y las provisiones de incobrabilidad, litigios y demandas ya que se asume que estas estimaciones crecerán por la aplicación de la NIIF. Para el caso del Estado de Situación Financiera las cuentas que se asumen que tendrán un impacto serán la de cartera de créditos y las cuentas por cobrar para las cuentas de total de activos, pero para las cuentas 
de pasivos, se consideró que las obligaciones con el público incrementaran en un 2\% adicional, considerando que a partir del 2018 comenzarán a realizar captaciones del público en general y se escogió como supuesto que la empresa decidirá no endeudarse mucho mediante la cuenta Valores y Títulos para no tener mucho impacto de la NIIF 9 por los instrumentos financieros, siendo por ello que se asume que la Financiera optará por tener mayor su cuenta de Adeudos por ello que a esta última cuenta se consideró un incremento adicional del $2 \%$ teniendo como resultado la proyección que se colocó líneas arriba.

Es importante mencionar que se utilizó el criterio anteriormente mencionados porque se esperan serán los impactos por la aplicación de la norma, pero estos pueden variar, ya que como se sabe la NIIF 9 en líneas generales para el sistema financiero es el registro y valuación del deterioro sobre los préstamos y cuentas por cobrar de la compañía la cual está basada en la perdida crediticia esperada. Es por ello que está perdida esperada va a requerir estimaciones de perdidas basadas en información razonables y fundamentadas de los hechos pasados, de las condiciones presentes y de los sucesos razonables y justificables respecto a las condiciones económicas futuras.

Se procedió a realizar un cuadro con las principales diferencias entre ambas normas, siendo estas la NIIF 9 y la NIC 39, en los tres puntos que se consideró importantes siendo estos la clasificación, medición y reconocimiento. El cual se presenta en el siguiente gráfico. 
Figura 4.19

Diferencias entre la NIC 39 y la NIIF 9

\begin{tabular}{|c|c|c|}
\hline Diferencias & NIIC 39 & WIIF9 \\
\hline \multirow[t]{2}{*}{ Clasificación } & $\begin{array}{l}\text { Para activos } \\
\text { - a valor razonable con cambios en el resultao } \\
\text { - disponible para la venta } \\
\text { - prestamos y cuentas por cobrar } \\
\text { - mantenido hasta el vencimiento }\end{array}$ & $\begin{array}{l}\text { Paraactivos } \\
\text { - valor razonable a través de otros resultados integrales } \\
\text { - valor razonable a través de resultados. } \\
\text { - costo amortizado }\end{array}$ \\
\hline & $\begin{array}{l}\text { Parapasivos } \\
\text { - pasivos financieros } \\
\text { - otros }\end{array}$ & $\begin{array}{l}\text { Parapasivos } \\
\text { - al valor razonable a través de resultados. } \\
\text { - costo amortizado }\end{array}$ \\
\hline Medición & Luego seran medidos según su clasificación & $\begin{array}{l}\text { Inicialmente se miden de la mismas manera } \\
\text { Luego seran medidos según clasificación: Sin embargo, para activos } \\
\text { - Costo amortizado: Debe cumplir con: } \\
\text { mantener el activo en un negocio contractual para cobrar flujos de efectivo } \\
\text { el cual debe tener una fecha y pago específico. } \\
\text { - Valor razonable a través de otros resultados integrales: Debe cumplir con: } \\
\text { mantener el activo en un negocio contractual para cobrar flujos de efectivo } \\
\text { yvendiendo los activos financieros, los cuales debe tener una fecha y pago específico. } \\
\text { - Valor razonable a través de resultados. }\end{array}$ \\
\hline Reconocimiento & uando la entidad se & forme parte de contrato, independientemente de ser pagado o no. \\
\hline
\end{tabular}

Fuente: Norma Internacional de Contabilidad 39 y Norma Internacional de Información Financiera 9

Elaboración: propia

Por último, las líneas generales la principal diferencia entre ambas normas es que la NIC 39 se basa en la perdida crediticia incurrida, en este sentido solo considera los hechos presentes y pasados, pero la NIIF 9 que entrará en vigencia, está basada en la perdida crediticia esperada, en este sentido solo considera lo que se espera pasará en el futuro. 


\section{CONCLUSIONES}

a) Financiera Oh S.A al ser una entidad financiera que forma parte del Grupo Intercorp tiene beneficios a futuro y es más probable su constante crecimiento en el mercado, mediante los convenios que mantiene vigentes con sus establecimientos asociados.

b) La fuerte estrategia que está comenzando a implementar desde el presente año, mediante el uso de publicidad televisiva y marketing, general que el público logre asociar con mayor facilidad a la tarjeta con las ofertas de los establecimientos afiliados.

c) Sin duda su oportuna toma de decisiones le ha permitido su contante crecimiento, en este sentido se menciona cuáles son las que se ha identificado que realizo la financiera. En primer momento, con la firma por la exclusividad de sus tarjetas en tiendas Supermercados Peruanos como los otros establecimientos le permite que su cartera se encuentre en constante crecimiento.

d) Continuando con el detalle de lo identificado, se observa que la financiera implementa fuertes barreras de selección a las personas que podrán contar con su tarjeta ya que en este corto tiempo que se encuentra en el sistema financiero, cuenta con un menor índice de morosidad en comparación con sus competidores directos.

e) En nuestro análisis de ratios, se determinó que no cuentan con un alto índice de liquidez, el cual a largo plazo puede generar algunos inconvenientes a la compañía, ya que puede correr el riesgo de no contar con la disponibilidad oportuna para la constante rotación de su cartera. 
f) Otro resultado de su oportuna toma de decisiones es por la oportuna determinación del monto de liquidez que necesitaran en un tiempo en específico permite que sus cuentas por adeudos y valores y títulos no son muy elevadas. 


\section{RECOMENDACIONES}

a) Como se sabe a partir de inicios del 2017, la Financiera cuenta con la autorización de la SBS en obtener las captaciones por CTS y DLP, si bien se entiende que, al estar en un proceso de adaptación de los programas adecuados como la correcta administración de la misma, ellos hayan determinado que este primer año solo ofrecerán a los trabajadores pertenecientes al grupo. Se le recomienda que para el próximo año puedan ofrecer al público en general, para que de esta manera pueda contar con mayor liquidez.

b) Continuar con la estrategia comercial que está aplicando hasta el momento, ya que estas transacciones le permite ser más rentable a la compañía. Al ya no tener un resultado acumulado en negativo el posible efecto a corto plazo que se tendría será que las entidades bancarias ya no solicitaran fondos en garantía como tienen registrados a la fecha por los adeudos, valores y títulos.

c) Ver posibles alianzas, acuerdos o convenios que puedan firmar, el cual le permita tener mayor diversificación o de llegar a mayor cantidad de público con sus tarjetas. Se le recomienda este punto ya que es importante mencionar que su convenio firmado con Supermercados Peruanos S.A en el 2013 está por vencer en el2018. Aunque aún quedaría vigente el convenio de Supermercados Peruanos y Tiendas Peruanas, lo adecuado es ver la posibilidad de nuevas alianzas.

d) Como último punto, se comentó que a la fecha la Superintendencia de Banca, Seguros y AFP (S.B.S) aún no se pronuncia sobre la aplicación de la NIIF 9 para las entidades financieras, ni cuando sería su próxima aplicación o no. En este sentido, se le recomienda a la entidad financiera que como le es permitido, mediante la provisión voluntaria consideré los riesgos o costos que le puede incurrir al implementar dicha norma. 


\section{REFERENCIAS}

Banco Central de Reserva del Perú (2018). Encuesta de Expectativas

Macroeconómicas. Recuperado el 26 de setiembre, 2018 del sitio de Internet del

Banco Central de Reserva del Perú:

http://www.bcrp.gob.pe/estadisticas/encuesta-de-expectativas-

macroeconomicas.html.

Financiera OH S.A (2017). Estados financieros al 31 de diciembre de 2016 y de 2015 junto con el dictamen de los auditores independientes. Recuperado del sitio de Internet de la Superintendencia del Mercado de Valores:

http://www.smv.gob.pe/ConsultasP8/temp/FUNO_EEFF\%20AUDITADOS_31 $\underline{1216 . p d f}$

Financiera OH S.A (2018). Estados financieros al 31 de diciembre de 2017 y de 2016 junto con el dictamen de los auditores independientes. Recuperado del sitio de Internet de la Superintendencia del Mercado de Valores: http://www.smv.gob.pe/ConsultasP8/temp/FUNO_EEFF\%20AUDITADOS_31 1217.pdf

Financiera Oh S.A (2018). Documento de Información Anual 2017. Recuperado del sitio de Internet de Tarjeta Oh:

https://www.tarjetaoh.com.pe/repositorioaps/0/0/jer/memoria_anual/Memoria\% 20Anual\%202017.pdf

IFRS Foundation (2014). NIIF 9 - Instrumentos Financieros. Recuperado del sitio de Internet del Ministerio de Economía y Finanzas:

https://www.mef.gob.pe/contenidos/conta_publ/con_nor_co/vigentes/niif/NIIF9 2014_v12112014.pdf 
IFRS Foundation (2014). Norma Internacional de Contabilidad 39 - Instrumentos

Financieros: Reconocimiento y Medición. Recuperado del sitio de Internet del Ministerio de Economía y Finanzas:

https://www.mef.gob.pe/contenidos/conta_publ/con_nor_co/vigentes/nic/NIC_0 39_2014.pdf

Inteligo Bank Ltd. (2017). Empresas Grupo Intercorp. Recuperado del sitio de Internet de Inteligo Bank Ltd.: https://www.inteligobank.com/es/acerca-delbanco/grupo-interbank/empresas-grupo-intercorp.html

Oficio N 9210-2017-SBS (Resolución S.B.S. N 1045 - 2017). La Superintendenta de Banca, Seguros y Administradoras Privadas de Fondos de Pensiones. Recuperado del sitio de Internet de Bolsa de Valores de Lima S.A.A:https://www.bvl.com.pe/hhii/OE4256/20170315125601/RES95SBS9510 4595201795AUTO95CAPTACIONES.PDF

Tarjeta Oh (2018). Buen Gobierno Corporativo - Estructura de la sociedad. Recuperado del sitio de internet de Tarjetas Oh:

https://www.tarjetaoh.com.pe/repositorioaps/0/0/jer/buen_gobierno_corporativo /Estructura_Sociedad.pdf 
ANEXOS 


\section{Anexo 1: Estado de situación financiera 2017 - 2016}

Estado de situación financiera

Al 31 de diciembre de 2017 y de 2016

Nota

2017

$\mathrm{S} /(000)$

2016

$\mathrm{S} /(000)$

\section{Activo}

Disponible -

3

Depósitos en el Banco Central de

Reserva del Perú

Depósitos en bancos del país

72,771

63,809

Depósitos en bancos del exterior

564

305

Fondos sujetos a restricción

19,503

17,261

Cartera de créditos, neto

114,997

107,719

945,121

785,280

Mobiliario y equipos, neto

11,336

10,958

Intangibles, neto

8,832

Cuentas por cobrar y otros activos

79,029

Activo por impuesto a la renta

diferido

Total activo

Obligaciones con el público 9

125,122

250,465

Adeudados

10

707,551

477,151

Cuentas por pagar

55,697

47,060

Otros pasivos

12

8,646

13,331

Total del pasivo

918,153

790,335

Patrimonio neto

13

Capital social

220,256

220,256

Resultados acumulados

30,743

$(15,910)$

Total patrimonio

250,999

204,346

Total pasivo y patrimonio 


\section{Anexo 2: Estado de resultados integrales 2017 - 2016}

Estado de resultados integrales

Por los años terminados el 31 de diciembre de 2017 y de 2016

\begin{tabular}{|c|c|c|c|}
\hline & Nota & 2017 & 2016 \\
\hline & & $\mathrm{S} /(000)$ & $\mathrm{S} /(000)$ \\
\hline Ingresos financieros & 16 & 456,061 & 373,053 \\
\hline Gastos financieros & 17 & $(57,729)$ & $(51,531)$ \\
\hline Margen financiero bruto & & 398,332 & 321,522 \\
\hline \multicolumn{4}{|l|}{$\begin{array}{l}\text { Provisión para créditos de cobranza dudosa, neto } \\
\text { de recupero }\end{array}$} \\
\hline & $4(d)$ & $(121,182)$ & $(94,804)$ \\
\hline Margen financiero, neto & & 277,150 & 226,718 \\
\hline Ingresos por servicios financieros & 18 & 45,369 & 31,815 \\
\hline Gastos por servicios financieros & & $(55)$ & - \\
\hline Resultado por operaciones financieras & 19 & $(34,957)$ & $(39,902)$ \\
\hline Margen operacional & & 287,507 & 218,631 \\
\hline Gastos de administración & 20 & $(196,715)$ & $(156,508)$ \\
\hline Depreciación & $5(\mathrm{a})$ & $(3,331)$ & $(3,338)$ \\
\hline Amortización & $6(a)$ & $(8,667)$ & $(8,429)$ \\
\hline Superávit operacional, neto & & 78,794 & 50,356 \\
\hline Provisión para incobrabilidad, litigios y demandas & & $(847)$ & $(1,001)$ \\
\hline Utilidad de operación & & 77,947 & 49,355 \\
\hline Otros ingresos (gastos), neto & & $(5,866)$ & $(2,990)$ \\
\hline Utilidad antes del impuesto a la renta & & 72,081 & 46,365 \\
\hline Impuesto a la renta & $8(b)$ & $(25,428)$ & $(15,827)$ \\
\hline Utilidad neta & & 46,653 & 30,538 \\
\hline Otro resultado integral del año & & - & - \\
\hline Total resultados integrales & & 46,653 & 30,538 \\
\hline
\end{tabular}




\section{Anexo 3: Estado de situación financiera 2016 - 2015}

Estado de situación financiera

Al 31 de diciembre de 2016 y de 2015

\begin{tabular}{|c|c|c|c|}
\hline \multirow{3}{*}{$\begin{array}{l}\text { Activo } \\
\text { Disponible - }\end{array}$} & \multirow[t]{2}{*}{ Nota } & \multirow[t]{2}{*}{$\begin{array}{c}2016 \\
S /(000)\end{array}$} & \multirow[t]{2}{*}{$\begin{array}{c}\mathbf{2 0 1 5} \\
\mathrm{S} /(000)\end{array}$} \\
\hline & & & \\
\hline & 3 & & \\
\hline $\begin{array}{l}\text { Depósitos en el Banco Central de Reserva del } \\
\text { Perú }\end{array}$ & & 26,344 & 35,506 \\
\hline Depósitos en bancos del país & & 63,809 & 63,146 \\
\hline Depósitos en bancos del exterior & & 305 & - \\
\hline Fondos sujetos a restricción & & 17,261 & 17,145 \\
\hline & & 107,719 & 115,797 \\
\hline Cartera de créditos, neto & 4 & 785,280 & 586,009 \\
\hline Mobiliario y equipos, neto & 5 & 10,958 & 10,756 \\
\hline Intangibles, neto & 6 & 14,682 & 21,394 \\
\hline Activo por impuesto a la renta diferido & $8(a)$ & 7,469 & 5,405 \\
\hline Cuentas por cobrar y otros activos & 7 & 68,573 & 52,157 \\
\hline Total activo & & 994,681 & 791,518 \\
\hline Pasivo y patrimonio neto & & & \\
\hline Obligaciones con el público & & 2,328 & 1,749 \\
\hline Adeudados & 9 & 250,465 & 256,807 \\
\hline Cuentas por pagar & 10 & 47,060 & 33,594 \\
\hline Valores y títulos en circulación & 11 & 477,151 & 322,957 \\
\hline Otros pasivos & 7 & 13,331 & 2,603 \\
\hline Total del pasivo & & 790,335 & 617,710 \\
\hline Patrimonio neto & 12 & & \\
\hline Capital social & & 220,256 & 220,256 \\
\hline Resultados acumulados & & $(15,910)$ & $(46,448)$ \\
\hline Total patrimonio & & 204,346 & 173,808 \\
\hline Total pasivo y patrimonio & & 994,681 & 791,518 \\
\hline
\end{tabular}




\section{Anexo 4: Estado de resultados integrales 2016 - 2015}

Estado de resultados integrales

Por los años terminados el 31 de diciembre de 2016 y de 2015

\begin{tabular}{|c|c|c|c|}
\hline & Nota & 2016 & 2015 \\
\hline & & $\mathrm{S} /(000)$ & $\mathrm{S} /(000)$ \\
\hline Ingresos financieros & 15 & 373,053 & 278,007 \\
\hline Gastos financieros & 16 & $(51,531)$ & $(32,923)$ \\
\hline Margen financiero bruto & & 321,522 & 245,084 \\
\hline $\begin{array}{l}\text { Provisión para créditos de cobranza dudosa, neto } \\
\text { de recupero }\end{array}$ & $4(d)$ & $(94,804)$ & $(69,154)$ \\
\hline Margen financiero, neto & & 226,718 & 175,930 \\
\hline Ingresos por servicios financieros & 17 & 31,815 & 22,580 \\
\hline Resultado por operaciones financieras & 18 & $(39,902)$ & $(28,616)$ \\
\hline Margen operacional & & 218,631 & 169,894 \\
\hline Gastos de administración & 19 & $(156,508)$ & $(134,988)$ \\
\hline Depreciación & $5(\mathrm{a})$ & $(3,338)$ & $(2,459)$ \\
\hline Amortización & $6(a)$ & $(8,429)$ & $(8,198)$ \\
\hline Superávit operacional, neto & & 50,356 & 24,249 \\
\hline Provisión para litigios y demandas & & $(1,001)$ & $(1,196)$ \\
\hline Utilidad de operación & & 49,355 & 23,053 \\
\hline Otros ingresos (gastos), neto & & $(2,990)$ & 1,212 \\
\hline Utilidad antes del impuesto a la renta & & 46,365 & 24,265 \\
\hline Impuesto a la renta & $8(b)$ & $(15,827)$ & $(9,593)$ \\
\hline Utilidad neta & & 30,538 & 14,672 \\
\hline Otro resultado integral del año & & - & - \\
\hline Total resultados integrales & & 30,538 & 14,672 \\
\hline Utilidad por acción básica y diluida & $2(0)$ & 0.14 & 0.07 \\
\hline
\end{tabular}




\section{Anexo 5: Encuesta de expectativa macroeconómica del P.B.I/1}

\begin{tabular}{|c|c|c|c|}
\hline Fecha de encuesta & $\begin{array}{l}\text { Analistas } \\
\text { Económicos }\end{array}$ & $\begin{array}{l}\text { Sistema } \\
\text { Financiero }\end{array}$ & $\begin{array}{l}\text { Empresas } \\
\text { No Financieras }\end{array}$ \\
\hline \multicolumn{4}{|c|}{ Expectativas anuales de 2018} \\
\hline 31 de enero de 2018 & $3.6 \%$ & $3.5 \%$ & $3.7 \%$ \\
\hline 28 de febrero de 2018 & $3.5 \%$ & $3.5 \%$ & $3.0 \%$ \\
\hline 28 de marzo de 2018 & $3.5 \%$ & $3.5 \%$ & $3.1 \%$ \\
\hline 30 de abril de 2018 & $3.5 \%$ & $3.3 \%$ & $3.2 \%$ \\
\hline 31 de mayo de 2018 & $3.6 \%$ & $3.5 \%$ & $3.5 \%$ \\
\hline 30 de junio de 2018 & $3.8 \%$ & $3.6 \%$ & $3.5 \%$ \\
\hline 31 de julio de 2018 & $4.0 \%$ & $3.8 \%$ & $3.5 \%$ \\
\hline 31 de agosto de 2018 & $4.0 \%$ & $3.8 \%$ & $3.5 \%$ \\
\hline \multicolumn{4}{|c|}{ Expectativas anuales de 2019} \\
\hline 31 de enero de 2018 & $4.0 \%$ & $3.8 \%$ & $4.0 \%$ \\
\hline 28 de febrero de 2018 & $3.8 \%$ & $3.7 \%$ & $3.5 \%$ \\
\hline 28 de marzo de 2018 & $3.8 \%$ & $3.6 \%$ & $3.6 \%$ \\
\hline 30 de abril de 2018 & $3.8 \%$ & $3.6 \%$ & $3.7 \%$ \\
\hline 31 de mayo de 2018 & $3.8 \%$ & $3.8 \%$ & $3.8 \%$ \\
\hline 30 de junio de 2018 & $4.0 \%$ & $3.8 \%$ & $3.8 \%$ \\
\hline 31 de julio de 2018 & $4.0 \%$ & $3.8 \%$ & $3.9 \%$ \\
\hline 31 de agosto de 2018 & $4.0 \%$ & $4.0 \%$ & $3.8 \%$ \\
\hline \multicolumn{4}{|c|}{ Expectativas anuales de 2020} \\
\hline 28 de febrero de 2018 & $4.0 \%$ & $4.0 \%$ & $4.0 \%$ \\
\hline 28 de marzo de 2018 & $4.0 \%$ & $3.7 \%$ & $4.0 \%$ \\
\hline 30 de abril de 2018 & $4.0 \%$ & $3.9 \%$ & $4.0 \%$ \\
\hline 31 de mayo de 2018 & $4.0 \%$ & $4.0 \%$ & $4.0 \%$ \\
\hline 30 de junio de 2018 & $4.0 \%$ & $3.7 \%$ & $4.0 \%$ \\
\hline 31 de julio de 2018 & $4.0 \%$ & $4.0 \%$ & $4.0 \%$ \\
\hline 31 de agosto de 2018 & $4.0 \%$ & $4.0 \%$ & $4.0 \%$ \\
\hline
\end{tabular}

1/ Mediana

Fuente: Encuesta de expectativas macroeconómicas BCRP

Elaboración: Departamento de Indicadores de Actividad Económica 
Anexo 6: Estados financieros al 31 de diciembre de 2017 y de 2016 junto con el dictamen de los auditores independientes

¡Financiera OH! S.A.

Estados financieros al 31 de diciembre de 2017 y de 2016 junto con el dictamen de los auditores independientes

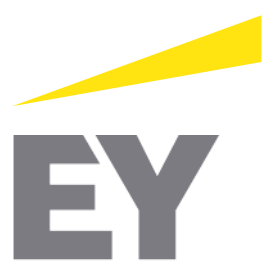

Building a better working world 
Financiera OH! S.A.

Estados financieros al 31 de diciembre de 2017 y de 2016 junto con el dictamen de los auditores independientes

\section{Contenido}

Dictamen de los auditores independientes

\section{Estados financieros}

Estado de situación financiera

Estado de resultados integrales

Estado de cambios en el patrimonio neto

Estado de flujos de efectivo

Notas a los estados financieros 


\section{Dictamen de los auditores independientes}

A los Accionistas y Directores de Financiera OH S.A.

Hemos auditado los estados financieros adjuntos de Financiera OH S.A. (una empresa financiera peruana, integrante del Grupo Intercorp Perú cuya matriz principal es Intercorp Perú Ltd.), que comprenden los estados de situación financiera al 31 de diciembre de 2017 y de 2016 y los correspondientes estados de resultados integrales, de cambios en el patrimonio neto y de flujos de efectivo por los años terminados en esas fechas, así como el resumen de políticas contables significativas y otras notas explicativas.

Responsabilidad de la Gerencia sobre los Estados Financieros

La Gerencia es responsable de la preparación y presentación razonable de estos estados financieros de acuerdo con las normas contables establecidas por la Superintendencia de Banca, Seguros y AFP para entidades financieras en el Perú, y del control interno que la Gerencia determina que es necesario para permitir la preparación de estados financieros que estén libres de errores materiales, ya sea debido a fraude o error.

Responsabilidad del Auditor

Nuestra responsabilidad consiste en expresar una opinión sobre estos estados financieros basada en nuestras auditorías. Nuestras auditorías fueron realizadas de acuerdo con las Normas Internacionales de Auditoría aprobadas para su aplicación en Perú por la Junta de Decanos de Colegios de Contadores Públicos del Perú. Tales normas requieren que cumplamos con requerimientos éticos y planifiquemos y realicemos la auditoría para 
tener una seguridad razonable de que los estados financieros están libres de errores materiales.

Una auditoría comprende la aplicación de procedimientos para obtener evidencia de auditoria sobre los importes y la información revelada en los estados financieros. Los procedimientos seleccionados dependen del juicio del auditor, incluyendo la evaluación del riesgo de que los estados financieros contengan errores materiales, ya sea debido a fraude o error. Al efectuar esta evaluación del riesgo, el auditor toma en consideración el control interno pertinente de la Financiera para la preparación y presentación razonable de los estados financieros a fin de diseñar procedimientos de auditoría de acuerdo con las circunstancias, pero no con el propósito de expresar una opinión sobre la efectividad del control interno de la Financiera. Una auditoría también comprende la evaluación de si los principios de contabilidad aplicados son apropiados y si las estimaciones contables realizadas por la Gerencia son razonables, así como una evaluación de la presentación general de los estados financieros.

Consideramos que la evidencia de auditoría que hemos obtenido es suficiente y apropiada para proporcionarnos una base para nuestra opinión de auditoría. 


\section{EY}

Building a better

Dictamen de los auditores independientes (continuación)

Opinión

En nuestra opinión, los estados financieros adjuntos presentan razonablemente, en todos sus aspectos significativos, la situación financiera de Financiera OH S.A. al 31 de diciembre de 2017 y de 2016, así como su desempeño financiero y sus flujos de efectivo por los años terminados en esas fechas, de acuerdo con las normas contables establecidas por la Superintendencia de Banca, Seguros y AFP (SBS) para las entidades financieras en el Perú, ver nota 2.

Lima, Perú,

16 de febrero de 2018

Refrendado por:

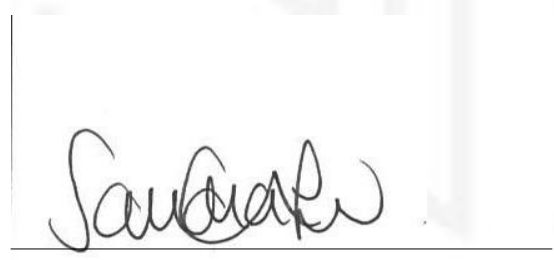

\section{Paredes, Burga \& Adociados}

Sandra Luna Victoria

C.P.C.C. Matrícula No. 50093 


\section{¿Financiera OH!S.A.}

\section{Estado de situación financiera}

Al 31 de diciembre de 2017 y de 2016

Nota

2017

$\mathrm{S} /(000)$

2016

$\mathrm{S} /(000)$

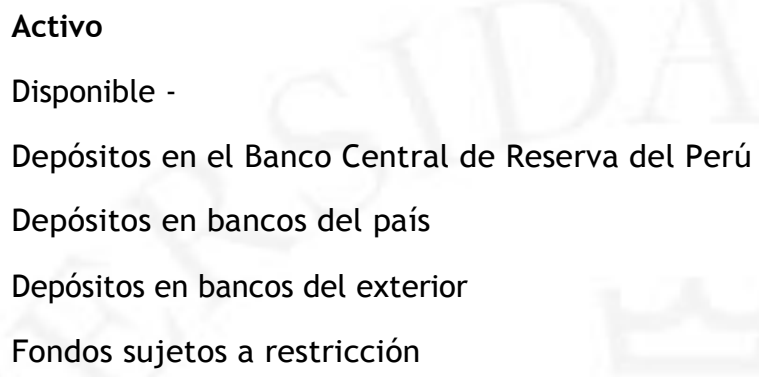

\section{Pasivo y patrimonio neto}

Obligaciones con el público

Adeudados

125,122

Valores y títulos en circulación

707,551

477,151

Cuentas por pagar

55,697

47,060

Otros pasivos

8,646

13,331

Total del pasivo

918,153

790,335

Patrimonio neto

13

Capital social

Resultados acumulados

Total patrimonio

Total pasivo y patrimonio 


\section{Estado de resultados integrales}

Por los años terminados el 31 de diciembre de 2017 y de 2016

\begin{tabular}{|c|c|c|c|}
\hline & Nota & 2017 & 2016 \\
\hline & & $S /(000)$ & $S /(000)$ \\
\hline Ingresos financieros & 16 & 456,061 & 373,053 \\
\hline Gastos financieros & 17 & $(57,729)$ & $(51,531)$ \\
\hline Margen financiero bruto & & 398,332 & 321,522 \\
\hline $\begin{array}{l}\text { Provisión para créditos de cobranza dudosa, neto d } \\
\text { recupero }\end{array}$ & $4(d)$ & $(121,182)$ & $(94,804)$ \\
\hline Margen financiero, neto & & 277,150 & 226,718 \\
\hline Ingresos por servicios financieros & 18 & 45,369 & 31,815 \\
\hline Gastos por servicios financieros & & $(55)$ & - \\
\hline Resultado por operaciones financieras & 19 & $(34,957)$ & $(39,902)$ \\
\hline Margen operacional & & 287,507 & 218,631 \\
\hline Gastos de administración & 20 & $(196,715)$ & $(156,508)$ \\
\hline Depreciación & $5(a)$ & $(3,331)$ & $(3,338)$ \\
\hline Amortización & $6(a)$ & $(8,667)$ & $(8,429)$ \\
\hline Superávit operacional, neto & & 78,794 & 50,356 \\
\hline Provisión para incobrabilidad, litigios y demandas & & $(847)$ & $(1,001)$ \\
\hline Utilidad de operación & & 77,947 & 49,355 \\
\hline Otros ingresos (gastos), neto & & $(5,866)$ & $(2,990)$ \\
\hline Utilidad antes del impuesto a la renta & & 72,081 & 46,365 \\
\hline Impuesto a la renta & $8(b)$ & $(25,428)$ & $(15,827)$ \\
\hline Utilidad neta & & 46,653 & 30,538 \\
\hline Otro resultado integral del año & & & - \\
\hline Total resultados integrales & & 46,653 & 30,538 \\
\hline Utilidad por acción básica y diluida (en soles) & $2(0)$ & 0.21 & 0.14 \\
\hline $\begin{array}{l}\text { Número de acciones promedio ponderado } \\
\text { en circulación (en unidades) }\end{array}$ & & $220,255,793$ & $220,255,793$ \\
\hline
\end{tabular}


Estado de cambios en el patrimonio neto

Por los años terminados el 31 de diciembre de 2017 y de 2016

\begin{tabular}{|c|c|c|c|}
\hline & $\begin{array}{c}\text { Capital } \\
\text { Social } \\
\text { S/(000) }\end{array}$ & $\begin{array}{c}\text { Resultados } \\
\text { acumulados } \\
\mathrm{S} /(000)\end{array}$ & $\begin{array}{c}\text { Total } \\
\text { S/(000) }\end{array}$ \\
\hline Saldos al 1 de enero de 2016 & 220,256 & $(46,448)$ & 173,808 \\
\hline Utilidad neta & - & 30,538 & 30,538 \\
\hline Saldos al 31 de diciembre de 2016 & 220,256 & $(15,910)$ & 204,346 \\
\hline Utilidad neta & - & 46,653 & 46,653 \\
\hline Saldos al 31 de diciembre de 2017 & 220,256 & 30,743 & 250,999 \\
\hline
\end{tabular}




\section{Estado de flujos de efectivo}

Por los años terminados el 31 de diciembre de 2017 y de 2016

Actividades de operación

Conciliación de la utilidad neta con el efectivo y equivalente de efectivo neto, proveniente de las actividades de operación Utilidad neta

Más (menos) ajustes al resultado neto del ejercicio

Depreciación y amortización del periodo, nota 5(a) y 6(a)

Provisión para créditos de cobranza dudosa, nota 4(d)

Variación neta en los activos y pasivos

Aumento de la cartera de créditos

\section{Actividades de financiamiento}

Disminución de adeudados

Flujos de efectivo netos de actividades de financiamiento 


\section{Notas a los estados financieros}

Al 31 de diciembre de 2017 y de 2016

\section{Identificación y actividad económica de la Financiera}

Financiera $\mathrm{OH}$ ! S. A., en adelante "la Financiera", es una entidad financiera peruana constituida en mayo de 2009. La Financiera es una subsidiaria de IFH Retail Corp. (nota 13), la cual posee en forma directa el 96 por ciento de su capital social. IFH Retail Corp. pertenece al Grupo Intercorp Perú, el cual está constituido por diversas empresas que operan en el Perú y en el exterior. El domicilio legal de la Financiera, donde se encuentran sus oficinas administrativas, está ubicado en Av. Aviación 2405, Piso 9 San Borja, Lima.

De acuerdo con sus estatutos, la Financiera está facultada para recibir depósitos de terceros e invertir los junto con su capital en colocaciones, otorgara vales y fianzas, adquirir y negociar certificados de depósitos, efectuar todo tipo de operaciones de intermediación financiera y otras actividades permitidas por la Ley General del Sistema Financiero y del Sistema de Seguros (en adelante "la Ley General") o que sean autorizadas por la Superintendencia de Banca, Seguros y AFP (en adelante "SBS").

Con fecha 18 de enero de 2010, la Financiera recibió el oficio N²007-2010-SBS, mediante el cual la SBS hace llegar la Resolución N³97-2010, la cual otorga la autorización para el funcionamiento de la Financiera como una empresa financiera para realizar las operaciones señaladas en la Ley General, debiendo para la captación de depósitos contar con la autorización de la SBS. La Financiera inició operaciones como empresa financiera el 1 de marzo de 2010.

Los estados financieros al 31 de diciembre de 2016, han sido aprobados por la Junta General de Accionistas realizada el 24 de marzo de 2017. Los estados financieros del ejercicio 2017 han sido aprobados por la Gerencia y el Directorio el 31 de enero de 


\section{Financiera OH! S. A.}

2018 y serán presentados para la aprobación de la Junta General de Accionistas dentro de los plazos establecidos por Ley. En opinión de la Gerencia, los estados financieros adjuntos serán aprobados por la Junta General de Accionistas sin modificaciones.

\section{Principios y prácticas contables}

(a) Bases de presentación, uso de estimados y cambios en principios contables

(i) Bases de presentación y uso de estimados:

Los estados financieros adjuntos han sido preparados y presentados en Soles a partir de los registros de contabilidad de la Financiera, los cuales se llevan en términos monetarios nominales de la fecha de las transacciones, de acuerdo con las normas de la SBS vigentes en el Perú al 31 de diciembre de 2017 y de 2016 y supletoriamente, cuando no haya norma específica de la SBS, con las Normas Internacionales de Información Financiera - NIIF oficializadas en el Perú a través de las resoluciones emitidas por el Consejo Normativo de Contabilidad (CNC) y vigentes al 31 de diciembre de 2017 y de 2016, ver párrafo (p.1). Estos principios contables son consistentes con los utilizados en el 2017 y 2016. 
La preparación de los estados financieros adjuntos requiere que la Gerencia realice estimaciones que afectan las cifras reportadas de activos y pasivos, de ingresos y gastos y la divulgación de eventos significativos en las notas a los estados financieros. Las estimaciones son continuamente evaluadas y están basadas en la experiencia histórica y otros factores. Los resultados finales podrán diferir de dichas estimaciones; sin embargo, la Gerencia espera que las variaciones, si las hubiera, no tengan un efecto importante sobre los estados financieros de la Financiera. Las estimaciones más significativas en relación con los estados financieros adjuntos corresponden a la provisión para créditos de cobranza dudosa, la determinación de las vidas útiles del mobiliario y equipo se intangibles y el cálculo del impuesto a la renta corriente y diferido, cuyos criterios contables se describen más adelante en esta nota.

(b) Instrumentos financieros-

Los instrumentos financieros se clasifican en activos, pasivos o patrimonio según la sustancia del acuerdo contractual que les dio origen. Los intereses, dividendos, las ganancias y las pérdidas generadas por un instrumento financiero clasificado como activo o pasivo, se registran como ingresos o gastos. Los instrumentos financieros se compensan cuando La Financiera tiene el derecho legal de compensarlos y la Gerencia tiene la intención de cancelarlos sobre una base neta o de realizar el activo y cancelar el pasivo simultáneamente.

Los activos y pasivos financieros presentados en el estado de situación financiera corresponden al disponible, la cartera de créditos, cuentas por cobrar, otros activos y los pasivos en general, con excepción de las provisiones incluidas dentro del rubro "Otros pasivos", ver nota7. 
Las políticas contables sobre el reconocimiento y la valuación de estas partidas se describen en esta nota.

(c) Reconocimiento de ingresos y gastos-

Los ingresos y gastos por intereses son registrados en los resultados del período en que se devengan, en función al tiempo de vigencia de las operaciones que los generan y las tasas de interés pactadas libremente con los clientes; excepto en el caso de los intereses generados por créditos en situación de vencidos, refinanciados y en cobranza judicial y de los créditos clasificados en las categorías de dudoso y pérdida, los cuales se reconocen como ingresos en la medida en que son cobrados. Cuando la Gerencia determina que la condición financiera del deudor ha mejorado y el crédito es reclasificado a la situación de vigente y/o a las categorías de normal, con problema potencial o deficiente; los intereses se reconocen nuevamente sobre la base de lo devengado de acuerdo con las normas vigentes.

Los otros ingresos y gastos son registrados en el período en que se devenga 
(d) Cartera de créditos y provisión para créditos de cobranza dudosa-

Los créditos se registran cuando se realiza el desembolso de los fondos a favor de los clientes. En caso de las operaciones con tarjeta de crédito, éstas se registran como créditos por el monto de los consumos y/o retiros realizados. Los créditos indirectos (contingentes) se registran cuando se emiten los documentos que soportan dichas facilidades de crédito. Al 31 de diciembre de 2017 y de 2016, la Financiera no presenta créditos indirectos.

Se consideran como refinanciados a los créditos o financiamientos directos respecto del cual se producen variaciones de plazo y/o monto del contrato original que obedecen a dificultad es en la capacidad de pago del deudor.

Los créditos otorgados se clasifican en corporativos, a grandes empresas, a medianas empresas, a pequeñas empresas, a microempresas, de consumo (revolvente y no revolvente) e hipotecarios. La Financiera otorga principalmente créditos de consumo revolventes, bajo la modalidad de tarjeta de crédito y créditos de consumo no revolventes bajo la modalidad de préstamos de libre disponibilidad.

La provisión de cobranza dudosa se determina siguiendo los criterios establecidos por la SBS vigentes a la fecha de cada estado de situación financiera e incluye en términos generales tres componentes que son: (i) la provisión que resulta de la clasificación de la cartera, (ii) la provisión procíclica que es activada por la SBS considerando el comportamiento de determinadas variables macroeconómicas del país y (iii) la provisión por sobrendeudamiento de la cartera minorista.

La provisión por la clasificación de la cartera se realiza en base a la 
revisión que realiza periódicamente la Gerencia de la Financiera, clasificando cada deudor en las categorías de normal, con problema potencial, deficiente, dudoso o pérdida; dependiendo del grado de riesgo de incumplimiento del pago.

En el caso de los créditos que otorga la Financiera (de consumo); la clasificación se realiza principalmente sobre la base del número de días de atraso en los pagos y de la clasificación asignada por otras entidades del sistema financiero (alineamiento).

El cálculo de la provisión es realizado según la clasificación otorgada y considerando porcentajes específicos.

La provisión procíclica es calculada para los créditos clasificados en la categoría normal y de acuerdo a los porcentajes establecidos por la SBS. Con fecha 27 de noviembre del 2014 la SBS mediante la Circular $\mathrm{N}^{\circ}$ B2224-2014 procedió a desactivar la regla procíclica.

La provisión por sobreendeudamiento de la cartera minorista es requerida por la Resolución SBS N6941-2008, de fecha 25 de agosto de 2008, "Reglamento para la Administración del Riesgo de Sobreendeudamiento de Deudores Minoristas”. Esta norma requiere que las empresas del sistema financiero establezcan un sistema de administración del riesgo de sobreendeudamiento que permita reducir el riesgo antes y después del otorgamiento del crédito; efectuar un seguimiento permanente de la cartera para identificar a los deudores sobre endeudados que 
incluye la evaluación periódica de los mecanismos de control utilizados, así como de las acciones correctivas o mejoras requeridas, según sea el caso. Las empresas que no cumplan con tales disposiciones a satisfacción de la SBS deberán, para fines de provisión, calcular la exposición equivalente al riesgo crediticio aplicando un factor del 20 por ciento al monto no usado de las líneas de crédito revolventes de tipo microempresa y consumo (a la Financiera sólo le aplica consumo), y sobre dicho monto calcular la provisión según la clasificación del deudor. Al 31 de diciembre de 2017 y de 2016, la SBS no ha comunicado a la Gerencia de la Financiera la exigencia de mayores provisiones en aplicación a esta Norma.

Las provisiones para los créditos directos se presentan deduciendo el saldo de los mismos en el activo, ver nota 4(a).

(e) Transacciones en moneda extranjera-

De acuerdo con las normas de la SBS, la Financiera tiene como moneda funcional y de presentación al Sol. Los activos y pasivos en moneda extranjera se registran al tipo de cambio de la fecha en que se realizan las transacciones. Los activos y pasivos monetarios denominados en moneda extranjera son convertidos a Soles al cierre de cada mes utilizando el tipo de cambio fijado por la SBS, nota 23.2(ii). Las ganancias o pérdidas que resultan de reexpresar los activos y pasivos monetarios en moneda extranjera a las tasas de cambio vigentes a la fecha del estado de situación financiera se registran en los resultados del ejercicio como "Ganancia o Pérdida por diferencia en cambio" del rubro "Resultados por operaciones financieras", ver nota 19.

Los activos y pasivos no monetarios que se adquieren en moneda extranjera se registran en Soles al tipo de cambio de la fecha de su adquisición. 
(f) Instrumentos financieros derivados-

El registro de los instrumentos financieros derivados se realiza de acuerdo con la Resolución SBS N 1737-2006 "Reglamento para la Negociación y Contabilización de Productos Financieros Derivados en las Empresas del Sistema Financiero" y sus modificatorias.

Los instrumentos financieros derivados mantenidos por la Financiera han sido clasificados como instrumentos financieros derivados para negociación. Los cuales son inicialmente reconocidos en el estado de situación financiera al costo y posteriormente son llevados a su valor razonable reconociéndose un activo o pasivo en el estado de situación financiera, y la correspondiente ganancia o pérdida en el estado de resultados integrales. Asimismo, las operaciones con instrumentos financieros derivados son registradas como riesgos y compromisos contingentes a su valor de referencia en la moneda comprometida, nota 15.

Los valores razonables son obtenidos sobre la base de los tipos de cambio y las tasas de interés de mercado.

(g) Mobiliario y equipos -

El rubro mobiliario y equipos se registra al costo de adquisición menos la depreciación y el importe acumulados de las pérdidas por deterioro del activo de ser aplicable, ver párrafo (j) siguiente. 
El costo de adquisición incluye los gastos que son directamente atribuibles a la adquisición de los activos. Los costos de mantenimiento y reparación se cargan a resultados, toda renovación y mejora significativa se capitaliza únicamente cuando es probable que se produzcan beneficios económicos futuros que excedan el rendimiento estándar originalmente evaluado para el activo.

La depreciación es calculada siguiendo el método de línea recta, utilizando las siguientes vidas útiles estimadas por tipo de activo:

\section{Ã̃os}

Equipos de cómputo

Mobiliario y equipo

Entre 2 y 10

Vehículos

Instalaciones en locales alquilados

El mobiliario y equipo en curso representan instalaciones, mobiliarios y equipos por recibir o en construcción, y se registran al costo. Estos bienes no se deprecian hasta que los activos relevantes se reciban o terminen y estén operativos.

Cuando se venden o retiran los activos, se elimina su costo y depreciación, y cualquier ganancia o pérdida que resulte de su disposición se incluye en el estado de resultados integrales.

El valor residual, la vida útil y el método de depreciación se revisan periódicamente para asegurar que el método y el periodo de la depreciación sean consistentes con el beneficio económico futuro y las expectativas de vida de las partidas de mobiliario y equipos. 
(h) Activos intangibles de vida limitada-

Los activos intangibles de vida limitada se registran inicialmente al costo. Después del reconocimiento inicial, los intangibles se miden al costo menos la amortización acumulada.

Los activos intangibles están relacionados principalmente con la inversión efectuada en el derecho de exclusividad de la tarjeta Oh! en los establecimientos de Supermercados Peruanos S.A., así como, en la adquisición y desarrollo de programas de cómputo, utilizados en las operaciones propias de la Financiera, los cuales se capitalizan sobre la base de los costos incurridos para adquirir o poner en uso el programa específico. Estos activos intangibles son amortizados siguiendo el método de línea recta, sobre la base de su vida útil estimada en un máximo de 5 años.

La vida útil y el método de amortización se revisan periódicamente para asegurar que sean consistentes con el patrón previsto de beneficios económicos de las partidas de intangibles.

(i) Valores, títulos y obligaciones en circulación-

El rubro Valores, títulos y obligaciones en circulación incluye los pasivos por la emisión de bonos, los cuales son contabilizados inicialmente a su valor razonable más los costos incrementales relacionados a la transacción que sean atribuibles directamente a la emisión del instrumento.

Después del reconocimiento inicial, son medidos al costo amortizado usando el método de la tasa de interés efectiva. El costo amortizado es calculado considerando cualquier descuento o prima en la emisión y los costos que son parte integral de la tasa de interés efectiva. Asimismo, los intereses devengados son reconocidos en el estado de resultados del rubro “Gastos por intereses” según los términos del contrato. 
(j) Desvalorización de activos de larga duración-

Cuando existen acontecimientos o cambios económicos que indiquen que el valor del mobiliario y equipos e intangibles pueda no ser recuperable, la Gerencia de la Financiera revisa el valor de dichos activos para verificar que no existe ningún deterioro permanente en su valor. Cuando el valor del activo en libros excede su valor recuperable, se reconoce una pérdida por desvalorización en el estado de resultados integrales. El valor recuperable es el mayor entre el precio de venta neto y su valor en uso. El precio de venta neto es el monto que se puede obtener en la venta de un activo en un mercado libre, mientras que el valor en uso es el valor presente de los flujos futuros estimados del uso continuo de un activo y de su disposición al final de su periodo de depreciación. En opinión de la Gerencia no existen evidencias de deterioro en el valor de dichos activos al 31 de diciembre de 2017 y de 2016.

(k) Impuesto a la renta-

El impuesto a la renta comprende la suma del impuesto corriente por pagar estimado y el impuesto a la renta diferido.

El impuesto a la renta corriente se calcula sobre la base de la renta imponible determinada para fines tributarios, la cual es determinada utilizando criterios que difieren de los principios contables que utilizan la Financiera.

Asimismo, la Financiera ha registrado el impuesto a la renta diferido considerando los lineamientos de la NIC12 - Impuesto a las Ganancias. El impuesto a la renta diferido refleja los efectos de las diferencias temporales entre los saldos de activos y pasivos para fines contables y los determinados para fines tributarios. Los activos y pasivos diferidos semi den utilizando las tasas de impuestos que se 
espera aplicar a la renta imponible en los años en que estas diferencias se recuperen o eliminen. En consecuencia, el impuesto a la renta diferido al 31 de diciembre de 2017 ha sido actualizado aplicando las tasas que se encontrarán vigentes a partir del 1 de enero de 2018. La medición de los activos y pasivos diferidos refleja las consecuencias tributarias derivadas de la forma en que se espera, a la fecha del estado de situación financiera, recuperar o liquidar el valor de los activos y pasivos.

El activo y pasivo diferido se reconocen sin tomar en cuenta el momento en que se estime que las diferencias temporales se anularán. Los activos diferidos son reconocidos cuando es probable que existan beneficios tributarios futuros suficientes para que el activo diferido se pueda aplicar. A la fecha del estado de situación financiera, la Gerencia evalúa los activos diferidos no reconocidos y el saldo de los reconocidos; registrando un activo diferido previamente no reconocido en la medida en que sea probable que los beneficios futuros tributarios permitan su recuperación o reduciendo un activo diferido en la medida en que no sea probable que se disponga de beneficios tributarios futuros suficientes para permitir que se utilice parte o la totalidad del activo diferido reconocido contablemente. Conforme lo establece la NIC 12, la Financiera determina su impuesto a la renta diferido sobre la base de la tasa de impuesto a la renta aplicable a sus utilidades no distribuidas.

\section{(l) Provisiones-}

Se reconoce una provisión sólo cuando la Financiera tiene una obligación presente (legal o implícita) como resultado de un evento pasado, es probable que se requieran recursos para cancelar la obligación y se puede estimar confiablemente el monto de la obligación. Las provisiones se revisan cada período y se ajustan para reflejar la mejor estimación que se tenga a la fecha del estado de situación financiera. Cuando el efecto del valor del dinero en el tiempo es importante, el monto de la provisión es el 
valor presente de los desembolsos que se espera incurrir para cancelarla.

(m) Contingencias-

Los pasivos contingentes no se reconocen en los estados financieros. Estos se divulgan en notas a los estados financieros, a menos que la posibilidad de que se desembolse un flujo económico sea remota.

Un activo contingente no se reconoce en los estados financieros, pero se revela cuando su grado de contingencia es probable.

(n) Efectivo y equivalentes de efectivo-

El efectivo y equivalentes de efectivo presentado en el estado de flujos de efectivo está conformado por el saldo del disponible con vencimientos originales menores a tres meses, excluyendo los rendimientos devengados y los fondos restringidos.

Al 31 de diciembre de 2017, los rendimientos devengados y los fondos restringidos ascienden a $\mathrm{S} / 3,653$ y $\mathrm{S} / 19,503,115$, respectivamente (S/8,832 y $\mathrm{S} / 17,260,895$ al 31 de diciembre de 2016

(o) Utilidad por acción-

La utilidad básica por acción es calculada dividiendo la utilidad neta correspondiente a los accionistas comunes entre el promedio ponderado de las acciones ordinarias en circulación a la fecha del estado de situación financiera. Al 31 de diciembre de 2017 y de 2016, la Financiera no tiene instrumentos financieros con efecto dilutivo, por lo que la utilidad básica y diluida por acción es la misma. Al 31 de diciembre de 2017 y de 2016, el promedio ponderado de acciones en circulación fue determinado de la siguiente manera: 


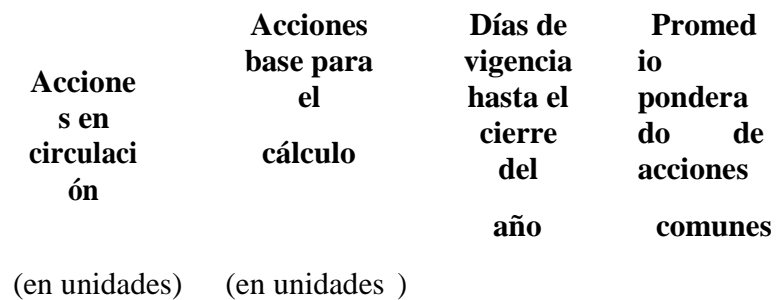

\section{Ejercicio 2016}

Saldo al $1^{\circ}$ de enero y al 31 de diciembre de 2016

Ejercicio 2017

Saldo al $1^{\circ}$ de enero y al 31 de

(p) Nuevos pronunciamientos contables -

(p.1) NIIF emitidas y vigentes en el Perú al 31 de diciembre de 2017 -

El CNC, a través de la Resolución $N^{\circ} 001-2017-E F / 30$ emitida el 17 de enero de 2017, oficializó las modificaciones a la NIIF 4; a través de la Resolución N$^{\circ}$ 002-2017-EF/30 emitida el 27 de abril de 2017, oficializó las mejoras anuales a las normas NIIF ciclo 2014 - 2016, la CINIIF 22 y las modificaciones a la NIC 40; a través de la Resolución $N^{\circ} 003$ - 2017 -EF/ 30 emitida el 25 de agosto de 2017, oficializó las versiones 2017 de las Normas Internacionales de Información Financiera (NIC, NIIF, CINIIF, SIC) y a través de la Resolución $N^{\circ} 004-2017$-EF/ 30 emitida el 28 de setiembre de 2017, oficializó la NIIF 7, CINIIF 23

La aplicación de las versiones es según la entrada en vigencia estipulada en cada norma específica, a excepción de la NIIF 15 "Ingresos de Actividades Ordinarias Procedentes de Contratos con Clientes", cuya vigencia fue postergada al 01 de enero de 2019, mediante Resolución Nº05 - 2017 EF/ 30 emitida el 28 de diciembre de 2017. 
(p.2) Normas Internacionales de Información Financiera - NIIF emitidas, pero no vigentes al 31 de diciembre de 2017 -

NIIF 9 "Instrumentos financieros", efectiva para períodos anuales que comiencen en o a partir del 01 de enero de 2018.

NIIF 15 "Ingresos de Actividades Ordinarias Procedentes de Contratos con Clientes", efectiva para períodos anuales que comiencen en o a partir del 01 de enero de 2019 (según Resolución Nº 005 - 2017 EF/ 30 del CNC).

NIIF 16 “Arrendamientos", efectiva para períodos anuales que comiencen e a partir del 01 de enero de2019.

CINIIF 22 "Transacciones en Moneda Extranjera y Contra prestaciones anticipadas", efectiva para períodos anuales que comiencen en o a partir del 01 de enero de 2018.

CINIIF 23 "Incertidumbre frente a los tratamientos del impuesto a las ganancias", efectiva para períodos anuales que comiencen en o a partir del 01 de enero de 2019.

Aclaraciones a la NIIF15 "Ingresos de Actividades Ordinarias Procedentes de Contratos con Clientes", efectiva para períodos anuales que comiencen en o a partir del 01 de enero de 2018.

Modificaciones a la NIIF 10 "Estados Financieros Consolidados" y a la NIC 28" Inversiones en Asociadas y 
Negocios Conjuntos", en lo relacionado con la venta o contribución de activos entre un inversor y sus asociadas y negocios conjuntos, cuya aplicación efectiva fue pospuesta de manera indefinida por la IASB en diciembre de 2015.

Modificaciones a la NIIF 2 "Pagos Basados en Acciones", en lo relacionado a la clasificación y medición de estas transacciones. Estas modificaciones son efectivas para períodos anuales, que comiencen en o a partir del 01 de enero del 2018.

Modificaciones a la NIC 40 "Propiedades de Inversión", que clarifican los requerimientos de transferencias desde o hacia propiedades de inversión. Estas modificaciones son efectivas para períodos anuales que comiencen en o a partir del 01 de enero de 2018.

Modificaciones a la NIIF 9 "Instrumentos financieros", efectiva para períodos anuales que comiencen en o a partir del 01 de enero de 2019.

Modificaciones a la NIC 28 "Inversión en Asociadas y Negocios Conjuntos", efectiva para periodos anuales que comiencen en o a partir del 01 de enero de 2019.

Mejoras (ciclos 2015 - 2017) a la NIIF 1 “Adopción por Primera vez de las Normas Internacionales de Información Financiera", NIC 28 "Inversiones en Asociadas y Negocios Conjuntos", NIC 23 "Costos por préstamos", NIC 12 "Impuesto a las ganancias “, NIIF 3 "Combinaciones de 
negocios" y NIIF 11 “Acuerdos conjuntos", efectivas para períodos anuales que comiencen en o a partir del 01 de enero de 2018.

Debido a que las normas antes detalladas sólo aplican en forma supletoria a las desarrolladas por las normas de la SBS, la Gerencia estima que, dadas sus operaciones, las mismas no tendrán ningún efecto importante en la preparación de los estados financieros, a menos que la SBS las adopte en el futuro a través de la modificación del Manual de Contabilidad para Empresas de Sistemas Financieros o la emisión de normas específicas.

\section{Disponible}

Al 31 de diciembre de 2017 y de 2016, los depósitos en bancos del país corresponden a saldos en soles y en dólares estado unidenses que son de libre disponibilidad y generan intereses a tasas de mercado. A continuación, se presenta el detalle del saldo:

2017

$\mathrm{S} /(000)$

53,593

474

18,704

72,771
2016

$\mathrm{S} /(000)$

11,216

809

51,784

63,809

Total $(*)$

-

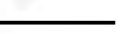

(*) Al 31 de diciembre de 2017, los depósitos a plazo tienen un vencimiento de 3 días (de 2 a 25 días los depósitos a plazo al 31 de diciembre de 2016).

Al 31 de diciembre de 2017, los depósitos en bancos del exterior incluyen depósito en una cuenta corriente ascendente a US\$173,946 (US\$90,832 al 31 de diciembre de 2016). 
Asimismo, el rubro incluye S/22,157,621 y US\$245 correspondiente al encaje legal que la Financiera debe mantener por sus obligaciones sujetas a encaje (S/26,342,663 y US\$245 al 31 de diciembre de 2016). Estos fondos están depositados en el Banco Central de Reserva del Perú (BCRP) y se mantienen dentro de los límites fijados por las disposiciones legales vigentes. Los fondos de encaje mantenidos en el BCRP no generan intereses, excepto por la parte de encaje exigible en moneda extranjera y moneda nacional que excedan el encaje mínimo legal.

Al 31 de diciembre de 2017, los fondos sujetos a restricción incluyen principalmente fondos restringidos por $\mathrm{S} / 19,319,672$, que corresponden a depósitos en garantía por los adeudados, ver nota 10, (S/ 10,979,235 y US\$ 1,829,925 al 31 de diciembre de 2016, que corresponden a depósitos en garantía por los adeudos y valores y títulos, ver notas 10 y 11).

\section{Cartera de créditos, neto}

(a) A continuación, se presenta el detalle de la cartera de créditos:

\section{Créditos directos}

Créditos vigentes

935,439

Créditos vencidos

Créditos refinanciados

Más (menos)

Rendimientos devengados de créditos 
Al 31 de diciembre de 2017 y de 2016, la cartera de créditos de la Financiera se concentró en 605,949 y 523,075 clientes, respectivamente. Los créditos han sido concedidos en soles y sólo a personas naturales.

(b) De acuerdo con las normas SBS, la cartera de créditos de la Financiera al 31 de diciembre de 2017 y de 2016 está clasificada por riesgo como sigue:

\section{Categoría de} riesgo

$\begin{array}{lrrrr} & \mathrm{S} /(000) & \% & \mathrm{~S} /(000) & \% \\ \text { Normal } & 875,043 & 87.84 & 725,270 & 87.85 \\ \begin{array}{l}\text { Con problema } \\ \text { potencial }\end{array} & 25,860 & 2.60 & 21,585 & 2.61 \\ \text { Deficiente } & 28,818 & 2.89 & 23,858 & 2.89 \\ \text { Dudoso } & 47,945 & 4.81 & 33,082 & 4.01 \\ \text { Pérdida } & 18,503 & 1.86 & 21,807 & 2.64 \\ \text { Total } & \underline{996.169} & \underline{10000} & \underline{825.602} & 100.00 \\ \end{array}$

(c) Al 31 de diciembre de 2017 y de 2016, las entidades financieras en el Perú deben constituir una provisión para créditos de cobranza dudosa sobre la base de la clasificación de riesgo indicada anteriormente y utilizando los porcentajes indicados en las Resoluciones SBS N $11356-2008$ y N69412008, según se detalla a continuación:

(i) Para los créditos clasificados en la categoría "Normal"-

\begin{tabular}{|c|c|c|c|}
\hline Tipos de crédito & $\begin{array}{c}\text { Tasa de } \\
\text { provisión fija }\end{array}$ & $\begin{array}{c}\text { Tasa } \\
\text { procíclica }\end{array}$ & Total \\
\hline & $\%$ & $\%$ & $\%$ \\
\hline Consumo revolvente & 1.00 & 1.50 & 2.50 \\
\hline
\end{tabular}


Consumo no

revolvente

Mediana empresa (*)
1.00

1.00

1.00

0.30

1.30

La SBS, mediante Circular SBS N${ }^{\circ}$-224-2014 de fecha 27 de noviembre de 2014, informó a las empresas del sistema financiero la desactivación de las tasas del componente procíclico de las provisiones sobre los créditos directos e indirectos de deudores clasificados en la categoría "Normal" desde noviembre 2014.

(*) Cabe señalar que el saldo de créditos clasificados como mediana empresa que mantiene la Financiera al 31 de diciembre de 2017 asciende a S/2,155,714 (S/1,153,387 al 31 de diciembre de 2016), originados por la reclasificación de los créditos de consumo que cuenten con un endeudamiento total en el sistema financiero mayor a $\mathbf{S} / 300,000$ por seis meses consecutivos, de acuerdo con los parámetros establecidos en la resolución SBS N 11356 - 2008.

(ii) Para las otras categorías de riesgos-

Categoría de riesgo

Con problema potencial

Deficiente

Dudoso

Pérdida
CSG (*)

$\%$

5.00

25.00

60.00

100.00

(*) Créditos sin garantía.

(d) El movimiento de la provisión para créditos de cobranza dudosa, determinada según la clasificación de riesgo y los porcentajes de provisión 
requeridos indicados anteriormente, fue como sigue:

2017

\begin{tabular}{|c|c|c|c|}
\hline & $\begin{array}{l}\text { Créditos } \\
\text { mediana } \\
\text { empresa }\end{array}$ & $\begin{array}{l}\text { Créditos } \\
\text { de } \\
\text { consumo }\end{array}$ & Total \\
\hline & $\mathrm{S} /(000)$ & $\mathrm{S} /(000)$ & $\mathrm{S} /(000)$ \\
\hline Saldo al inicio del ejercicio & 129 & 57,005 & 57,134 \\
\hline Provisión reconocida como gasto del ejercicio & 157 & 148,178 & 148,335 \\
\hline Castigo de créditos & $(136)$ & $(134,365)$ & $(134,501)$ \\
\hline Saldo al final del ejercicio & 150 & 70,818 & 70,968 \\
\hline
\end{tabular}

2016

\section{Créditos \\ mediana \\ empresa}

$\mathrm{S} /(000)$

123

Saldo al inicio del ejercicio

Provisión reconocida como gasto del ejercicio

Castigo de créditos

Saldo al final del ejercicio
129
Créditos

de

consumo

$\mathrm{S} /(000)$

40,060

115,270

$(98,325)$

57,005
Total

$\mathrm{S} /(000)$

40,183

115,341

$(98,390)$

$\underline{57,134}$

El gasto de provisión para créditos de cobranza dudosa en el estado de resultados integrales se presenta neto de los ingresos por recupero de créditos castigados ascendentes a $S / 27,153,052$ en el año 2017 y S/20,537,274 en el año 2016.

En opinión de la Gerencia de la Financiera, la provisión para créditos de cobranza dudosa registrada al 31 de diciembre de 2017 y de 2016, está de acuerdo con las normas y autorizaciones de la SBS vigentes en esas fechas, nota 2(d).

(e) Los intereses que genera la cartera de créditos son pactados 
libremente teniendo en cuenta las tasas de interés vigentes en el mercado.

(f) Los intereses, comisiones y gastos sobre créditos o cuotas que se encuentren en situación de refinanciados, vencidos, en cobranza judicial, o clasificados en las categorías Dudoso o Pérdida, se contabilizan como ingresos o rendimientos en suspenso y son reconocidos como ingreso en el estado de resultados integrales cuando son efectivamente cobrados. Los importes no reconocidos como ingresos por este concepto ascendieron a S/28,051,776 y S/24,816,829 al 31 de diciembre del 2017 y de 2016, respectivamente.

(g) A continuación, se presenta la cartera de créditos directos al 31 de diciembre de 2017 y de 2016, según su vencimiento:

\section{Por vencer -}

Hasta 1 mes

De 1 mes a 3 meses

De 3 meses a 1

año

De 1 año a más 
5. Mobiliario y equipos, neto

(a) A continuación, se presenta el movimiento del rubro por los ejercicios 2017 y de 2016 :

Costo -

Saldo al 1 de enero 2016

Adiciones (b)

Retiros y castigos

Transferencias

Saldo al 31 de diciembre 2016

Adiciones (b)

Retiros y castigos

Ventas

Transferencias

Saldo al 31 de diciembre 2017

Depreciación acumulada -

Saldo al 1 de enero 2016

Depreciación del año

Retiros y castigos

Saldo al 31 de diciembre 2016

Depreciación del año

Retiros y castigos

Ventas

Saldo al 31 de diciembre 2017

Valor neto en libros al 31 de diciembre de 2017

Valor neto en libros al 31 de diciembre de 2016

\begin{tabular}{|c|c|c|c|c|c|}
\hline $\begin{array}{l}\text { Mobiliario } \\
\text { y equipo }\end{array}$ & $\begin{array}{c}\text { Equipos de } \\
\text { Cómputo }\end{array}$ & Vehículos & $\begin{array}{l}\text { Instalaciones en } \\
\text { locales alquilados }\end{array}$ & $\begin{array}{c}\text { Mobiliario y } \\
\text { equipo en } \\
\text { curso }\end{array}$ & Total \\
\hline $\mathrm{S} /(000)$ & $\mathrm{S} /(000)$ & $\mathrm{S} /(000)$ & $\mathrm{S} /(000)$ & $\mathrm{S} /(000)$ & $\mathrm{S} /(000)$ \\
\hline 8,267 & 3,189 & 119 & 6,318 & 43 & 17,936 \\
\hline 1,192 & 1,382 & - & 1,228 & 9 & 3,811 \\
\hline (13) & (932) & - & (103) & - & $(1,048)$ \\
\hline 10 & & - & 12 & (22) & \\
\hline 9,456 & 3,639 & 119 & 7,455 & 30 & 20,699 \\
\hline 1,275 & 655 & & 1,834 & 16 & 3,780 \\
\hline (7) & - & - & (62) & - & (69) \\
\hline (18) & - & (119) & - & - & (137) \\
\hline 6 & - & - & 31 & (37) & - \\
\hline 10,712 & 4,294 & - & 9,258 & 9 & 24,273 \\
\hline 2,295 & 2,135 & 57 & 2,693 & - & 7,180 \\
\hline 1,371 & 729 & 23 & 1,215 & - & 3,338 \\
\hline (8) & (712) & - & (57) & - & (777) \\
\hline 3,658 & 2,152 & 80 & 3,851 & - & 9,741 \\
\hline 1,233 & 635 & 2 & 1,461 & - & 3,331 \\
\hline & - & 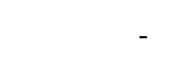 & (42) & - & (42) \\
\hline (11) & - & (82) & - & - & (93) \\
\hline 4,880 & 2,787 & - & 5,270 & - & 12,937 \\
\hline 5,832 & 1,507 & - & 3,988 & 9 & 11,336 \\
\hline 5,798 & 1,487 & 39 & 3,604 & 30 & 10,958 \\
\hline
\end{tabular}


(b) Las adiciones del ejercicio 2017 corresponden principalmente a la apertura de nuevas finantiendas (oficinas de la Financiera dentro de los establecimientos de Oeschle, Plaza Vea y Promart) y la remodelación y ampliación realizada en sus oficinas administrativas (las adiciones del ejercicio 2016 correspondieron principalmente a la apertura de nuevas finantiendas y la renovación de equipos de cómputo).

(c) Las entidades financieras establecidas en el Perú están prohibidas de entregar en garantía los bienes de su activo fijo.

(d) Al 31 de diciembre de 2017 y de 2016 el costo mantenido por los equipos adquiridos en arrendamiento financiero es S/458,988 y S/1,032,630, respectivamente, asimismo la depreciación acumulada es de S/173,219 y S/393,352, respectivamente.

(e) La Gerencia revisa periódicamente el método de depreciación utilizado, con la finalidad de asegurar que sea consistente con el beneficio económico de los activos fijos. En opinión de la Gerencia de la Financiera, no existe evidencia de deterioro de los activos fijos mantenidos al 31 de diciembre de 2017 y de 2016. 


\section{Intangibles, neto}

(a) El movimiento de los activos intangibles durante los años 2017 y 2016 fue como sigue:

\section{Descripción}

Programas Derecho de

de

cómputo

$\mathrm{S} /(000)$

Costo -

Saldo al 1 de enero de 2016

Adiciones (b)

8,849

868

Transferencias

1,269

Saldo al 31 de diciembre de $2016 \quad 10,986$

Adiciones (b)

600

Transferencias

1,826

Saldo al 31 de diciembre de 2017 13,412

Amortización acumulada -

Saldo al 1 de enero de 2016

Amortización del año

Saldo al 31 de diciembre de $2016 \quad 6,989$

Amortización del año

1,587

Saldo al 31 de diciembre de $2017 \quad 8,576$

Costo neto al 31 de diciembre de 4,836 2017 exclusividad

(c)

Intangible s en curso

$\mathrm{S} /(000)$

485 44,734

849

1,717

$(1,269)$

35,400

65

46,451

2,217

2,817

$(1,826)$

35,400

456

49,268

23,340

7,080

8,429

24,780

31,769

7,080

8,667

31,860

40,436

3,540

456

8,832

Costo neto al 31 de diciembre de $\quad 3,997$

10,620

65

14,682 2016 
(b) Las adiciones del período 2017 corresponden principalmente al desarrollo del Sistema "EBANK", el cual permite el procesamiento de las captaciones por CTS y depósitos a plazo, y el desarrollo del Sistema de Promociones con Tarjeta Oh! ¡Las adiciones del período 2016 correspondieron principalmente al desarrollo del proyecto "Microsoft Agenda Comercial", el cual permite monitorear el desarrollo de funciones del personal de las Finantiendas a través del área de canales y la adaptación de los sistemas para permitir el procesamiento de información relacionado con la Tarjeta Oh! Visa, la cual empezó a operar a partir del 2016.

(c) Con fecha 30 de junio de 2013, la Financiera y Supermercados Peruanos S.A. (SPSA) suscribieron el "Contrato de Emisión y Administración de la Tarjeta de Crédito Oh!”. Dicho contrato estableció que la Financiera pagaría a SPSA un importe de S/30,000,000 más IGV; ¡con la finalidad de que los descuentos y promociones que ofrezca SPSA en sus distintos establecimientos sea de manera exclusiva para clientes que realicen operaciones (compra de bienes) con la Tarjeta Oh! La Gerencia estima recuperar el importe pagado a SPSA en un periodo de 5años.

(d) La Gerencia revisa periódicamente el método de amortización utilizado, con la finalidad de asegurar que sea consistente con el beneficio económico de los intangibles. En opinión de la Gerencia de la Financiera, no existe evidencia de deterioro de los intangibles mantenidos al 31 de diciembre de 2017 y de 2016. 


\section{Cuentas por cobrar y otros activos y otros pasivos}

(a) A continuación, se presenta la composición de estos rubros:

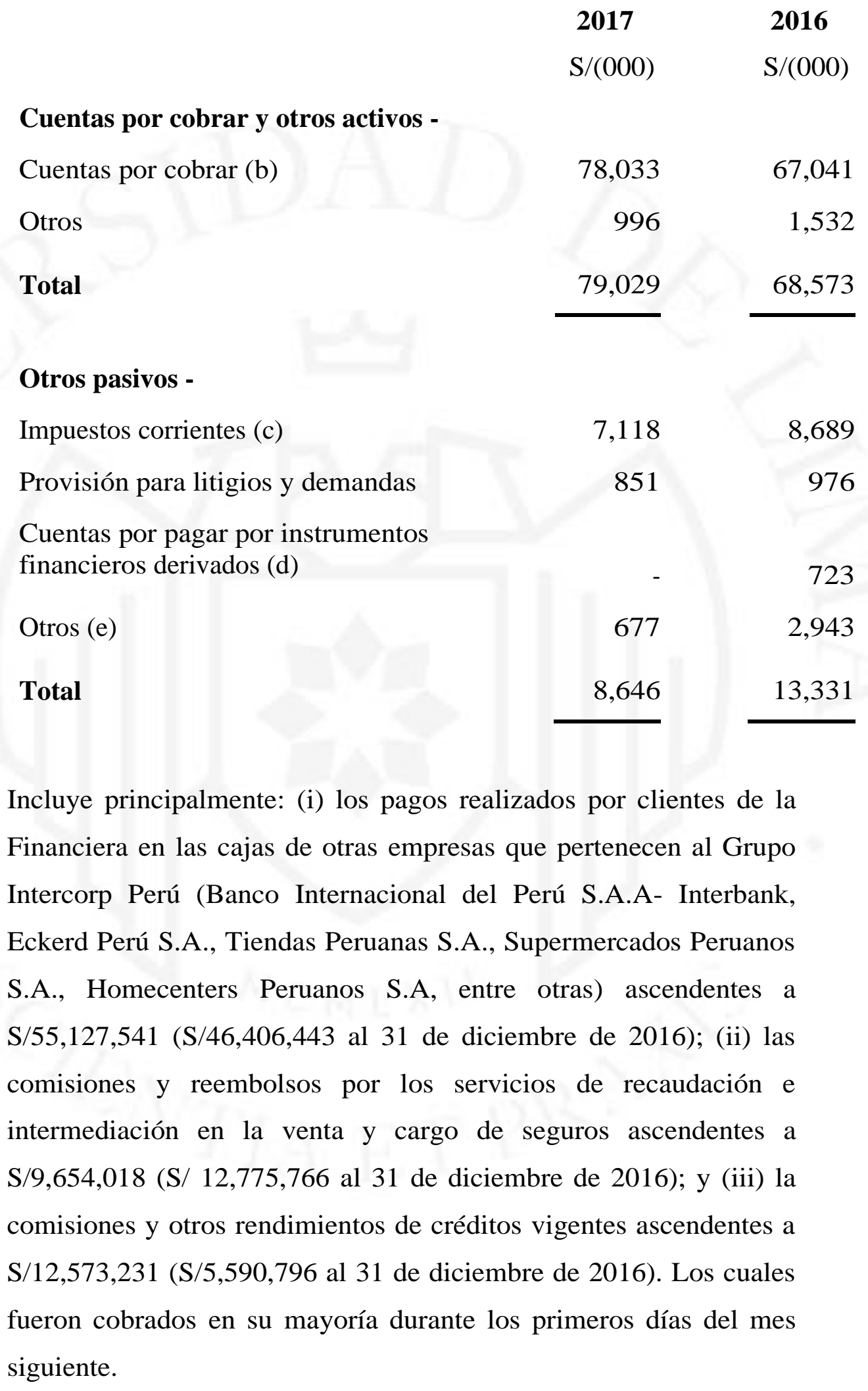


(c) Al 31 de diciembre de 2017, incluye impuesto a la renta por pagar ascendente a $\mathrm{S} / 9,029,713$, el cual se presenta neto del impuesto temporal a los activos netos por $\mathrm{S} / 1,878,918$ y el crédito fiscal del IGV por a $\mathrm{S} / 32,695$ (S/11,793,085, S/3,151,483 y S/47,380, respectivamente, al 31 de diciembre de 2016).

(d) Al 31 de diciembre de 2016, la Financiera mantuvo 2 contratos forwards

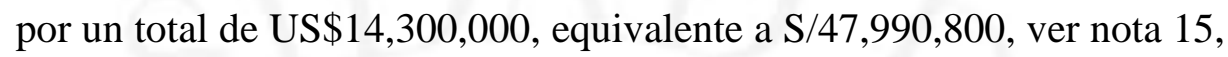
y su valor razonable representó una cuenta por pagar ascendente a $\mathrm{S} / 723,244$. Dichos instrumentos financieros derivados vencieron en enero 2017.

(e) Corresponde principalmente a los préstamos de libre disponibilidad aprobados en los últimos días del año y que quedaron pendientes de desembolso al cierre del ejercicio. 
8. Activo por impuesto a la renta diferido, neto

(a) A continuación, se presenta el detalle y el movimiento de este rubro:

\begin{tabular}{|c|c|c|c|c|c|}
\hline & $\begin{array}{l}\text { Saldos al } 1^{\circ} d e \\
\text { enero de } 2016 \\
\quad S /(000)\end{array}$ & $\begin{array}{l}\text { (Cargo) abono } \\
\text { a resultados } \\
\mathrm{S} /(000)\end{array}$ & $\begin{array}{c}\text { Saldos al } 31 \text { de } \\
\text { diciembre de } 2016 \\
\text { S/(000) }\end{array}$ & $\begin{array}{l}\text { (Cargo) abono } \\
\text { a resultados } \\
\mathrm{S} /(000)\end{array}$ & $\begin{array}{c}\text { Saldos al } 31 \text { de } \\
\text { diciembre de } 2017 \\
\text { S/(000) }\end{array}$ \\
\hline \multicolumn{6}{|l|}{ Activo diferido } \\
\hline Diferencia en tasas de depreciación y amortización & 3,535 & 1,291 & 4,826 & 935 & 5,761 \\
\hline Provisiones genéricas & 1,497 & 665 & 2,162 & 1,767 & 3,929 \\
\hline Servicios profesionales & 93 & (1) & 92 & 35 & 127 \\
\hline & 5,405 & 2,064 & 7,469 & 2,896 & 10,365 \\
\hline \multicolumn{6}{|l|}{ Pasivo diferido } \\
\hline Costos de transacción de Valores y títulos en circulación & - & - & - & $(528)$ & $(528)$ \\
\hline & _. & & - & (528) & (528) \\
\hline Total activo diferido, neto & 5,405 & 2,064 & 7,469 & 2,368 & 9,837 \\
\hline
\end{tabular}

(b) El gasto por impuesto a la renta registrado en el estado de resultados integrales se compone como sigue:

\begin{tabular}{lcc} 
& \multicolumn{2}{c}{ Impuesto a la renta } \\
& $\mathbf{2 0 1 7}$ & $\mathbf{2 0 1 6}$ \\
$\mathrm{S} /(000)$ & $\mathrm{S} /(000)$ \\
Corriente & $(27,796)$ & $(17,891)$ \\
Diferido - ingreso & 2,368 & 2,064 \\
Total impuesto a la renta & $(25,428)$ & $(15,827)$
\end{tabular}


Notas a los estados financieros (continuación)

(c) La reconciliación de la tasa efectiva del impuesto a la renta con la tasa tributaria es como sigue:

\begin{tabular}{lcccc} 
& \multicolumn{2}{c}{2017} & \multicolumn{2}{c}{2016} \\
& $\mathrm{~S} /(000)$ & $\%$ & $\mathrm{~S} /(000)$ & 100.00 \\
$\begin{array}{l}\text { Utilidad antes del impuesto a la } \\
\text { renta }\end{array}$ & 72,081 & 100.00 & 46,365 & $(28.00)$ \\
$\begin{array}{l}\text { Gasto teórico } \\
\begin{array}{l}\text { Efecto neto por gastos no deducibles } \\
\text { e ingresos } \\
\text { exonerados de carácter permanente }\end{array}\end{array}$ & $(21,264)$ & $(29.50)$ & $(12,982)$ & \\
$\begin{array}{l}\text { Efecto del cambio de tasa } \\
\text { Gasto por impuesto a la renta }\end{array}$ & $(25,164)$ & $(5.78)$ & $(3,742)$ & \\
\end{tabular}




\section{Obligaciones con el público}

(a) A continuación, se presenta la composición del rubro:

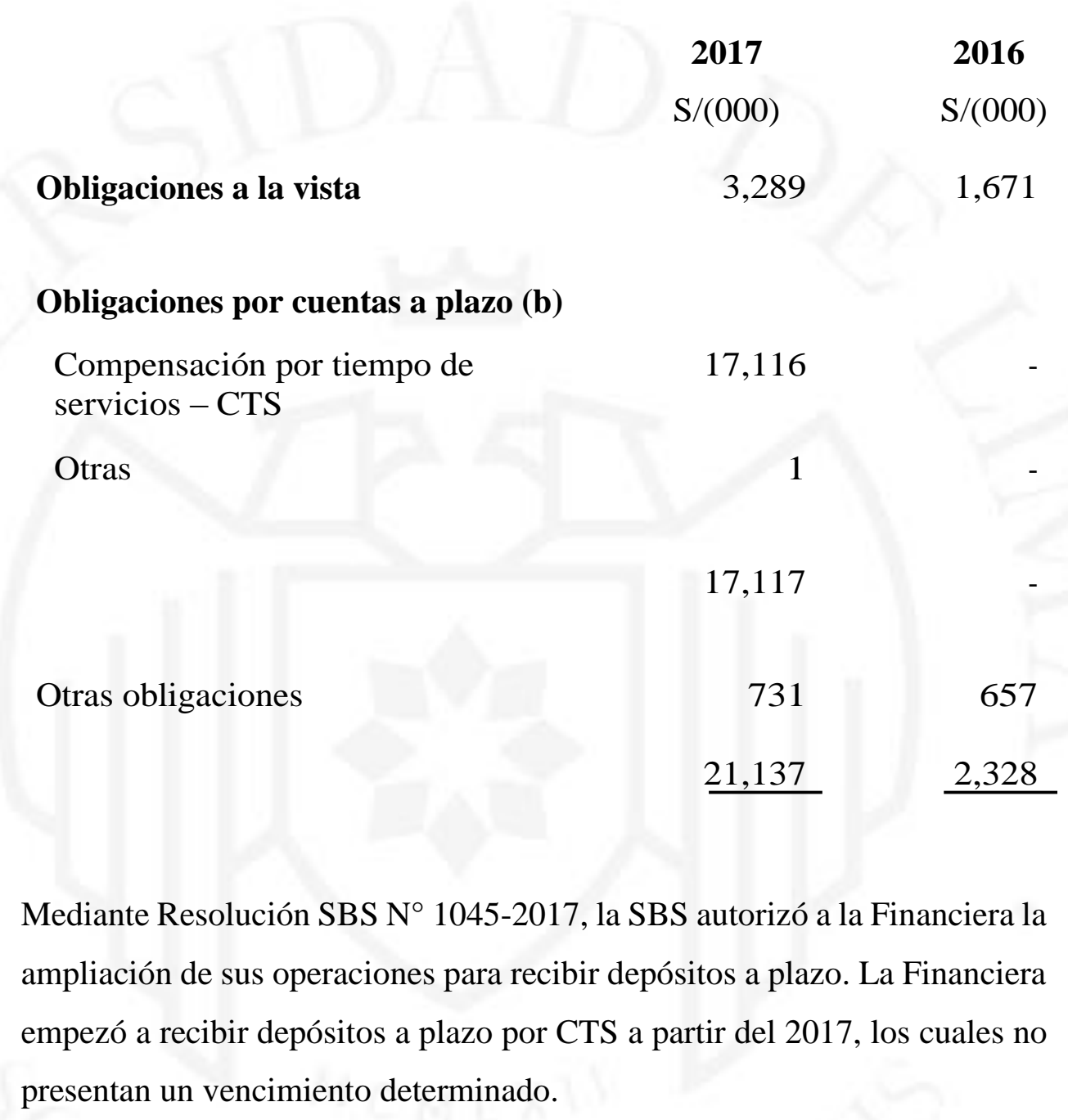

(b) Mediante Resolución SBS N 1045-2017, la SBS autorizó a la Financiera la ampliación de sus operaciones para recibir depósitos a plazo. La Financiera presentan un vencimiento determinado.

(c) Al 31 de diciembre de 2017, la cobertura del Fondo de Seguros de depósito por cada cliente es de hasta S/97,529. De acuerdo con lo establecido en el artículo $145^{\circ}$ de la Ley General, la Financiera deberá aportar al Fondo de Seguro de Depósitos durante 24 meses para que sus operaciones se encuentren cubiertas, para ello la Financiera deberá efectuar 9 pagos trimestrales; al 31 de diciembre de 2017, la Financiera ha efectuado 3 pagos trimestrales. 


\section{Adeudados}

(a) A continuación, se presenta la composición del rubro:

2017

Obligaciones con empresas financieras del país

123,273

(b)

Intereses devengados

(b) $\mathrm{Al} 31$ de diciembre de 2017 y de 2016 corresponde a los siguientes financiamientos:

Entidad
Banco GNB
Corporación Financiera de
Desarrollo (COFIDE) (c)
Banco Interamericano de
Finanzas S.A. (d)
Banco de Crédito del Perú (e)
Banco Internacional del Perú
S.A.A. - Interbank (f)
Banco GNB (f)
Corporación Financiera de
Desarrollo (COFIDE) (c)
Banco Interamericano de
Finanzas S.A. (g)
Banco de Crédito del Perú (h)
Fanco Interamericano de
Finanzas S.A. (d)
Bing

Vencimiento
Febrero de 2018
Entre febrero y mayo
de 2018
Entre enero y febrero
de 2018
Junio de 2018
Entre enero y febrero
de 2017
Enero de 2017
Entre mayo y julio de
2017

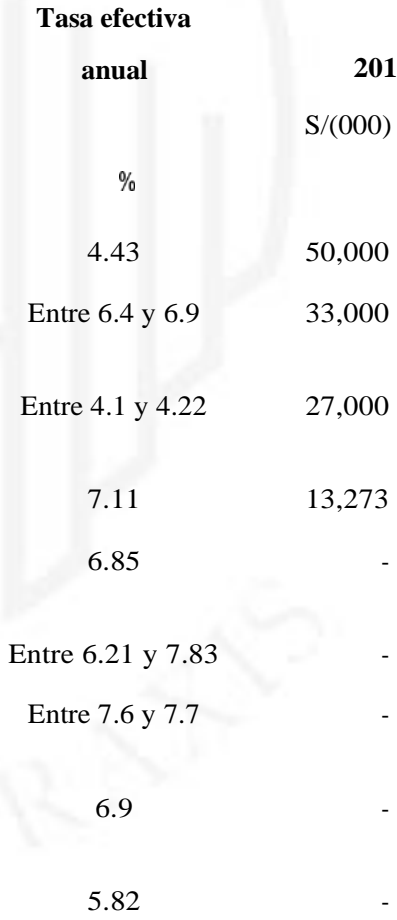

Entre 6.2 y 7.9
2016

$\mathrm{S} /(000)$

20,657

73,800

40,000

32,000

30,000

29,430

20,778

(c) En caso, a criterio de COFIDE, existan circunstancias especiales que 
dificulten la recuperación de los préstamos, la Financiera deberá transferir a COFIDE cartera crediticia bajo la modalidad de cesión de derechos y cesión de posición contractual.

(d) Estos préstamos se encuentran garantizados con depósitos a plazo en el mismo banco por S/ 9,515,004 (S/ 7,169,344 al 31 de diciembre de 2016), ver nota 3, y fianza solidaria de Intercorp Perú Ltd.

(e) Este saldo se presenta neto de los costos de transacción ascendentes a S/ 93,793 (S/ 505,962 al 31 de diciembre de 2016). Este préstamo se encuentra garantizado por una carta de crédito Stand By de Bancolombia, así como con un fideicomiso de flujos dinerarios, producto de los pagos efectuados por los clientes de la Financiera en las cajas de Supermercados Peruanos S.A. Al 31 de diciembre de 2017, los flujos dinerarios se encuentran restringidos en dos cuentas corrientes del Banco Internacional del Perú por S/ 5,154,668 y un depósito plazo de S/ 4,650,000 (S/ 14,533 al 31 de diciembre de 2016), nota3.

(f) Estos préstamos se encontraron garantizados por Intercorp Perú Ltd. En el caso del Banco GNB, dicha garantía fue hasta por el importe de S/ $27,000,000$.

(g) Este préstamo se encontraba garantizado con depósito a plazo en el mismo banco por $\mathrm{S} / 3,120,000$, ver nota3.

(h) Este saldo se presentó neto de los costos de transacción, ascendentes a S/ 420,442. Este préstamo se encontró garantizado por una carta de crédito Stand By de Bancolombia, así como con un fideicomiso de flujos dinerarios, producto de los pagos efectuados por los clientes de la Financiera en las cajas de Supermercados Peruanos S.A. 
(i) Los intereses devengados por adeudados con empresas financieras del país durante el 2017 ascendieron a S/9,773,345 (en el 2016 ascendieron a $\mathrm{S} / 18,768,177)$ y se encuentran registrados en la cuenta "Gastos financieros" del estado de resultados integrales, ver nota17.

(j) A continuación, se presenta el saldo del rubro al 31 de diciembre de 2017 y de 2016 clasificado por vencimiento:

Hasta 1 mes

De 1 mes a 3 meses

De 3 meses a 1 año

De 1 año a 3 años 
11. Valores y títulos en circulación

(a) A continuación, se presenta la composición del rubro:

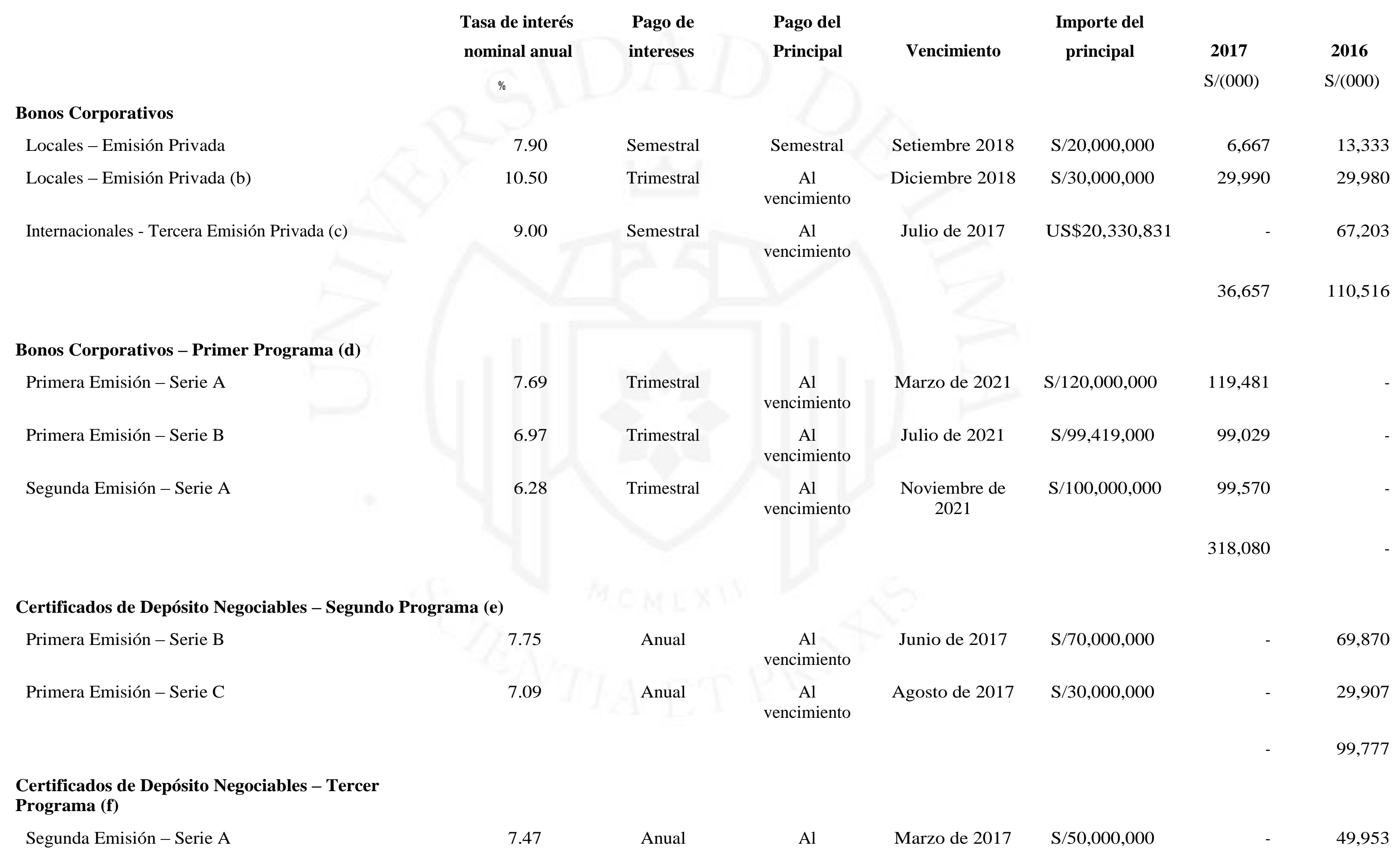


Tercera Emisión - Serie A

4.97

Anual

vencimiento

$\underset{\text { vencimiento }}{\mathrm{Al}}$

Diciembre de

S/70,000,000

69,755

69,755

49,953

Certificados de Depósito Negociables - Cuarto Programa (g)

Primera Emisión - Serie A

Segunda Emisión - Serie A

Segunda Emisión - Serie B

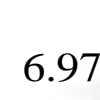

6.66

6.25

Anual

Anual

Anual

Ans

Certificados de Depósito Negociables - Emisión directa (h)

Tercera Emisión

Cuarta Emisión

Quinta Emisión

Sexta Emisión

Séptima Emisión

Octava Emisión

Intereses por pagar

Total
8.25

7.10

7.00

6.96

6.96

5.70

\section{Anual}

Anual

Anual

Anual

Anual

Anual

$\begin{array}{cccr}\begin{array}{c}\text { Al } \\ \text { vencimiento }\end{array} & \begin{array}{c}\text { Diciembre de } \\ 2017\end{array} & \text { S/120,000,000 } & \\ \begin{array}{c}\mathrm{Al} \\ \text { vencimiento }\end{array} & \text { Marzo de 2018 } & \text { S/60,000,000 } & 59,954 \\ \begin{array}{c}\mathrm{Al} \\ \text { vencimiento }\end{array} & \text { Mayo de 2018 } & \text { S/120,000,000 } & 119,842 \\ & & & \\ & & & 179,796\end{array}$

$\mathrm{Al}$
vencimiento

Al

vencimiento

\section{$\mathrm{Al}$}

vencimiento

$\mathrm{Al}$

vencimiento

$\mathrm{Al}$

vencimiento

$\mathrm{Al}$

vencimiento
Marzo de $2017 \quad$ S/45,000,000

Setiembre de$$
2017
$$

Noviembre de

$$
2017
$$

Marzo de 2018

Marzo de 2018

Octubre de 2018

S/10,000,000

S/10,000,000

S/30,000,000

S/50,000,000
179,796

119,614

119,614

-

44,996

20,000

14,000

50,000

90,000

78,996

13,263

18,295

707,551 
(b) Al 31 de diciembre de 2017, este saldo se presenta neto de los costos de transacción ascendentes a S/9,913 (S/19,718 al 31 de diciembre de 2016). Asimismo, la Financiera mantiene ciertos "covenants" financieros, los cuales, en opinión de la Gerencia, la Financiera cumple al 31 de diciembre de 2017 y de 2016. A solicitud de la Financiera, la Superintendencia del Mercado de Valores, mediante Resolución de Intendencia General SMV Nº53-2017- SMV/11.1 del 24 de julio de 2017, dispuso la inscripción de estos valores en el Registro de Valores de la Bolsa de Valores de Lima para su negociación pública secundaria.

(c) Al 31 de diciembre de 2016, este saldo se presentó neto de los costos de transacción ascendentes a S/1,027,555. Dichos bonos se encontraron garantizados con cartera crediticia; y un fideicomiso de derechos y flujos dinerarios en el Banco Internacional del Perú S.A.A. - Interbank, producto de los pagos efectuados por los clientes de la Financiera en las cajas de Interbank, y que se encontraron depositados en el mismo banco por $\mathrm{S} / 675,358$ y US $\$ 1,829,925$, ver nota 3 .

(d) Mediante Resolución SBS N 6320 - 2016 del 2 de diciembre de 2016, se autorizó el denominado "Primer Programa de Emisión de Bonos Corporativos de Financiera OH! S.A.”, hasta por un monto máximo en circulación de S/ 500,000,000.00. Al 31 de diciembre de 2017, este saldo se presenta neto de los costos de transacción ascendentes a $\mathrm{S} / 1,338,582$.

(e) Mediante Resolución SBS N ${ }^{\circ}$ 5316-2014 del 13 de agosto de 2014, se autorizó el denominado "Segundo Programa de Certificados de Depósitos Negociables de Financiera Uno S.A.”, hasta por un monto máximo en circulación de S/100,000,000.00. Dichos certificados tuvieron como garantía genérica el patrimonio de la Financiera. Al 31 de 
diciembre de 2016, este saldo se presentó neto de los costos de transacción ascendentes a S/222,727.

(f) Mediante Resolución SBS N 6711-2015 del 5 de noviembre de 2015, se autorizó el denominado “Tercer Programa de Certificados de Depósitos Negociables de Financiera Uno S.A.”, hasta por un monto máximo en circulación de S/100,000,000.00. Dichos certificados tienen como garantía genérica el patrimonio de la Financiera y como garantía específica la fianza de Intercorp Retail Inc. hasta por el 100 por ciento del importe emitido. Al 31 de diciembre de 2017, este saldo se presenta neto de los costos de transacción ascendentes a S/244,657 (S/47,667 al 31 de diciembre de 2016).

(g) Mediante Resolución SBS N 6321-2016 del 2 de diciembre de 2016, se autorizó el denominado "Cuarto Programa de Certificados de Depósitos Negociables de Financiera Oh! S.A.”, hasta por un monto máximo en circulación de S/300,000,000.00. Dichos certificados tienen como garantía genérica el patrimonio de la Financiera. Al 31 de diciembre de 2017, este saldo se presenta neto de los costos de transacción ascendentes a S/ 203,924 (S/ 386,116 al 31 de diciembre de 2016).

(h) Al 31 de diciembre de 2016 este saldo se presentó neto de los costos de transacción ascendentes a S/ 4,125. Al 31 de diciembre de 2017, los certificados de depósitos negociables no tuvieron costos de transacción.

(i) Los intereses devengados por los bonos corporativos y certificados de depósito negociables durante el 2017 ascendieron a S/ 43,868,258 (S/ 28,015,571 durante el 2016), y se encuentran registrados en la cuenta “Gastos financieros" del estado de resultados integrales, ver nota 17. 
(j) Al 31 de diciembre de 2017 y de 2016, el calendario de amortización de estas obligaciones es el siguiente:

Año

2017

2016

$\mathrm{S} /(000)$

$\mathrm{S} /(000)$

2017

422,209

2018

376,208

36,647

2021

318,080

Total

694,288

458,856

\section{Cuentas por pagar}

(a) A continuación, se presenta la composición del rubro:

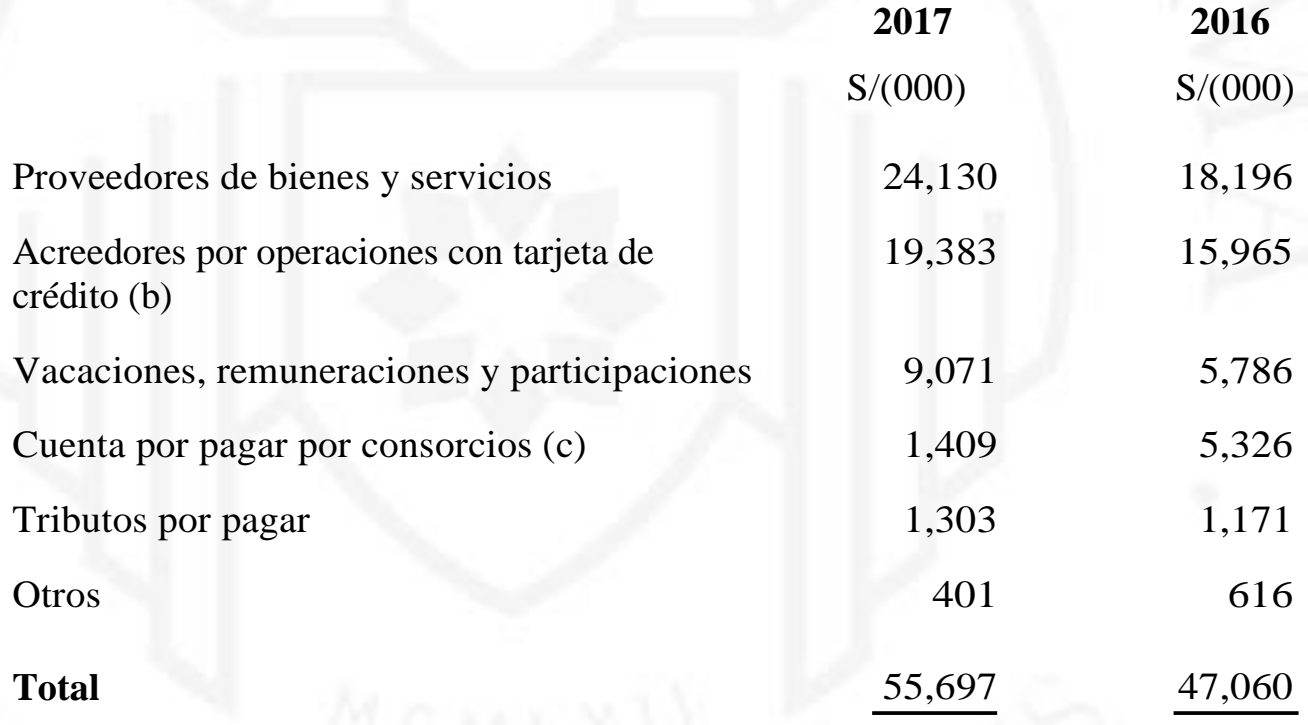

(b) Corresponde a consumos y disposiciones de efectivo de los clientes de la Financiera, y que se encuentran por pagar principalmente al operador de tarjeta Procesos de Medios de Pago S.A. Dichos conceptos fueron liquidados durante los primeros días de enero de 2018 y de 2017, respectivamente. 
(c) La Financiera mantiene contratos con Supermercados Peruanos S.A. y Tiendas Peruanas S.A., con la finalidad de que ambas compañías participen en los resultados obtenidos como consecuencia del negocio de colocación de créditos de consumo a los clientes que adquieran con la Tarjeta de Crédito Oh! Bienes en Supermercados, Hipermercados Plaza Vea y las tiendas por Departamento Échale, ver nota 19 (b) y (c).

\section{Patrimonio neto}

(a) Al 31 de diciembre de 2017 y de 2016, el capital social está representado por $220,255,793$ acciones comunes con valor nominal de S/1.00 por acción. Estas acciones se encuentran totalmente suscritas, pagadas e inscritas ante registros públicos.

Al 31 de diciembre de 2017 y de 2016, la participación accionaria está conformado por:

\section{Accionistas}

IFH Retail Corp.

Otros

(b) Reserva legal

De conformidad con las normas legales vigentes, la Financiera debe alcanzar una reserva legal no menor al 35 por ciento de su capital pagado. Esta reserva se constituye mediante el traslado anual de no menos del 10 por ciento de la utilidad neta distribuible y sólo puede utilizarse para compensar pérdidas o su capitalización, existiendo en ambos casos la obligación de reponerla. La Financiera constituye y registra la reserva 
legal de manera posterior a que la misma es aprobada por la Junta General de Accionistas.

(c) Patrimonio efectivo-

De acuerdo con lo dispuesto por el Decreto Legislativo $\mathrm{N}^{\circ} 1028$, el patrimonio efectivo deber ser igual o mayor al 10 por ciento de los activos y créditos contingentes ponderados por riesgo totales que corresponden a la suma de: el requerimiento de patrimonio efectivo por riesgo de mercado multiplicado por 10, el requerimiento de patrimonio efectivo por riesgo operacional multiplicado por 10 , y los activos y créditos contingentes ponderados por riesgo de crédito.

Al 31 de diciembre de 2017 y de 2016, en aplicación del Decreto Legislativo $\mathrm{N}^{\circ} 1028$ y modificatorias, la Financiera mantiene los siguientes importes con relación a los activos y créditos contingentes ponderados por riesgo y patrimonio efectivo (básico y suplementario):

Activos y créditos ponderados por riesgos totales

Patrimonio efectivo total

Patrimonio efectivo básico (Nivel 1)

Patrimonio efectivo suplementario (Nivel 2)

Ratio de capital global sobre el patrimonio efectivo

Al 31 de diciembre de 2017 y de 2016, la Financiera viene cumpliendo con las Resoluciones SBS N²115-2009, N6328-2009, N¹4354-2009, Reglamentos para el Requerimiento de Patrimonio 
Efectivo por Riesgo Operacional, por Riesgo de Mercado y por Riesgo de Crédito, respectivamente, y modificatorias. Estas Resolución es establecen, principalmente, las metodologías para utilizar por las entidades financieras para calcular los activos y créditos ponderados para cada tipo de riesgo.

En julio de 2011, la SBS emitió la Resolución Nº 8425 - 2011, mediante la cual establece que, para determinar el nivel de patrimonio efectivo adicional, las instituciones financieras deberán contar con un proceso para evaluar la suficiencia de su patrimonio efectivo en función a su perfil de riesgo, de acuerdo con cierta metodología descrita en dicha resolución. En aplicación de dicha norma, el requerimiento de patrimonio efectivo adicional será igual a la suma de los requerimientos de patrimonio efectivo calculados para cada uno de los siguientes componentes: ciclo económico, riesgo por concentración, riesgo por concentración de mercado, riesgo por tasa de interés en el libro bancario y otros riesgos. Asimismo, establece un período de adecuación gradual de cinco años a partir de julio de 2012. Al 31 de diciembre de 2017, el porcentaje de adecuación establecido por la SBS es el 100 por ciento, por lo que el requerimiento adicional estimado por la Financiera asciende a aproximadamente S/ 39,784,635 (S/ 37,208,042 con el 100 por ciento al 31 de diciembre de 2016).

En opinión de la Gerencia, la Financiera viene cumpliendo con los requerimientos establecidos en la resolución anteriormente mencionada y no tendrá inconveniente en seguir cumpliéndolos.

\section{Situación tributaria}

(a) La Financiera está sujeta al régimen tributario vigente peruano. La tasa del impuesto a la renta\%1 31 de diciembre de 2016 fue de 28 . La tasa del impuesto a la renta vigente al 31 de diciembre de 2017 es de 29.5 sobre la utilidad gravable. 
Las personas jurídicas no domiciliadas en el Perú y las personas naturales están sujetas a la retención de un impuesto adicional sobre los dividendos recibidos. Al respecto, en atención al Decreto Legislativo No. 1261, el impuesto aplicable a los dividendos por las utilidades generadas será el siguiente:

- \% 6.8 por las utilidades generadas desde el 1 de enero de 2015 hasta el 31 de diciembre de2016.

\% 5 por las utilidades generadas a partir del 1 de enero de 2017, cuya distribución se efectúen a partir de dicha fecha.

(b) Para propósito de la determinación del Impuesto a la Renta, los precios de transferencia de las transacciones con empresas relacionadas y con empresas residentes en países o territorios de baja o nula imposición, deben estar sustentados con documentación e información sobre los métodos de valoración utilizados y los criterios considerados para su determinación. Sobre la base del análisis de las operaciones de la Financiera, la Gerencia y sus asesores legales internos opinan que, como consecuencia de la aplicación de estas normas, no surgirán contingencias de importancia para la Financiera al 31 de diciembre de 2017 y de 2016.

(c) La Autoridad Tributaria tiene la facultad de revisar y, de ser aplicable, corregir el impuesto a la renta calculado por la Financiera en los cuatro años posteriores al año de presentación de la declaración de impuestos respectiva, siempre que este plazo no haya sido suspendido o interrumpido. Las declaraciones juradas del impuesto a la renta y del impuesto general a las ventas de los años 2014 al 2017 están sujetas a fiscalización por parte de la Autoridad Tributaria. Durante el año 2016, la Financiera se encontró en proceso de fiscalización por parte de la Administración Tributaria del ejercicio 2013. 
Debido a las posibles interpretaciones que la Autoridad Tributaria puede dar a las normas legales vigentes, no es posible determinar a la fecha si de las revisiones que se realicen resultarán o no pasivos para la Financiera, por lo que cualquier mayor impuesto o recargo que pudiera resultar de eventuales revisiones fiscales sería aplicado a los resultados del ejercicio en que éste se determine.

\section{Contingentes}

A continuación, se presenta la composición del rubro:

\section{Contingentes}

Líneas de crédito no utilizadas de tarjeta de

crédito

Instrumentos financieros derivados, nota 7(d)

Total contingentes

\section{Ingresos financieros}

A continuación, se presenta la composición del rubro:

$\begin{array}{lrr} & \mathbf{2 0 1 7} & \mathbf{2 0 1 6} \\ & \mathrm{S} /(000) & \mathrm{S} /(000) \\ \text { Intereses por cartera de créditos } & 316,369 & 263,543 \\ \text { Comisiones y gastos por cartera de créditos } & 137,587 & 107,630 \\ \text { Intereses por disponible } & 2,105 & 1,880 \\ \text { Total } & \underline{456,061} & \underline{373,053}\end{array}$




\section{Gastos financieros}

A continuación, se presenta la composición del rubro:

Intereses por valores y títulos en circularización, ver
nota 11 (i)
$\begin{aligned} & \text { Intereses por adeudos con empresas financieras del } \\ & \text { país, ver nota } 10(\mathrm{i})\end{aligned}$

Comisiones y cargos por adeudos y valores y

títulos

Otros

Total

18. Ingresos por servicios financieros

A continuación, se presenta la composición del rubro:

Comisiones por recaudación e intermediación en

Comisiones por venta de seguro de protección de tarjeta, protección financiera, SOAT, seguro oncológico y asistencia

Comisiones por venta de garantía extendida (supergarantía)

Reembolso de remuneraciones por venta de seguros 


\section{Resultado por operaciones financieras}

(a) A continuación, se presenta la composición del rubro:

2017

$\mathrm{S} /(000)$

622

Ganancia por diferencia en cambio

Venta de cartera

\section{Ingresos -}

\section{Gastos -}

Atribuciones del consorcio a SPSA (b)

Atribuciones del consorcio a TPSA (c)

Instrumentos financieros derivados

Otros

\section{Total}

$(304,957)$

(b) En abril 2015, ¡la Financiera suscribió un contrato con Supermercados Peruanos S.A. (SPSA), a través del cual ambas compañías participan en los resultados del negocio de venta de bienes y colocación de créditos de consumo a los clientes que adquieran, con la Tarjeta de Crédito Oh!, bienes en Supermercados e Hipermercados Plaza Vea operados por SPSA. La Financiera es la encargada del otorgamiento del crédito, y por lo tanto mantiene como parte de su cartera la colocación de los créditos.

Como consecuencia de dicho contrato y sus modificatorias, el cual tiene vigencia hasta el 31 de diciembre de 2020, la Financiera ha reconocido gastos por un total de $\mathrm{S} / 18,621,384$ (S/21,089,410 en el 2016), que corresponde al resultado del contrato atribuido a SPSA. La distribución del resultado se efectúa tomando en consideración la participación de 
\% cada una de las partes en los aportes al contrato. Al 31 de diciembre de 2017, el resultado se distribuyó de la siguiente manera: 30.49 a favor de la Financiera (28.54 al 31 de diciembre de 2016) y 69.51 a favor de SPSA (71.46 al 31 de diciembre de 2016).

(c) En junio 2015, ¡la Financiera suscribió un contrato con Tiendas Peruanas S.A. (TPSA), a través del cual ambas compañías participan en los resultados del negocio de venta de bienes y colocación de créditos de consumo a los clientes que adquieran, con la Tarjeta de Crédito Oh!, bienes en las Tiendas por Departamento Oechsle operados por TPSA. La Financiera es la encargada del otorgamiento del crédito, y por lo tanto mantiene como parte de su cartera la colocación de los créditos.

\% Como consecuencia\%de dicho contrato y sus modificatorias, el cual tiene vigencia hasta el 31 de diciembre de 2020, la Financiera ha reconocido gastos por un total de $S / 16,463,769$ (S/14,480,089 en el 2016), que corresponde al resultado del contrato atribuido a TPSA. La distribución del resultado se efectúa tomando en consideración la participación de cada una de las partes en los aportes al contrato. Al 31 de diciembre de 2017, el resultado se distribuyó de la siguiente manera: 24.38 a favor de la Financiera (23.02 al 31 de diciembre de 2016) y 75.62 a favor de TPSA (76.98 al 31 de diciembre de 2016).

\section{Gastos de administración}

(a) A continuación, se presenta la composición del rubro:

$\begin{array}{lcr} & \mathbf{2 0 1 7} & \mathbf{2 0 1 6} \\ & \mathrm{S} /(000) & \mathrm{S} /(000) \\ \text { Servicios recibidos de terceros (b) } & 124,017 & 96,011 \\ \text { Gastos de personal (c) } & 70,843 & 58,968 \\ \text { Impuestos y contribuciones } & 1,855 & 1,529 \\ \text { Total } & 196,715 & 156,508\end{array}$


(b) Los servicios recibidos de terceros corresponden principalmente a servicios de publicidad y marketing, descuentos exclusivos con la tarjeta Oh, comisiones asociadas al procesamiento de la tarjeta Oh (Merchant fee), seguros, alquileres de oficinas y agencias, transporte, procesamiento de transacciones de tarjeta, suministros, servicio de recaudación, gestión de cobranza, honorarios profesionales, entre otros.

(c) A continuación, se presenta la composición de los gastos de personal:

\begin{tabular}{lrr} 
& $\mathbf{2 0 1 7}$ & $\mathbf{2 0 1 6}$ \\
& $\mathrm{S} /(000)$ & $\mathrm{S} /(000)$ \\
Remuneraciones & 34,463 & 29,613 \\
Comisiones & 7,458 & 6,333 \\
Gratificaciones & 7,107 & 6,119 \\
Participaciones a los trabajadores & 8,561 & 4,641 \\
Seguridad y previsión social & 4,066 & 3,567 \\
Compensación por tiempo de servicios & 3,688 & 3,149 \\
Compensación vacacional, atenciones, & & 5,546 \\
$\quad$ indemnizaciones y otros & 5,500 & 58,968 \\
\cline { 2 - 2 } Total & 70,843 & 1,269 \\
\cline { 2 - 3 } & & 1,312 \\
\cline { 2 - 3 }
\end{tabular}

\section{Transacciones con partes relacionadas}

(a) A continuación, se detallan los principales saldos de las cuentas que la Financiera mantiene con sus vinculadas al 31 de diciembre de 2017 y de 2016: 


\section{Activos}

Disponible

Cuentas por cobrar

\section{Pasivos}

Adeudados y valores y títulos

Cuentas por pagar

\section{Resultados}

Ingresos financieros

Gastos financieros

Ingresos por servicios financieros

Gastos por resultado de operaciones

De acuerdo con la legislación peruana, los créditos otorgados a partes vinculadas no pueden efectuarse en condiciones más favorables que las que se otorga al público en general. La Gerencia de la Financiera considera que ha cumplido con todos los requerimientos establecidos en los dispositivos legales vigentes para las transacciones con entidades o personas vinculadas.

(b) Durante los años 2017 y 2016, los gastos por remuneraciónes y otros conceptos a los miembros de la Gerencia clave de la Financiera ascendieron a S/5,226,205 y S/4,426,005, respectivamente, y se presentan como parte del rubro de "Gastos de administración" del estado de resultados integrales. Asimismo, la Financiera lleva un 
control de los préstamos de sus funcionarios los cuales son reportados mensualmente a la SBS.

(c) Préstamos al personal-

La Financiera otorga préstamos a sus empleados y funcionarios que se presentan como parte del rubro de "Cartera de créditos, neto" del estado de situación financiera. Las tasas de interés aplicadas son las mismas que las del mercado.

\section{Clasificación de instrumentos financieros}

A continuación, se presentan los importes de los activos y pasivos financieros de los rubros del estado de situación financiera clasificados por categoría según la Norma Internacional de Contabilidad N 39 "Instrumentos Financieros":

\begin{tabular}{|c|c|c|c|c|c|c|}
\hline & \multicolumn{3}{|c|}{2017} & \multicolumn{3}{|c|}{2016} \\
\hline & $\begin{array}{l}\text { Préstamos } \\
\text { y partidas } \\
\text { por cobrar }\end{array}$ & $\begin{array}{c}\text { Pasivos } \\
\text { financieros } \\
\text { al costo } \\
\text { amortizado }\end{array}$ & Total & $\begin{array}{c}\text { Préstamos y } \\
\text { partidas } \\
\text { por cobrar }\end{array}$ & $\begin{array}{c}\text { Pasivos } \\
\text { financieros } \\
\text { al costo } \\
\text { amortizad } \\
o\end{array}$ & Total \\
\hline & $\mathrm{S} /(000)$ & $\mathrm{S} /(000)$ & $\mathrm{S} /(000)$ & $\mathrm{S} /(000)$ & $\mathrm{S} /(000)$ & $\mathrm{S} /(000)$ \\
\hline \multicolumn{7}{|l|}{ Activos financieros } \\
\hline Disponible & 114,997 & - & 114,997 & 107,719 & - & 107,719 \\
\hline Cartera de créditos & 945,121 & - & 945,121 & 785,280 & - & 785,280 \\
\hline Otros activos & 79,029 & - & 79,029 & 68,573 & - & 68,573 \\
\hline & $\begin{array}{r}1,139,14 \\
7\end{array}$ & - & $1,139,147$ & 961,572 & - & 961,572 \\
\hline \multicolumn{7}{|l|}{ Pasivos financieros } \\
\hline Obligaciones con el público & - & 21,137 & 21,137 & - & 2,328 & 2,328 \\
\hline Adeudos & - & 125,122 & 125,122 & - & 250,465 & 250,465 \\
\hline \multicolumn{7}{|l|}{ Valores y títulos en } \\
\hline circulación & - & 707,551 & 707,551 & - & 477,151 & 477,151 \\
\hline Cuentas por pagar & - & 55,697 & 55,697 & - & 47,060 & 47,060 \\
\hline Otros pasivos & - & 7,795 & 7,795 & - & 12,355 & 12,355 \\
\hline & - & 917,302 & 917,302 & - & 789,359 & 789,359 \\
\hline
\end{tabular}




\section{Gestión de riesgos financieros}

Comprende la administración de los principales riesgos, que por la naturaleza de sus operaciones enfrenta la Financiera, como son el riesgo de crédito, mercado, liquidez y operación.

Riesgo de crédito: es la posibilidad de pérdida por incapacidad o falta de voluntad de los deudores, contrapartes o terceros obligados para cumplir sus obligaciones contractuales.

Riesgos de mercado: es la posibilidad de pérdidas en posiciones dentro y fuera del balance derivadas de variaciones en las condiciones de mercado; incluye generalmente los siguientes tipos de riesgo: cambiario, valor razonable por tipo de interés, de precio, entre otros.

Riesgo de liquidez: es la posibilidad de pérdida por incumplir los requerimientos de financiamiento y de aplicación de fondos que surgen de los descalces de flujos de efectivo.

Riesgo de operación: es la posibilidad de pérdidas por procesos inadecuados, fallas del personal, de la tecnología de información o eventos externos.

Para el manejo de dichos riesgos, se cuenta con una estructura y organización especializada en la gestión, sistemas de medición y procesos de mitigación y cobertura.

(a) Estructura y organización de la gestión de riesgos-

La Financiera cuenta con una estructura de gobierno y gestión 
que le permite articular adecuadamente la administración y control de los riesgos que enfrenta.

(i) Directorio

El Directorio de la Financiera es responsable de establecer una adecuada gestión integral de los riesgos y de propiciar un ambiente interno que facilite su desarrollo. El Directorio se mantiene permanentemente informado sobre el grado de exposición de los diversos riesgos que administra la Financiera.

El Directorio ha creado diversos comités especializados en los cuales ha delegado funciones específicas con el objetivo de fortalecer la gestión de riesgos y el control interno.

(ii) Comité de Riesgos

El Comité de Riesgos es un órgano colegiado creado por acuerdo de Directorio. Es responsable de aprobar las políticas y la organización para la gestión integral de riesgos, así como las modificaciones que se realicen a los mismos. El Comité define el nivel de tolerancia y el grado de exposición al riesgo que la Financiera está dispuesta a asumir en el desarrollo del negocio y decide las acciones necesarias para la implementación de las medidas correctivas requeridas, en caso existan desviaciones con respecto a los niveles de tolerancia al riesgo y a los grados de exposición asumidos. El Comité sesiona de manera mensual y está compuesto por dos Directores, el Gerente General, el Gerente de Riesgos y Cobranzas y el Gerente de Finanzas. El Comité reporta mensualmente al Directorio los principales asuntos tratados y los acuerdos adoptados en la sesión anterior. 
(iii) Comité de Auditoría

El Comité de Auditoría es un órgano colegiado creado en sesión de Directorio. Su propósito principal es vigilar que los procesos contables y de reporte financiero sean apropiados, así como evaluar las actividades realizadas por los auditores internos y externos. El Comité está conformado por tres miembros del Directorio y podrán participar el Gerente General, el Auditor Interno y otros ejecutivos de la Financiera, en la medida que sean requeridos. El Comité se reúne al menos tres veces al año en forma ordinaria y pone en conocimiento de los miembros del Directorio los asuntos tratados.

(iv) Comité de Activos y Pasivos

El Comité de Activos y Pasivos (ALCO por sus siglas en inglés) es un órgano creado por acuerdo de Directorio. Tiene como principal función gestionar la estructura financiera del estado de situación de la Financiera, en función de la meta de rentabilidad y riesgo. El Comité también es responsable de proponer nuevos productos $\mathrm{u}$ operaciones que contengan componentes de riesgo de mercado. Asimismo, es el canal de comunicación con las áreas generadoras de riesgo de mercado. El Comité sesiona con frecuencia mensual y está conformado por el Gerente General, el Gerente de Riesgos y Cobranzas y el Gerente de Finanzas.

(v) Gerencia General

El Gerente General tiene la responsabilidad de implantar en la organización una adecuada gestión integral del riesgo. Dirige y coordina los esfuerzos de las diversas Gerencias, velando por establecer un adecuado balance entre el riesgo y la rentabilidad. La Gerencia de Riesgos es un órgano de línea y depende directamente de la Gerencia General, es la encargada de proponer las políticas, 
procedimientos y metodologías para una gestión integral de riesgos competente, promueve el alineamiento de las medidas de tratamiento de los riesgos de la Financiera con los niveles de apetito y tolerancia al riesgo y el desarrollo de controles apropiados.

\section{(vi) Auditoría Interna}

La Gerencia de Auditoría Interna reporta funcionalmente al Directorio. Proporciona servicios independientes y objetivos de aseguramiento y consulta, concebidos para agregar valor y mejorar la eficacia de las operaciones de la Financiera. Ayuda a la Financiera a cumplir sus objetivos, aplicando un enfoque sistemático y disciplinado para evaluar y mejorar la eficacia de los procesos de gobierno, gestión de riesgos y control.

(b) Sistemas de medición y reporte de riesgos-

La Financiera utiliza para la gestión de riesgo diferentes modelos y herramientas de calificación a nivel cliente o producto. Estas herramientas miden y valoran el riesgo con una visión prospectiva, permitiendo así tomar mejores decisiones de riesgo en las diferentes etapas o ciclo de vida del crédito.

Las herramientas son monitoreadas permanentemente y validadas periódicamente a fin de asegurar que los niveles de predicción y performance se mantengan y realizar las medidas correctivas o ajustes a los modelos de ser necesario. La Financiera viene trabajando en la estimación de los parámetros de riesgos (probabilidad de incumplimiento, severidad de la pérdida y factores de conversión crediticia) utilizando metodologías e información histórica interna. Estos parámetros nos permitirán medir y prospectar el nivel de riesgo de la cartera, estimar las pérdidas esperadas y capital económico. 
El control del riesgo es realizado sobre la base del presupuesto. Anualmente la Financiera establece la estrategia comercial y el nivel de riesgo máximo a asumir, con la finalidad de obtener una rentabilidad deseada y un nivel de capital o solvencia objetivo.

Los indicadores de gestión son revisados y analizados permanentemente, con la finalidad de identificar posibles desviaciones en el perfil del riesgo respecto al apetito de riesgo estipulado, con la finalidad de tomar medidas correctivas oportunamente. Esta información se presenta mensualmente al Comité de Riesgos y periódicamente al Directorio.

(c) Mitigación y cobertura de riesgos -

El riesgo de crédito es el principal riesgo que debe administrar la Financiera y a efectos de mitigar el riesgo de las exposiciones y brindarles una adecuada cobertura ha establecido una serie de medidas, entre las que destacan las siguientes:

Políticas, procedimientos, metodologías, modelos y parámetros que permitan identificar, medir, controlar y reportar el riesgo de crédito.

Revisión y evaluación del riesgo de crédito, a través de las unidades especializadas de admisión de riesgo, independientes del área comercial de la Financiera y que evalúan los riesgos de crédito previo a las aprobaciones de créditos a clientes.

Monitoreo y seguimiento oportuno del riesgo de crédito y su mantenimiento dentro del nivel de tolerancia definido. 
Cumplimiento de limites regulatorios y el establecimiento de límites internos a las concentraciones de exposición de deudores y contrapartes, como las relacionadas a calificación crediticia y liquidez.

\subsection{Riesgo crediticio-}

El riesgo de crédito se define como la probabilidad de incurrir en pérdidas financieras originadas por el incumplimiento de las obligaciones contractuales de una contraparte o terceros obligados por motivos de insolvencia, incapacidad o falta de voluntad de pago.

(a) La Financiera opta por una política de riesgos que asegura un crecimiento sostenido y rentable; para ello incorpora procedimientos de análisis para la adecuada toma de decisiones, herramientas y metodologías que permitan identificar, medir, mitigar y controlar los diferentes riesgos de la manera más eficiente y acorde a lo establecido por la Superintendencia de Banca, Seguros y AFP. Asimismo, desarrolla modelos de gestión que permita una adecuada medición, cuantificación y monitoreo de los créditos que se otorgan, impulsando la mejora continua de las políticas, herramientas, metodologías y procesos.

(b) Máxima exposición al riesgo de crédito-

Al 31 de diciembre de 2017 y de 2016, la Gerencia de la Financiera ha estimado que el monto máximo de riesgo crediticio al que se encuentra expuesta la Financiera está representado por el valor en libros de los activos financieros que presentan un riesgo crediticio potencial y que consisten principalmente en los depósitos en bancos, la cartera de créditos y los otros activos financieros. La exposición para cada prestatario, incluidos bancos, se establece mediante sub-límites que cubren los riesgos por operaciones en el 
estado de situación financiera y fuera de éste (cuentas contingentes). Las exposiciones reales y su comparación contra los límites establecidos se revisan diariamente.

En este sentido, al 31 de diciembre de 2017 y de 2016 el:

90.44 por ciento y 90.46 por ciento, respectivamente, de la cartera de créditos está clasificada en los dos niveles superiores definidos por la SBS.

87.02 y 86.94 por ciento, respectivamente de los créditos están consideradas como ni vencidos ni deteriorados.

19.27 y 24.46 por ciento, respectivamente, de los fondos disponibles representan los importes depositados en BCRP y el 45.57 y 39.83 por ciento, respectivamente, se encuentra depositado en un banco relacionado de reconocido prestigio; estando el saldo en otras entidades financieras locales e internacionales de primer nivel.

77.61 y 86.42 por ciento, respectivamente, de las cuentas por cobrar y otros activos son con compañías relacionadas, las cuales por el tipo de operación que las generan son cobradas en su mayoría durante los primeros días del mes siguiente.

Con respecto a la evaluación de la Cartera de Créditos, la Financiera efectúa la clasificación de los deudores en las categorías de riesgo establecidos por las SBS y de acuerdo con los criterios de clasificación señalados para cada tipo de crédito: es decir, para los deudores de la Cartera de Consumo y Mediana empresa, ver nota 2(d).

Adicionalmente y en línea con lo dispuesto por la SBS, la 
Financiera revisa su cartera de créditos constantemente con el objeto de minimizar su exposición al riesgo y determinar adecuadamente las provisiones por incobrabilidad de los créditos. El objeto de esta labor es identificar y mitigar el riesgo de pérdida en los créditos colocados, así como planificar adecuadas estrategias de recuperación.

Las provisiones por riesgo de incobrabilidad de créditos se constituyen de acuerdo a lo establecido por la SBS; en ese sentido, se constituyen provisiones genéricas y específicas. 
(i) Préstamos no vencidos ni deteriorados, que comprenden aquellos préstamos directos que actualmente no tienen características de morosidad y están relacionados con clientes clasificados como "Normal" y "Con problemas potenciales",

(ii) Préstamos vencidos, pero no deteriorados, que comprenden préstamos vencidos de clientes clasificados como normales o con problemas potenciales y

(iii) Préstamos deteriorados, aquellos préstamos vencidos clasificados como deficientes, dudosos o pérdida; también se presenta la provisión para créditos de cobranza dudosa para cada uno de los tipos de préstamos.

Clasificación de la cartera de créditos

No vencidos ni deteriorados

Normal

Con problema potencial

\section{Vencidos pero no deteriorados}

Normal

Con problema potencial

\section{Deteriorados}

Deficiente

Dudoso

Pérdida

Total colocaciones brutas neto de ingresos diferidos

Menos: Provisión para créditos de cobranza dudosa

Total, neto
2017

\begin{tabular}{|c|c|c|c|c|c|c|c|}
\hline $\begin{array}{c}\begin{array}{c}\text { Créditos } \\
\text { mediana } \\
\text { empresa }\end{array} \\
\text { S/(000) }\end{array}$ & $\begin{array}{l}\text { Créditos de } \\
\text { consumo }\end{array}$ & $\mathrm{S} /(000)$ & $\%$ & $\begin{array}{c}\begin{array}{c}\text { Créditos } \\
\text { mediana } \\
\text { empresa }\end{array} \\
\\
S /(000)\end{array}$ & $\begin{array}{l}\text { Créditos de } \\
\text { consumo }\end{array}$ & $\mathrm{S} /(000)$ & $\%$ \\
\hline 1,721 & 862,520 & 864,241 & 99.70 & 876 & 716,112 & 716,988 & 99.89 \\
\hline 31 & 2,593 & 2,624 & 0.30 & 9 & 809 & 818 & 0.11 \\
\hline 1,752 & 865,113 & 866,865 & 100.00 & 885 & 716,921 & 717,806 & 100.00 \\
\hline - & 10,802 & 10,802 & 31.74 & - & 8,282 & 8,282 & 28.51 \\
\hline 191 & 23,045 & 23,236 & 68.26 & 96 & 20,671 & 20,767 & 71.49 \\
\hline 191 & 33,847 & 34,038 & 100.00 & 96 & 28,953 & 29,049 & 100.00 \\
\hline 62 & 28,756 & 28,818 & 30.25 & 19 & 23,839 & 23,858 & 30.30 \\
\hline 108 & 47,837 & 47,945 & 50.33 & 106 & 32,976 & 33,082 & 42.01 \\
\hline 39 & 18,464 & 18,503 & 19.42 & 47 & 21,760 & 21,807 & 27.69 \\
\hline 209 & 95,057 & 95,266 & 100.00 & 172 & 78,575 & 78,747 & 100.00 \\
\hline 2,152 & 994,017 & 996,169 & & 1,153 & 824,449 & 825,602 & \\
\hline (150) & $(70,818)$ & $(70,968)$ & & (129) & $(57,005)$ & $(57,134)$ & \\
\hline 2,002 & $\underline{923,199}$ & $\underline{925,201}$ & & 1,024 & $\underline{767,444}$ & $\underline{768,468}$ & \\
\hline
\end{tabular}


Al 31 de diciembre de 2017 y de 2016, los créditos refinanciados, en situación de vigentes y vencidos ascienden a S/31,984,375 y S/14,747,249, respectivamente, de los cuales S/2,704,513 y S/914,952, respectivamente, son clasificadas como no vencidas ni deterioradas, S/139,732 y S/16,425 respectivamente son clasificadas como vencidos, pero no deteriorados y $\mathrm{S} / 29,140,130$ y $\mathrm{S} / 13,815,872$ respectivamente son clasificadas como deteriorados.

A continuación, se detallan los días de atraso de los créditos que están vencidos, pero no deteriorados:

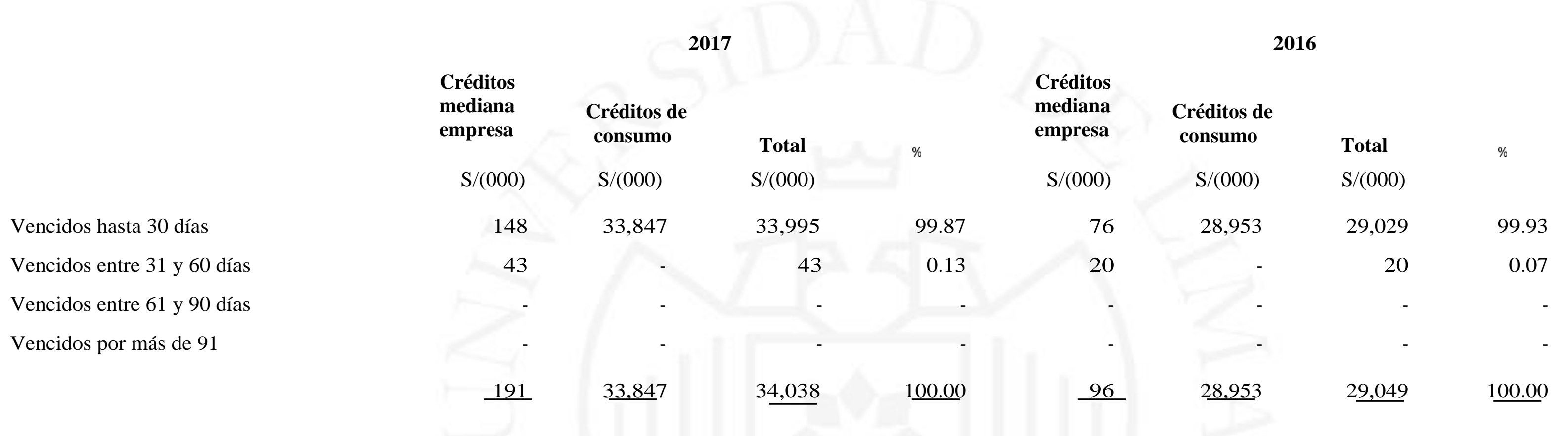

A continuación, se presenta el detalle del monto bruto de los créditos deteriorados por tipo de crédito y los montos de su provisión para créditos de cobranza dudosa son como sigue:

\begin{tabular}{|c|c|c|c|c|c|c|}
\hline \multirow{3}{*}{ Créditos deteriorados } & \multicolumn{3}{|c|}{2017} & \multicolumn{3}{|c|}{2016} \\
\hline & $\begin{array}{l}\text { Créditos } \\
\text { mediana } \\
\text { empresa }\end{array}$ & $\begin{array}{l}\text { Créditos de } \\
\text { consumo }\end{array}$ & Total & $\begin{array}{l}\text { Créditos } \\
\text { mediana } \\
\text { empresa }\end{array}$ & $\begin{array}{l}\text { Créditos de } \\
\text { consumo }\end{array}$ & Total \\
\hline & $\mathrm{S} /(000)$ & $\mathrm{S} /(000)$ & $\mathrm{S} /(000)$ & $S /(000)$ & $S /(000)$ & $S /(000)$ \\
\hline Préstamos deteriorados & 209 & 95,057 & 95,266 & 172 & 78,575 & 78,747 \\
\hline Provisión para créditos de cobranza dudosa & 121 & $\underline{56,592}$ & $\underline{56,713}$ & 115 & $\underline{48,683}$ & 48,798 \\
\hline
\end{tabular}


(c) Gestión de riesgo de crédito para colocaciones-

Para la gestión del riesgo de crédito, la Gerencia de Riesgos cuenta con procesos que comprenden tres etapas fundamentales: la admisión de los riesgos, el seguimiento y monitoreo de estos y la recuperación de la cartera problema; procesos que tienen la finalidad de mantener una calidad de cartera acorde al apetito de riesgo definido por la Alta Dirección de la Financiera.

El proceso de admisión de créditos se basa fundamentalmente en el buen conocimiento del cliente y su actividad económica, siendo determinante la evaluación de su capacidad de pago, historial crediticio y solvencia. Este proceso se apoya en la utilización de metodologías y herramientas de gestión de riesgos que permiten medir y valorar la calidad del riesgo a otorgar, el mismo que se apoya en modelos y sistemas de calificación automáticos para la admisión de créditos.

Para el proceso de seguimiento y monitoreo de la cartera se cuenta con un sistema integrado de alertas para la detección temprana del riesgo crediticio, que permiten identificar a clientes con riesgos potenciales que afectarían su capacidad de pago con posible impacto en el desarrollo crediticio del deudor y sobre los cuales se deben tomar acciones inmediatas como preventivas, correctivas y de seguimiento, contando para ello con sistemas, modelos y lineamientos mediante los cuales se realiza el seguimiento a los deudores respecto a la evolución de los riesgos detectados, toma de decisiones y gestión de los mismos para su normalización o cobranza.

Se hace un monitoreo permanente de las principales tendencias de la cartera, en términos de evolución de indicadores de calidad, concentración geográfica, entre otros. 
Finalmente, el proceso de cobranza de los créditos de la cartera problema, se realiza a través de un conjunto de acciones coordinadas y aplicadas para la adecuada y oportuna recuperación de los créditos que tienen como finalidad minimizar pérdidas en exposiciones con elevado riesgo de crédito.

\subsection{Riesgo de mercado-}

El riesgo de mercado es la posibilidad de pérdida por variaciones en las condiciones del mercado financiero. Las principales variaciones a las que está expuesta la Financiera se pueden dar en: los tipos de cambio y las tasas; estas variaciones pueden afectar el valor de los activos y pasivos financieros de la Financiera.

La Financiera tiene posiciones que no son activamente negociadas y forman parte de sus activos y pasivos.

\section{(i) Riesgo de tasa de interés-}

Las tasas de interés fluctúan de manera permanente en el mercado. Estas fluctuaciones afectan de dos maneras a la Financiera: la primera, a través del cambio en la valorización de los activos y pasivos; y la segunda, afectando los flujos de caja al momento de su re- precio. La variación en la valorización de activos y pasivos es más sensible en la medida que aumente el plazo en el cual el activo o pasivo se re-precia, para ello se lleva a cabo análisis de los periodos de re-precio. Por otra parte, los flujos de caja se ven afectados al momento de los vencimientos de los instrumentos, al ser éstos invertidos o colocados a las nuevas tasas vigentes en el mercado.

El seguimiento del riesgo de tasa de interés es informado al Comité de 
Riesgos, así como también al Comité ALCO. El Comité de Riesgos aprueba los diversos límites aplicables para la gestión de los instrumentos financieros, mientras que el seguimiento está a cargo de la Unidad de Riesgos de Mercado y Liquidez.

Brecha de reprecio -

A efectos de determinar el impacto de los movimientos de las tasas de interés se realiza un análisis de brechas de reprecio. El análisis consiste en asignar en diferentes brechas de tiempo los saldos de las operaciones que cambiarán de tasa de interés. En función de este análisis se calcula el impacto para cada brecha de la variación en la valorización de activos y pasivos. 
El siguiente cuadro resume la exposición de la Financiera a los riesgos de tasas de interés. Los instrumentos financieros de la Financiera se muestran a sus valores en libros, clasificados entre el periodo de reprecio de tasa de interés del contrato o fecha de vencimiento, lo que ocurra primero:

\begin{tabular}{|c|c|c|c|c|c|c|}
\hline & & & 017 & & & \\
\hline & Hasta 1mes & De 1 a 3 meses & De 3 a 12 meses & De 1 a 5 años & $\begin{array}{l}\text { No devengan } \\
\text { intereses }\end{array}$ & Total \\
\hline & $\mathrm{S} /(000)$ & $\mathrm{S} /(000)$ & $S /(000)$ & $S /(000)$ & $S /(000)$ & $S /(000)$ \\
\hline Disponible & 114,997 & & - & - & - & 114,997 \\
\hline Cartera de créditos & 279,891 & 181,215 & 309,042 & 185,210 & $(10,237)$ & 945,121 \\
\hline Obligaciones con el público & 3,762 & 946 & 1 & 15,697 & 731 & 21,137 \\
\hline Adeudados & 9,030 & 82,385 & 33,707 & - & - & 125,122 \\
\hline Total pasivos y patrimonio & 14,274 & 193,350 & 311,678 & 333,777 & 316,073 & $\begin{array}{r}1,169,15 \\
2\end{array}$ \\
\hline Brechas marginal & 380,614 & $(12,135)$ & $(2,636)$ & $(148,567)$ & $(217,276)$ & - \\
\hline Brechas acumulada & 380,614 & 368,479 & 365,843 & 217,276 & - & - \\
\hline
\end{tabular}


2016

\section{Disponible}

Cartera de créditos

Otros activos

Total activos

Obligaciones con el público

Adeudados

Valores y títulos en circulación

Otros pasivos

Patrimonio

Total pasivos y patrimonio

Brechas marginal

Brechas acumulada

\begin{tabular}{|c|c|c|c|c|c|}
\hline \multirow[b]{2}{*}{ Hasta 1mes } & \multicolumn{3}{|c|}{2016} & \multirow[b]{2}{*}{$\begin{array}{l}\text { No devengan } \\
\text { intereses }\end{array}$} & \multirow[b]{2}{*}{ Total } \\
\hline & De 1 a 3 meses & De 3 a 12 meses & De 1 a 5 años & & \\
\hline $\mathrm{S} /(000)$ & $\mathrm{S} /(000)$ & $\mathrm{S} /(000)$ & $S /(000)$ & $\mathrm{S} /(000)$ & $\mathrm{S} /(000)$ \\
\hline 107,719 & - & & - & - & 107,719 \\
\hline 122,398 & 221,691 & 301,511 & 149,016 & $(9,336)$ & 785,280 \\
\hline - & & & & 101,682 & 101,682 \\
\hline 230,117 & 221,691 & 301,511 & 149,016 & 92,346 & 994,681 \\
\hline 1,670 & - & - & - & 658 & 2,328 \\
\hline 106,209 & 54,110 & 76,877 & 13,269 & - & 250,465 \\
\hline 1,747 & 104,331 & 334,426 & 36,647 & & 477,151 \\
\hline & & & & 60,391 & 60,391 \\
\hline & & & & 204,346 & 204,346 \\
\hline 109,626 & 158,441 & 411,303 & 49,916 & 265,395 & 994,681 \\
\hline 120,491 & 63,250 & $(109,792)$ & 99,100 & $(173,049)$ & \\
\hline 120,491 & 183,741 & 73,949 & 173,049 & - & - \\
\hline
\end{tabular}


Sensibilidad a los cambios en las tasas de interés-

A continuación, se muestra la sensibilidad del estado de resultados integrales ante diversas fluctuaciones de tasa de interés. Las fluctuaciones afectan tanto los flujos esperados como el valor de los saldos.

Para el caso del estado de resultados integrales, el cálculo refleja la variación esperada del margen financiero en el periodo equivalente de un año. Para ello se considera la posición de ingresos y egresos actual y anualiza el efecto de las variaciones de las tasas. Las cifras expresan el cambio esperado de valor de los activos menos los pasivos para diversas brechas de tiempo.

Las fluctuaciones de tasas de interés consideradas se aplican por igual a lo largo de toda la curva de rendimiento; es decir, se considera un movimiento paralelo de la curva. Los efectos se consideran de manera independiente para cada una de las dos monedas presentadas.

Los cálculos son basados sobre el modelo de riesgo de tasa de interés regulatorio aprobado por la SBS, vigente a la fecha del estado de situación financiera. Las sensibilidades son calculadas antes del efecto del impuesto a la renta.

La exposición a tasa de interés es supervisada por el Comité de Activos y Pasivos, así como por el Comité de Riesgos, siendo este último quien aprueba los límites máximos permitidos.

Los efectos de los cambios estimados en las tasas de interés al 31 de diciembre de 2017 y 2016, son los siguientes: 
2017

Moneda

Dólares estadounidenses

Dólares estadounidenses

Dólares estadounidenses

Dólares estadounidenses

Soles

Soles

Soles

Soles

Moneda

Dólares estadounidenses

Dólares estadounidenses

Dólares estadounidenses

Dólares estadounidenses

Soles

Soles

Soles

Soles

\section{Cambios en Sensibilidad en puntos básicos los resultados netos}

$+/-50$

$+/-75$

$+/-100$

$+/-150$

$+/-50$

$+/-75$

$+/-100$

$+/-150$
$\mathrm{S} /(000)$

1,708

2,561

3,415

5,123

8

13

17

25

2016

$\begin{array}{cl}\begin{array}{c}\text { Cambios en } \\ \text { puntos }\end{array} & \begin{array}{l}\text { Sensibilidad en } \\ \text { los resultados }\end{array} \\ \text { básicos } & \text { netos }\end{array}$

$\mathrm{S} /(000)$

$+/-50$

238

$+/-75$

357

$+/-100$

476

$+/-150$

713

$+/-50$

472

$+/-75$

708

$+/-100$

944

$+/-150$

1,417

(ii) Riesgo de cambio de moneda extranjera-

El riesgo de cambio de moneda extranjera es el relacionado con la variación del valor de las posiciones dentro y fuera del estado de situación financiera que se vean afectadas negativamente por los 
movimientos de los tipos de cambio. La Gerencia fija límites en los niveles de exposición por moneda, los cuales son monitoreados diariamente. La mayoría de los activos y pasivos en moneda extranjera se mantienen en dólares estadounidenses.

Al 31 de diciembre de 2017, el tipo de cambio promedio ponderado del mercado libre publicado por la SBS para las transacciones en dólares estadounidenses era de $\mathrm{S} / 3.238$ por US $\$ 1$ para la compra y $\mathrm{S} / 3.245$ por US\$1 para la venta (S/3.352 y S/3.36 al 31 de diciembre de 2016, respectivamente). Al 31 de diciembre de 2017, el tipo de cambio para la contabilización de las cuentas del activo y del pasivo en moneda extranjera fijado por la SBS era de S/3.241 por US\$1 (S/3.356 al 31 de diciembre de2016).

A continuación, se presenta el detalle de la posición de la Financiera en moneda extranjera, expresados en dólares estadounidenses:

\section{Activos}

Disponible

Cuentas por cobrar y otros activos

\section{Pasivos}

Cuentas por pagar

Adeudados, valores y títulos, y otros pasivos

\section{Derivados}

Forwards

Posición pasiva neta 
Durante el ejercicio 2017, la Financiera ha registrado una ganancia neta por diferencia de cambio de S/622,156 (ganancia neta de S/1,650,563 en el ejercicio 2016), ver nota 19(a).

La Financiera está expuesta a los efectos de las fluctuaciones en los tipos de cambio de la moneda extranjera prevaleciente en suposición financiera y flujos de caja. La Gerencia fija límites en los niveles de exposición por moneda y el total de las operaciones diarias las cuales son monitoreadas diariamente.

Los activos y pasivos en moneda extranjera se mantienen en dólares estadounidenses. Las transacciones en moneda extranjera se efectúan a tasas de mercado.

A continuación, se presentan las sensibilidades para el caso de las variaciones del dólar estadounidense. Por su volumen, la posición en dólares estadounidenses es la única exposición que podría causar una pérdida material para la Financiera. Las variaciones negativas representan potenciales pérdidas mientras que las positivas representan potenciales ganancias.

$\begin{array}{lccr}\text { Análisis de sensibilidad } & \begin{array}{c}\text { Cambio en tipos } \\ \text { de cambio }\end{array} & \mathbf{2 0 1 7} & \mathbf{2 0 1 6} \\ & \% & \mathrm{~S} /(000) & \mathrm{S} /(000) \\ \text { Devaluación - } & 5 & 6 & 31 \\ \text { Dólar estadounidense } & 10 & 11 & 62 \\ \text { Dólar estadounidense } & & & \\ \text { Revaluación - } & 5 & (6) & (31) \\ \text { Dólar estadounidense } & 10 & (11) & (62) \\ \text { Dólar estadounidense } & & & \end{array}$




\subsection{Riesgo de liquidez-}

El riesgo de liquidez consiste en la incapacidad de la Financiera de poder cumplir con el vencimiento de sus obligaciones incurriendo en pérdidas que afectan de manera importante su posición patrimonial. Este riesgo puede manifestarse como resultado de eventos diversos, como pueden ser: la reducción inesperada de fuentes de fondeo, la incapacidad de liquidar activos de manera rápida, entre otros.

La Financiera toma financiamientos de corto plazo y los transforma en préstamos a plazos mayores; por lo tanto, aumenta su exposición al riesgo de liquidez.

La liquidez de la Financiera es gestionada por la Gerencia de Finanzas. Dicha Gerencia preside el Comité de Activos y Pasivos (ALCO) donde se presentan las posiciones, movimientos, indicadores y límites sobre la gestión de liquidez. El riesgo de liquidez es a su vez supervisado por el Comité de Riesgos, donde se define el nivel de riesgo que se está dispuesto a asumir y se revisan los indicadores, límites y controles correspondientes.

La Financiera posee un conjunto de indicadores que se controlan y reportan a diario, dichos indicadores establecen los niveles mínimos de liquidez permitidos en el corto plazo. Los indicadores reflejan diversos aspectos del riesgo como son: concentración, estabilidad, posición por monedas, principales depositantes, etc. La Gerencia de Riesgos es la encargada de hacer seguimiento a dichos indicadores.

Asimismo, la Financiera evalúa la liquidez a mediano y largo plazo a través de un análisis estructural de sus ingresos y salidas de fondos en diversos plazos de vencimientos. Este proceso permite conocer para cada moneda las diversas fuentes de fondeo, cómo se incrementan las necesidades de liquidez y qué plazos están descalzados. Tanto por la parte de los activos como de los 
pasivos se consideran supuestos para las operaciones que no tienen fechas de vencimiento determinadas, estos productos incluyen: préstamos revolventes y similares. También se incluyen las obligaciones estimadas producto de pasivos contingentes como pueden ser líneas de crédito no utilizadas. En base a de esta información se toman las decisiones necesarias para mantener los niveles de liquidez objetivo. 
A continuación, se presentan los flujos de efectivo por pagar de la Financiera al 31 de diciembre de 2017 y de 2016, de acuerdo a plazos contractuales pactados. Para el caso de pasivos con vencimiento no determinado, se asumen plazos de acuerdo a modelos estadísticos. Los importes revelados son los flujos de efectivo de acuerdo a plazos contraídos sin descontar e incluyen sus respectivos intereses devengados.

Obligaciones con el público Adeudados

Valores y títulos en circulación

Otros pasivos

$-$

Obligaciones con el público

Adeudados

Valores y títulos en circulación Otros pasivos

\section{Total}

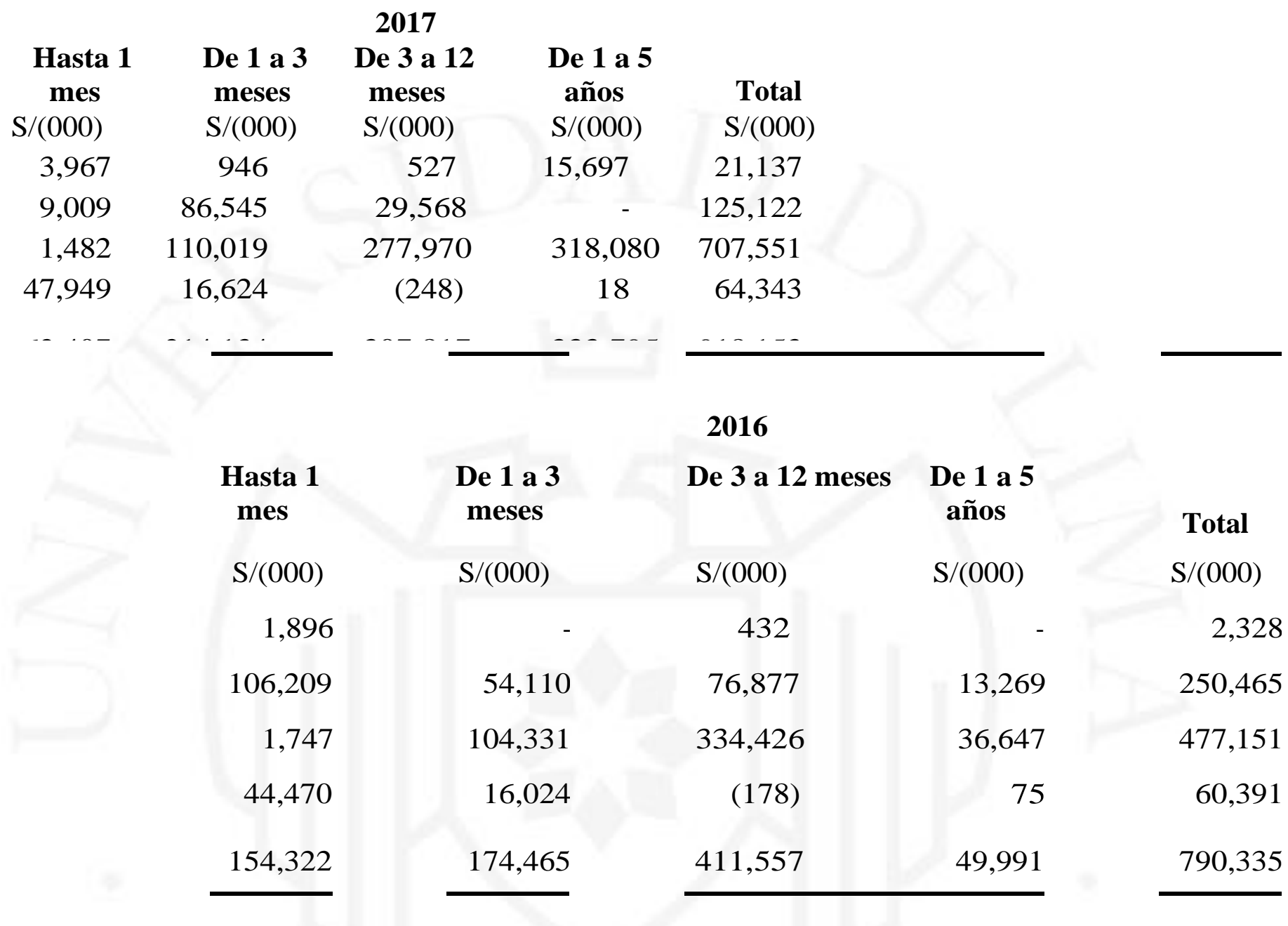


A continuación, se presenta los cambios en pasivos provenientes de actividades de financiación:

\begin{tabular}{|c|c|c|c|c|c|c|}
\hline & $\begin{array}{c}1 \text { de enero de } \\
2017\end{array}$ & Cancelaciones & $\begin{array}{c}\text { Nuevos préstamos } \\
\text { y emisiones }\end{array}$ & $\begin{array}{c}\text { Costos } \\
\text { amortizados }\end{array}$ & Otros $(*)$ & $\begin{array}{c}31 \text { de diciembre } \\
\text { de } 2017\end{array}$ \\
\hline & $\mathrm{S} / 000$ & $\mathrm{~S} / 000$ & $\mathrm{~S} / 000$ & $\mathrm{~S} / 000$ & $\mathrm{~S} / 000$ & $\mathrm{~S} / 000$ \\
\hline \multicolumn{7}{|l|}{ Adeudados } \\
\hline Préstamos y créditos a corto plazo & 233,396 & $(670,031)$ & 545,806 & 833 & 13,269 & 123,273 \\
\hline Préstamos y créditos a largo plazo & 13,269 & - & - & & $(13,269)$ & - \\
\hline Total adeudados & 246,665 & $(670,031)$ & 545,806 & 833 & - & 123,273 \\
\hline \multicolumn{7}{|l|}{ Valores y títulos en circulación } \\
\hline Valores y títulos en circularización a corto plazo & 422,209 & $(417,230)$ & 340,000 & (90) & 31,319 & 376,208 \\
\hline Valores y títulos en circularización a largo plazo & 36,647 & $(6,667)$ & 319,419 & - & $(31,319)$ & 318,080 \\
\hline Total valores y títulos en circulación & 458,856 & $(423,897)$ & 659,419 & (90) & 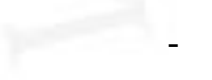 & 694,288 \\
\hline Leasing & 483 & (396) & - & - & (14) & 73 \\
\hline Total actividades de financiación & $\underline{706,004}$ & $(1,094,324)$ & $1,205,225$ & 743 & $(14)$ & $\underline{817,634}$ \\
\hline
\end{tabular}

(*) Incluye principalmente el efecto de la reclasificación entre no corriente y corriente debido al paso del tiempo. 


\subsection{Riesgo operacional-}

El riesgo operacional es la posibilidad de pérdidas debido a fallas en los procesos, sistemas, personas y ante eventos externos. La definición incluye el riesgo legal.

Para gestionar adecuadamente este riesgo la Financiera ha desplegado una metodología y estructura que le permite identificar, valorar, monitorear y mitigar el riesgo operacional y mantener su exposición dentro de los límites de apetito y tolerancia al riesgo operacional aprobado por el Comité de Riesgos.

\subsection{Gestión de capital-}

Al 31 de diciembre de 2017 y de 2016, la Financiera ha cumplido con el Decreto Legislativo $\mathrm{N}^{\circ} 1028$ y con las Resoluciones SBSN ${ }^{\circ} 2115-2009$, No6328-2009, $\quad \mathrm{N}^{\circ}$ 14354-2009, $\quad \mathrm{N}^{\circ} 8425-2011$ y modificatorias, Reglamentos para el Requerimiento de Patrimonio Efectivo por Riesgo Operacional, por Riesgo de Mercado y por Riesgo de Crédito, respectivamente, y modificatorias. Estas Resoluciones establecen, principalmente, las metodologías a ser utilizadas por las entidades financieras para calcular los activos y créditos ponderados para cada tipo de riesgo, ver nota 13(c).

\subsection{Valor razonable-}

El valor razonable es definido como el importe por el cual un activo podría ser intercambiado o un pasivo liquidado, entre partes conocedoras y dispuestas a ello en una transacción corriente, bajo el supuesto de que la entidad es una empresa en marcha.

Cuando un instrumento financiero es comercializado en un mercado 
líquido y activo, su precio estipulado en el mercado en una transacción real brinda la mejor evidencia de su valor razonable. Cuando no se cuenta con el precio estipulado en el mercado o este no puede ser un indicativo del valor razonable del instrumento, para determinar dicho valor razonable entonces se pueden utilizar el valor de mercado de otro instrumento, sustancialmente similar, el análisis de flujos descontados u otras técnicas aplicables; las cuales se ven afectadas de manera significativa por los supuestos utilizados. No obstante que la Gerencia ha utilizado su mejor juicio en la estimación de los valores razonables de sus instrumentos financieros, cualquier técnica para efectuar dicho estimado conlleva cierto nivel de fragilidad inherente. Como resultado, el valor razonable no puede ser indicativo del valor realizable neto o de liquidación.

A continuación, presentamos las metodologías y supuestos empleados para determinar los valores estimados de mercado de los instrumentos financieros no medidos a su valor razonable, los cuales dependen de los términos y características de riesgo de cada tipo de instrumento:

(a) Activos y pasivos cuyo valor razonable es similar al valor en libros - Para los activos y pasivos financieros que son líquidos o tienen vencimientos a corto plazo (menor a un año), se considera que el valor en libros es similar al valor razonable. Este supuesto también es aplicable para los depósitos a plazo y cuentas de ahorros en un vencimiento específico.

(b) Instrumentos financieros a tasa fija - El valor razonable de los activos y pasivos financieros que se encuentran a tasa fija y a costo amortizado se determina comparando las tasas de interés del mercado en el momento de su reconocimiento inicial con las tasas de mercado actuales relacionadas con instrumentos financieros similares. Cuando no se cuenta con precios de mercado, se usa el modelo de flujo de caja descontado en base a la curva de 
rendimiento de la tasa de interés por el plazo que queda por vencer. El valor razonable de la cartera de créditos y de los depósitos y obligaciones, según el oficio múltiple SBS Nº1575-2014, corresponde a su valor en libros.

Sobre la base de lo mencionado anteriormente, a continuación, se establece una comparación entre los valores en libros y los valores razonables de los instrumentos financieros de la Financiera presentados en el estado de situación financiera. La tabla no incluye los valores razonables de los activos y pasivos no financieros:

2017

2016

$\begin{array}{cccc}\begin{array}{c}\text { Valor en } \\ \text { libros }\end{array} & \begin{array}{c}\text { Valor } \\ \text { razonable }\end{array} & \begin{array}{c}\text { Valor en } \\ \text { libros }\end{array} & \begin{array}{c}\text { Valor } \\ \text { razonable }\end{array} \\ \mathrm{S} /(000) & \mathrm{S} /(000) & \mathrm{S} /(000) & \mathrm{S} /(000)\end{array}$

\section{Activos}

Disponible 114,997

114,997

$107,719 \quad 107,719$

Colocaciones, neto

945,121

945,121

$785,280 \quad 785,280$

Cuentas por cobrar y otros activos

79,029

79,029

$68,573 \quad 68,573$

Total

$\begin{array}{ll}1,139,147 & 1,139,14 \\ 7\end{array}$

$961,572 \quad 961,572$

\section{Pasivos}

Obligaciones con el público 21,137

21,137

2,328

2,328

Adeudos

125,122

125,122

250,465

250,465

Valores, títulos y obligaciones en

707,551

714,701

$477,151 \quad 477,151$

circulación

Cuentas por pagar

$$
55,697
$$

55,697

47,060

47,060

Otros pasivos

$$
8,646
$$

8,646

13,331

13,331

Total

$918,153 \quad 925,303$

$790,335790,335$ 
Los criterios para la determinación del valor razonable, que son consistentes con las disposiciones establecidas en el acápite "Consideraciones del Valor Razonable" del numeral 2 "Instrumentos Financieros" del literal E "Normas Contables Generales" del Capítulo I del Manual Contable de la SBS, es el siguiente:

Instrumentos financieros registrados a valor razonable según métodos de valoración

Activo

Disponible

Colocaciones, neto

Cuentas por cobrar y otros activos

Total

Pasivo

Obligaciones con el público

Adeudos

Valores, títulos y obligaciones en circulación Cuentas por pagar

Otros pasivos

Total
Año 2017

Nivel 1

Nivel 2

Nivel 3

114,997

945,121

79,029

$1,139,147$

21,13

$125, \overline{122}$

714,701

55,697

8,646

925,303
Año 2016

Nivel 2

Nivel 3

107,719

785,280

68,573

961,572

2,328

250,465

477,151

47,060

13,331

790,335 
EY | Auditoría | Consultoría | Impuestos | Transacciones y Finanzas Corporativas

\section{Acerca de EY}

EY es la firma líder en servicios de auditoría, consultoría, impuestos, transacciones $\mathrm{y}$ finanzas corporativas. La calidad de servicio y conocimientos que aportamos ayudan a brindar confianza en los mercados de capitales y en las economías del mundo. Desarrollamos líderes excepcionales que trabajan en equipo para cumplir nuestro compromiso con nuestros stakeholders. Así, jugamos un rol fundamental en la construcción de un mundo mejor para nuestra gente, nuestros clientes y nuestras comunidades.

Para más información visite ey.com/pe

\section{CEY}

All Rights Reserved. 